\title{
Machine Learning Indices, Political Institutions, and Economic Development
}

\author{
Dissertation \\ zur Erlangung des akademischen Grades eines \\ Doktors der Wirtschaftswissenschaften (Dr.rer.pol.) \\ vorgelegt von \\ Tommy Krieger \\ an der
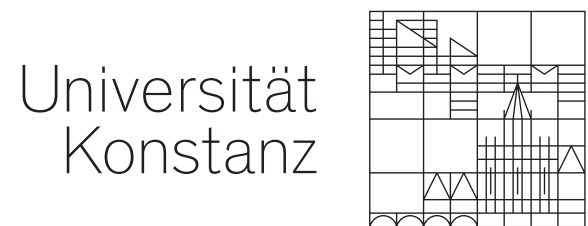 \\ Sektion Politik - Recht - Wirtschaft \\ Fachbereich Wirtschaftswissenschaften
}

Konstanz, 2019 
Tag der mündlichen Prüfung: 20. Mai 2019

1. Referent: Prof. Dr. Heinrich Ursprung

2. Referent: Prof. Dr. Guido Schwerdt

3. Referent: Prof. Dr. Martin Gassebner 


\section{Danksagung}

Mein erster Dank gilt meinem Doktorvater, Heinrich Ursprung. Ich danke Ihnen dafür, dass Sie mich als Doktoranden aufgenommen haben, nachdem mein erster Betreuer und ich entschieden haben, getrennte Wege zu gehen. Ich danke Ihnen insbesondere für all Ihre weisen Ratschläge, die Sie mir während der letzten Jahre gegeben haben, und für die Ausdauer und Geduld, mit der Sie meine Texte gelesen und verbessert haben. Der Austausch mit Ihnen war mir stets ein Vergnügen und ich hoffe, dass ich auch in Zukunft die Gelegenheit haben werde, Sie nach Ihrer wissenschaftliche Meinung zu fragen.

Mein Dank gilt auch Guido Schwerdt and Martin Gassebner. Ich bedanke mich, dass ihr euch bereit erklärt habt, die Zweit- bzw. Drittbetreuung meiner Doktorarbeit zu übernehmen. Eure Hinweise haben mir sehr geholfen.

Bedanken möchte ich mich auch bei all jenen, die durch ihre zahlreichen Kommentare meine Arbeiten verbessert haben. Hervorheben möchte ich: Toke Aidt, Luna Bellani, Friedrich Breyer, Raphael Franck, Kai Gehring, Jerg Gutmann, Katharina Hofer, Stephan Maurer, und Niklas Potrafke. Toke Aidt und Raphael Franck danke ich auch dafür, dass sie es mir ermöglicht haben, Teile meiner Doktorarbeit an der Universtät zu Cambridge bzw der Hebrew Universtät zu Jerusalem zu schreiben. Herzlich danken möchte ich auch Klaus Gründler, der mir bei zwei Aufsätzen als Koautor zur Seite stand.

Ein großer Dank gilt auch meinen Weggefährten an der Universität zu Konstanz. Die zahlreichen Diskussionen mit Enzo Brox, Michael Dörsam, Lisa Leschnig, Moritz Janas, Michal Marencak, Carl Maier, Jan Mellert, Arash Nagavi, Timm Prein, sowie Maurizio Strazzeri haben mich oft auf neue Ideen gebracht. Für die vielen privaten Erlebnisse danke ich euch ebenfalls.

Herzlich bedanken möchte ich mich auch bei Heike Knappe, Susanne Fuchs, und Ilse Geigges-Marschall für ihre Unterstützung bei zahlreichen administrativen Belangen.

Mein letzter und größter Dank gebührt meiner Familie. Meinen Eltern, Kathrin Krieger und Mario Krieger, sowie meinen Großeltern, Hanni Hähnel, Gerhard Hähnel und Ruth Krieger, danke ich für die moralische und finanzielle Unterstützung, die sie mir während meines gesamten Lebens zuteil werden lassen haben, und dafür, dass sie mir ermöglicht haben, meinen Lebensweg selbst zu gestalten. Meiner Freundin, Svenja Schmid, danke ich für ihre Liebe, ihre Geduld, ihr Vertrauen, und ihre Lebensfreude, mit der sie mich meine Sorgen und trüben Gedanken vergessen lässt. 


\section{Contents}

1 Introduction 1

$1.1 \quad$ Summary . . . . . . . . . . . . . . . . . . 1

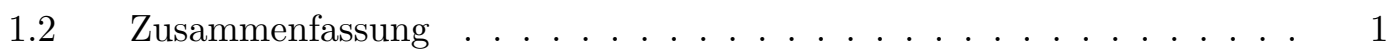

2 Using machine learning for measuring democracy 3

2.1 Introduction . . . . . . . . . . . . . . . . . . . . 4

$2.2 \quad$ Support Vector Machine . . . . . . . . . . . . . . . . 5

2.2.1 Support Vector Classification . . . . . . . . . . . . 6

$2.2 .2 \quad$ Support Vector Regression . . . . . . . . . . . . . 9

$2.3 \quad$ SVM indices . . . . . . . . . . . . . . . . 10

$2.3 .1 \quad$ Literature review . . . . . . . . . . . . . . . 10

2.3.2 Machine learning procedure . . . . . . . . . . . . 12

$2.3 .3 \quad$ Country examples . . . . . . . . . . . . . . . . . 14

$2.3 .4 \quad$ Discussion . . . . . . . . . . . . . . . 18

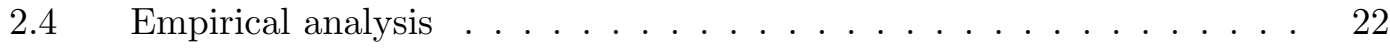

2.4 Literature review . . . . . . . . . . . . . . . . . 22

$2.4 .2 \quad$ Identification strategies . . . . . . . . . . . . 23

2.4.3 Estimation results . . . . . . . . . . . . . . . 24

2.4.4 Explanation . . . . . . . . . . . . . 26

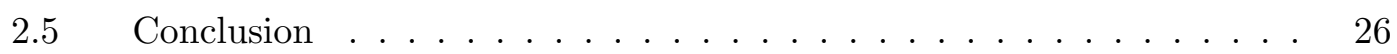

A.1 Additional tables . . . . . . . . . . . . . . . . . . . 27

$\begin{array}{lll}3 & \text { Should we care (more) about data aggregation? } & \mathbf{3 7}\end{array}$

3.1 Introduction . . . . . . . . . . . . . . . . . . . . . 38

3.2 Measuring democracy . . . . . . . . . . . . . . . . 40

3.2.1 Conceptualization . . . . . . . . . . . . . . 40

3.2.2 Operationalization . . . . . . . . . . . . . 40

3.2.3 Aggregation . . . . . . . . . . . . . . . . 41

3.2.4 Comparing aggregation methods . . . . . . . . . . . . 42

3.2.5 Discussion . . . . . . . . . . . . . . . 46

$3.3 \quad$ Econometric model . . . . . . . . . . . . . . . . . . . . . . . 48

3.3.1 Ordinary least squares estimator . . . . . . . . . . . 48

3.3.2 Two-stage least squares estimator . . . . . . . . . . . . 49

3.4 Democracy and economic growth . . . . . . . . . . . . 50 
3.4.1 Identification strategies . . . . . . . . . . . 50

3.4.2 Results from ordinary least squares regressions . . . . . . . 51

3.4.3 Results from two-stage least squares regressions . . . . . . 52

3.4.4 Robustness . . . . . . . . . . . . . . . . . 53

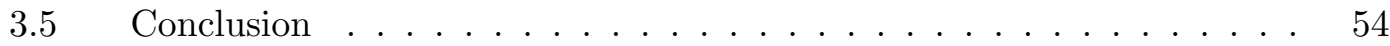

B.1 Supplementary material for Section $3.2 .4 \ldots \ldots \ldots \ldots 6$

B.1.1 Additive approach . . . . . . . . . . . . 56

B.1.2 Multiplicative approach . . . . . . . . . . . 56

B.1.3 Combining the additive and the multiplicative approach . . . 56

B.1.4 Bayesian latent variable approach . . . . . . . . . 57

B.1.5 Machine learning approach . . . . . . . . . . . . 57

B.2 Supplementary material for Section $3.2 .5 \ldots \ldots \ldots$. . . . . . 57

B.2.1 Additional country examples . . . . . . . . . . . 58

B.2.2 Alternative regime characteristics . . . . . . . . . . 59

B.2.3 Methodological explanations . . . . . . . . . . . . 60

B.3 Additional figures . . . . . . . . . . . . . . . . . . 62

B.4 Additional tables . . . . . . . . . . . . . . . . . . . 65

4 Democracy and institutional quality: Theory and evidence $\quad 74$

4.1 Introduction . . . . . . . . . . . . . . . . . . . 75

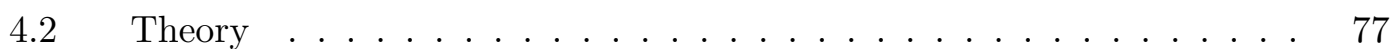

$4.2 .1 \quad$ Basic model . . . . . . . . . . . . . . . . . . 77

$4.2 .2 \quad$ Theoretical results . . . . . . . . . . . . . . . 79

4.2 .3 Discussion . . . . . . . . . . . . . . . 81

$4.3 \quad$ Empirical analysis . . . . . . . . . . . . . . . . . . 84

4.3.1 Data . . . . . . . . . . . . . . . 84

4.3.2 Instrumental variables . . . . . . . . . . . . . . 85

$4.3 .3 \quad$ Baseline results . . . . . . . . . . . . . . . 85

4.3.4 Robustness checks . . . . . . . . . . . . . 87

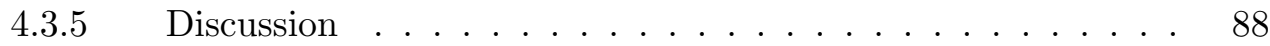

4.4 Conclusion . . . . . . . . . . . . . . . . . . . 90

C.1 Data on institutional quality . . . . . . . . . . . . . . . 91

C.2 Additional tables . . . . . . . . . . . . . . . . . . . . 94

$\begin{array}{ll}\text { Bibliography } & 100\end{array}$

$\begin{array}{ll}\text { Abgrenzung } & 106\end{array}$ 


\section{Chapter 1}

\section{Introduction}

\subsection{Summary}

This doctoral thesis consists of three research papers that have been written during my studies in the PhD program of the Graduate School of Decision Science at the University of Konstanz. The first two papers are joint projects with Dr. Klaus Gründler (LMU Munich, ifo Institute). The third paper is a single author project.

The first paper (Chapter 2) presents a machine learning method for creating democracy indices and shows how the results of empirical studies change when a continuous index is replaced with a dichotomous index. The findings of the paper suggest that dichotomous indices create smaller OLS estimates than continuous indices. The reason for this difference is that dichotomous indices suffer more from classical measurement error than continuous indices. The paper also shows that continuous and dichotomous indices produce similar 2SLS estimates.

The second paper (Chapter 3) compares data aggregation methods and shows that most of the available aggregation techniques produce indices that are implausibly low (high) for democratic (autocratic) regimes. The exception is the machine learning technique proposed in the second chapter of my doctoral thesis. This paper also presents a stylized model to illustrate that applying biased indices in empirical studies causes upward-biased OLS and 2SLS estimates. The results of an analysis of the effect of democracy on economic growth suggest that the distortions in the OLS and 2SLS estimates are substantial.

The third paper (Chapter 4) presents a simple political economy model to illustrate why democratic transitions may cause improvements in the quality of economic institutions. The model predicts in particular that the effect of democracy on institutional quality increases when people command a high level of human capital, and that the quality of economic institutions varies more across autocracies than across democracies. Using a new panel data set, covering 140 countries and the 1920 - 2015 period, the paper also presents regression results that confirm the key predictions of the model.

\subsection{Zusammenfassung}

Meine Doktorarbeit besteht aus drei wissenschaftlichen Aufsätzen und entstand während meines Promotionsstudiums an der Graduate School of Decision Science (Universität Konstanz). Die ersten beiden Aufsätze meiner Dissertation sind in Zusammenarbeit mit Klaus Gründler (LMU München, ifo Institut) entstanden. Der dritte Aufsatz ist ausschließlich von mir verfasst worden. 
Der erste Aufsatz (Kapitel 2) stellt ein, auf einer Methode des Maschinellen Lernens basierendes Verfahren zur Demokratiemessung vor und zeigt auf, wie sich die Ergebnisse von empirischen Studien ändern, wenn man anstatt eines binären Demokratiemaßes ein kontinuierliches Demokratiemaß verwendet. Die Resultate des Aufsatzes zeigen, dass die Verwendung eines binären Demokratiemaßes in OLS Regressionen zu wesentlich kleineren Regressionkoeffizieten führt als die Verwendung eines kontinuierlichen Demokratiemaßes. Der Unterschied entsteht, weil binäre Demokratiemaße anfälliger für Meßfehler sind. Der Aufsatz zeigt außerdem, dass binäre und kontinuierliche Demokratiemaße ähnliche Ergebnisse liefern, wenn sie in 2SLS Analysen verwendet werden.

Der zweite Aufsatz (Kapitel 3) vergleicht Methoden der Datenaggregation und zeigt, dass die meisten dieser Verfahren implausible Demokratiemaße für Autokratien und Demokratien hervorbringen. Die einzige Methode, bei der dieses Problem nicht auftritt, ist das Verfahren, das im zweiten Kapitel dieser Dissertationsschrift vorgestellt wurde. Anhand eines einfachen ökonometrischen Modells zeigt dieser Aufsatz weiterhin, dass die Verwendung von ungeeigneten Aggregationsmethoden zu OLS bzw. 2SLS Koeffizieten führt, die den wahren Effekt von Demokratie überschätzen. Die Resultate einer Studie des Effekts von Demokratie auf Wirtschaftswachstum illustrieren, dass diese Überschätzung erheblich ist.

Der dritte Aufsatz (Kapitel 4) präsentiert ein politökonomisches Modell, das zeigt, dass die Qualität der ökonomischen Institutionen eines Landes in Folge einer Demokratisierung steigen kann. Das Modell prognostiziert des Weiteren, dass die Qualität der ökonomischen Institutionen in Folge einer Demokratisierung stärker ansteigt, wenn das Bildungsniveau der Bevölkerung hoch ist. Außerdem zeigt das Modell, dass sich die ökonomischen Institutionen von Autokratien mehr voneinander unterscheiden als die ökonomischen Institutionen von Demokratien. Um die Vorhersagen des Modells zu bestätigen, beinhaltet der Aufsatz die Analyse eines Paneldatensatzes, der aus 140 Ländern besteht und die Periode von 1920 bis 2015 abdeckt. 


\title{
Chapter 2
}

\section{Using machine learning for measuring democracy}

\author{
with KLAUS GründLER (LMU Munich, ifo Institute)
}

\begin{abstract}
We present a new aggregation method and use this technique to create democracy indices for 186 countries (1919 - 2016). Our method is based on a machine learning tool for pattern recognition, known as Support Vector Machine, and has three notable features: first, specifying the shape of the aggregation function is unnecessary, second, it creates both continuous and dichotomous indices, and third, it produces indicators of measurement uncertainty. We use these features to examine whether the results of empirical studies depend on the scale of the democracy index. Our results suggest that dichotomous indices create smaller OLS estimates than continuous indices because they suffer more from classical measurement error. We also observe that the differences in the regression estimates disappear when using an instrumental variable approach.
\end{abstract}




\subsection{Introduction}

The question of whether continuous or dichotomous indices are more appropriate for the measurement of democracy is the subject of a controversial discussion in economics and political science (Alvarez et al., 1996, Boix et al., 2013, Bollen and Jackman, 1989, Cheibub et al., 2010, Elkins, 2000). We contribute to this long-standing debate in two ways: first, we present a machine learning method that creates continuous and dichotomous measures of democracy, and second, we examine how replacing a continuous index with a dichotomous index affects the results of empirical analyses.

Measuring democracy is a procedure that consists of three steps (Munck and Verkuilen, 2002): first, choosing a concept of democracy, second, finding regime characteristics that reflect the components of the concept, and third, defining an aggregation rule that transforms the multidimensional raw data into an uni-dimensional index. The latter step includes the decision about the scale of the index. Two types of scaling exist, each of which posses several pros and cons. Proponents of continuous indices praise their discriminating power, while critics often complain about the simplicity of the aggregation rules (Bollen and Jackman, 1989, Cheibub et al., 2010).

Although a lot has been written about the advantages and disadvantages of continuous and dichotomous indices, we know little about the extent to which results of empirical studies depend on the scale of the democracy index. ${ }^{1}$ A key reason for this dearth of research is that creating conceptually equivalent continuous and dichotomous indices is difficult. Elkins (2000) address this issue by exploiting a continuous index and defining a threshold value up to which a regime can be considered as democratic. Bogaards (2010), Boix et al. (2013) and Cheibub et al. (2010) argue, however, that this simple approach is inadequate because of the arbitrariness of the threshold value. We propose a new approach for creating continuous and dichotomous indices. Our approach exploits a supervised machine learning technique for pattern recognition, known as Support Vector Machine (SVM). Choosing a threshold value is not necessary in our case because the SVM toolbox includes methods for both classification and regression analyses.

We use SVM to produce conceptually equivalent continuous and dichotomous indices. These indices are available for 186 countries and cover the 1919 - 2016 period. We use the SVM indices to study how the estimation results on the effect of democracy on economic growth depend on the scale of the democracy index. We observe that the dichotomous SVM index creates significantly smaller OLS estimates than the continuous SVM index. Our analysis also shows that the differences in the size of the regression coefficients disappear when we use a two- stage least squares (2SLS) approach. We find the same pattern when using other outcome variables.

\footnotetext{
${ }^{1}$ The literature includes some studies that compare the performance of different democracy indices (see e.g. Cheibub et al., 2010, Casper and Tufis, 2003, Gründler and Krieger, 2016). However, these studies compare democracy indices that differ not only with regard to their scale but also with regard to other aspects, such as the concept of democracy.
} 
Another feature of our machine learning method is that it creates an indicator of measurement uncertainty for each country-year observation. We use this key feature to explain our finding that the OLS estimates are sensitive to the scale of the index, whereas the 2SLS estimates are not. In line with the theory of Alvarez et al. (1996), we observe that continuous and dichotomous indices are subject to different types of measurement uncertainty: the number of country-year observations with measurement uncertainty is higher in case of a continuous index, while the extent of measurement uncertainty is higher in case of a dichotomous index. We also find that the average measurement uncertainty in a continuous index is greater than in a dichotomous index and thus argue that a dichotomous index suffers more from classical measurement error. Since the attenuation bias in OLS estimates is increasing in the size of the classical measurement error, the dichotomous index creates smaller OLS estimates than the continuous index. 2SLS estimates are robust to classical measurement error which is why we do not find systematic differences between the continuous index and the dichotomous index.

This paper is organized as follows. Section 2.2 gives an introduction to SVM. Section 2.3 shows how we use SVM to create continuous and dichotomous indices. Section 2.4 presents our empirical results. Section 2.5 concludes.

\subsection{Support Vector Machine}

Support Vector Machine (SVM) is a machine learning tool designed for pattern recognition. It reveals an unknown functional relationship $\mathfrak{F}: \mathcal{X} \rightarrow \mathcal{Z}$ that links a set of inputs $\mathbf{x}=\left(x_{1}, \ldots, x_{m}\right)^{\prime} \in \mathcal{X} \subseteq \mathbb{R}^{m}$ to an outcome $z \in \mathcal{Z} \subseteq \mathbb{R}$ for all observations $i$ in the sample $\mathcal{S}=\left\{\left(\mathbf{x}_{i}, z_{i}\right) \mid i=1, \ldots, n\right\}$ :

$$
\mathfrak{F}\left(\mathbf{x}_{i}\right) \stackrel{!}{=} z_{i} \quad \forall i=1, \ldots, n .
$$

In contrast to conventional methods of statistical modeling - e.g. Ordinary Least Squares (OLS) or Generalized Methods of Moments (GMM) - machine learning tools do not require prior assumptions about the shape of the functional relationship (Breiman et al., 2001). The literature distinguishes between supervised and unsupervised machine learning methods. ${ }^{2}$ SVM is a supervised method because its application needs a set of observations for learning the rule that maps $\mathbf{x}$ onto $z$ (Steinwart and Christmann, 2008). ${ }^{3}$

The mathematical foundations of SVM tools and their properties with regard to pre-

\footnotetext{
${ }^{2}$ The application of supervised machine learning requires the existence of observable input variables $(\mathbf{x})$ and an observable output variable $(z)$. The main objective is to estimate a mapping function that allows predicting the output variable for new input data. In contrast, unsupervised machine learning techniques are applied when there is no output variable and aim to structure the data.

${ }^{3}$ In this context, "learning the rule" means that an empirical model is estimated which adequately predicts the output $z$ of any input $\mathbf{x}$; it does not mean that SVM provides a closed form description of the functional relationship that facilitates a causal interpretation of the impact of component $x_{j}(j=1, \ldots, m)$ on the outcome $z$ (Steinwart and Christmann, 2008).
} 
diction accuracy, statistical robustness, and practicability are well documented (Abe, 2005, Bennett and Campbell, 2000, Steinwart and Christmann, 2008). In this study, we exploit two SVM tools to arrive at dichotomous classifications and to run nonlinear regressions. In the remainder of this section, we introduce the mathematical formulations of the Support Vector Classification and the Support Vector Regression. ${ }^{4}$

\subsubsection{Support Vector Classification}

A Support Vector Classification (SVC) is a non-linear extension of the General Portrait Algorithm (GPA). In its initial form, the GPA assumes the existence of hyperplanes

$$
H_{\mathbf{w}, b}(\mathbf{x})=\langle\mathbf{w}, \mathbf{x}\rangle+b \quad \mathbf{w} \in \mathbb{R}^{m},\|\mathbf{w}\|=1, b \in \mathbb{R}, \mathbf{x} \in \mathbb{R}^{m}
$$

that separate the observations in $\mathcal{S}=\left\{\left(\mathbf{x}_{i}, z_{i}\right) \mid i=1, \ldots, n\right\}$ according to their labels $z \in\{-1,1\} .{ }^{5}$ Panel (I) in Figure 2.1 illustrates this separation in an one-dimensional example.

The primary objective of the GPA is to find a linear classification function that assigns any input $\mathbf{x}_{i}$ to its output $z_{i}(i=1, \ldots, n)$. Panel (II) in Figure 2.1 shows that the number of eligible decision functions may be infinite. To arrive at an unique solution, the distance - called the margin - between a separating hyperplane and the nearest observation is calculated. GPA selects the hyperplane with the greatest margin in $\mathcal{S}$ (Abe, 2005, Steinwart and Christmann, 2008). Panels (III) and (IV) in Figure 2.1 illustrate this procedure.

In formal terms, the GPA solves the quadratic optimization problem

$$
\min _{\mathbf{w} \in \mathbb{R}^{m}, b \in \mathbb{R}} \frac{1}{2}\langle\mathbf{w}, \mathbf{w}\rangle \quad \text { s.t. } y_{i}\left(\left\langle\mathbf{w}, \mathbf{x}_{i}\right\rangle+b\right) \geq 1
$$

and uses the solution $\left(\mathbf{w}^{*}, b^{*}\right)$ to calculate the classification function

$$
\mathfrak{F}(\mathbf{x})=\operatorname{sign}\left(\left\langle\mathbf{w}^{*}, \mathbf{x}\right\rangle+b^{*}\right) \quad \mathbf{w}^{*} \in \mathbb{R}^{m}, b^{*} \in \mathbb{R} .
$$

GPA attracts little attention in applied research since a linear separation usually does not exist (see Panel (I) in Figure 2.2). Boser et al. (1992) extend the GPA to allow for the estimation of non-linear classification functions. They propose the use of a nonlinear function $\Phi: \mathcal{X} \rightarrow \mathcal{H}$ that maps the inputs $\mathbf{x} \in \mathcal{X}$ onto a Reproducing Hilbert Space $\mathcal{H}^{6}{ }^{6}$ The GPA is then applied to the adjusted sample $\mathcal{S}_{\mathcal{H}}=\left\{\left(\Phi\left(\mathbf{x}_{i}\right), z_{i}\right) \mid i=\right.$

\footnotetext{
${ }^{4}$ For further reading, we refer interested readers to Abe (2005), Smola and Schölkopf (2004), Steinwart and Christmann (2008) and Vapnik (1995, 1998)

${ }^{5}$ Note that $\langle\cdot, \cdot\rangle$ indicates the dot product of two vectors.

${ }^{6}$ The non-linear extension suggested by Boser et al. (1992) is based on mathematical theorems that prove the existence of a feature space $\mathcal{H}$, in which a hyperplane can perfectly separate the sample data $\mathcal{S}$. For details, see Steinwart and Christmann (2008).
} 
Figure 2.1 Linear separation - One-dimensional case.

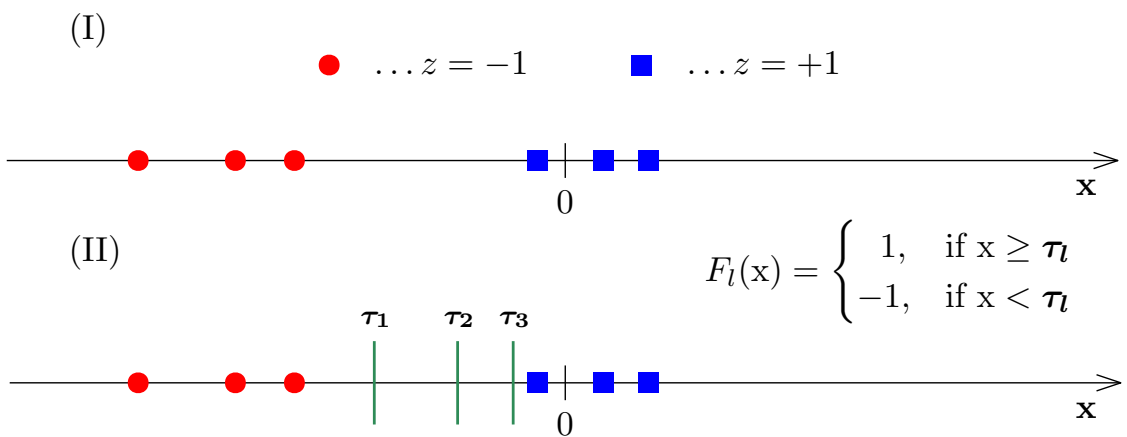

(III)

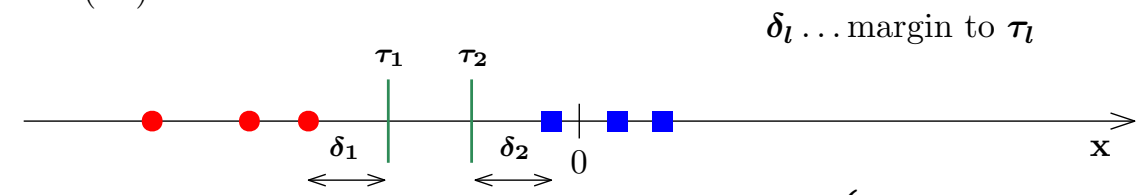

(IV)

$$
F_{\mathrm{GPA}}(\mathrm{x})=\left\{\begin{aligned}
1, & \text { if } \mathrm{x} \geq \boldsymbol{\tau}_{o p t} \\
-1, & \text { if } \mathrm{x}<\boldsymbol{\tau}_{\text {opt }}
\end{aligned}\right.
$$

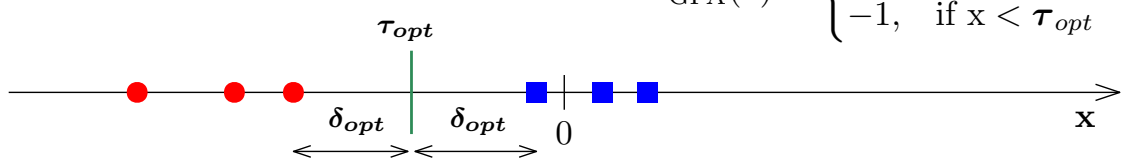

Notes: Panel I is a one-dimensional example in which GPA is applicable. Panel II shows that more than one hyperplane may separate the observations according to their labels. Panel III explains how the margin $\delta$ is calculated. Panel IV illustrates that GPA selects the hyperplane with the largest margin.

$1, \ldots, n\}$ and a dividing hyperplane is computed in $\mathcal{H}$ :

$$
H_{\mathbf{w}_{\mathcal{H}}^{*}, b_{\mathcal{H}}^{*}}^{\mathcal{H}}(\Phi(\mathbf{x}))=\left\langle\mathbf{w}_{\mathcal{H}}^{*}, \Phi(\mathbf{x})\right\rangle+b_{\mathcal{H}}^{*} \quad \mathbf{w}_{\mathcal{H}}^{*} \in \mathcal{H}, b_{\mathcal{H}}^{*} \in \mathbb{R} .
$$

The resulting classification function

$$
\mathfrak{F}(\mathbf{x})=\operatorname{sign}\left(\left\langle\mathbf{w}_{\mathcal{H}}^{*}, \Phi(\mathbf{x})\right\rangle+b_{\mathcal{H}}^{*}\right) \quad \mathbf{w}_{\mathcal{H}}^{*} \in \mathbb{R}^{m}, b_{\mathcal{H}}^{*} \in \mathbb{R}
$$

is non-linear in $\mathbf{x} \in \mathcal{X}$. Panels (II) and (III) in Figure 2.2 illustrate the mapping approach with the help of a simple example (Steinwart and Christmann, 2008).

Cortes and Vapnik (1995) argue that random noise and measurement error may lead to mislabeling. They therefore relax the auxiliary conditions of the GPA by including slack variables $\xi_{i} \geq 0$. Together with the non-linear GPA extension of Boser et al. (1992), this adjustment yields the optimization problem

$$
\min _{\mathbf{w}_{\mathcal{H}} \in \mathcal{H}, b_{\mathcal{H}} \in \mathbb{R}, \xi \in \mathbb{R}_{+}^{n}} \frac{1}{2}\left\langle\mathbf{w}_{\mathcal{H}}, \mathbf{w}_{\mathcal{H}}\right\rangle+C \sum_{i=1}^{n} \xi_{i} \quad \text { s.t. } \quad z_{i}\left(\left\langle\mathbf{w}_{\mathcal{H}}, \Phi\left(\mathbf{x}_{i}\right)\right\rangle+b_{\mathcal{H}}\right) \geq 1-\xi_{i} \forall i,
$$

where $C>0$ denotes a fixed cost parameter for penalizing misclassifications.

If the dimension of $\mathcal{H}$ is large, solving optimization problem (2.7) may turn out to be computationally infeasible (Steinwart and Christmann, 2008). In this case, the 
Figure 2.2 Non-linear separation - One-dimensional case.

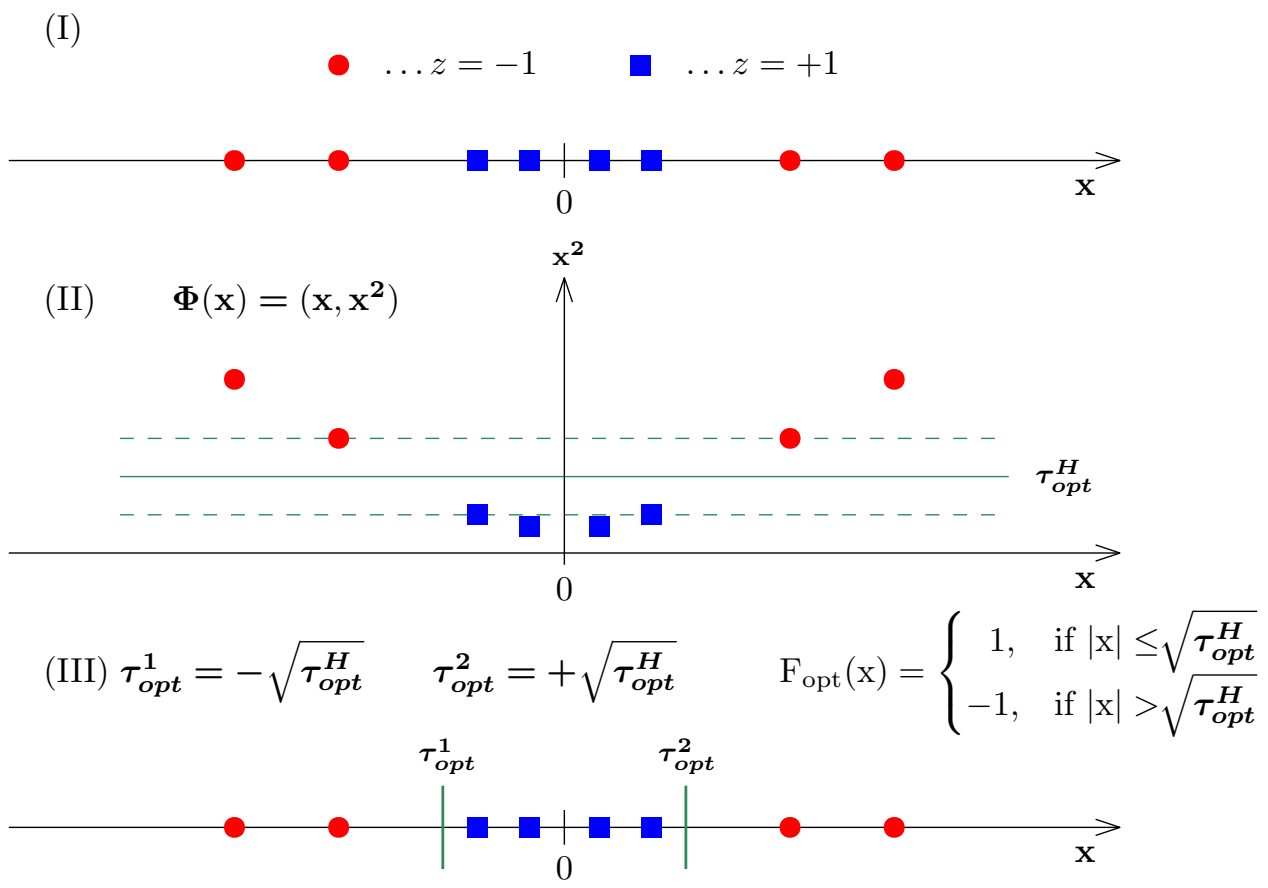

Notes: Panel I shows an example in which GPA is not applicable in $\mathcal{X}=\mathbb{R}$. In Panel II, a function $\Phi(x)=\left(x, x^{2}\right)$ is used to map the input data from $\mathcal{X}=\mathbb{R}$ onto a feature space $\mathcal{H}=\mathbb{R}^{2}$ and GPA computes a dividing hyperplane in $\mathcal{H}$. Panel III illustrates that the linear solution in $\mathcal{H}$ implies a non-linear solution in $\mathcal{X}$.

corresponding dual program

$$
\max _{\alpha \in[0, C]^{n}} \sum_{i=1}^{n} \alpha_{i}-\frac{1}{2} \sum_{i, j=1}^{n} z_{i} z_{j} \alpha_{i} \alpha_{j}\left\langle\Phi\left(\mathbf{x}_{i}\right), \Phi\left(\mathbf{x}_{j}\right)\right\rangle_{\mathcal{H}} \quad \text { s.t. } \sum_{i=1}^{n} z_{i} \alpha_{i}=0
$$

can be considered where $\alpha_{1}, \ldots, \alpha_{n}$ denote the Lagrange multipliers of the primal program. The dual program implies a closed form solution for the classification function

$$
\mathfrak{F}(\mathbf{x})=\operatorname{sign}\left(\sum_{i=1}^{n} z_{i} \alpha_{i}^{*}\left\langle\Phi\left(\mathbf{x}_{i}\right), \Phi(\mathbf{x})\right\rangle_{\mathcal{H}}+b_{\mathcal{H}}^{*}\right) .
$$

Since an appropriate feature map $\Phi: \mathcal{X} \rightarrow \mathcal{H}$ is usually not known, Schölkopf et al. (1998) apply the "kernel trick", i.e. they replace the unknown inner product $\left\langle\Phi\left(\mathbf{x}_{i}\right), \Phi(\mathbf{x})\right\rangle_{\mathcal{H}}$ with a known kernel function $\mathfrak{K}: \mathcal{X} \times \mathcal{X} \rightarrow \mathbb{R}:$

$$
\mathfrak{F}(\mathbf{x})=\operatorname{sign}\left(\sum_{i=1}^{n} z_{i} \alpha_{i}^{*} \mathfrak{K}\left(\mathbf{x}_{i}, \mathbf{x}\right)+b_{\mathcal{H}}^{*}\right) \cdot{ }^{7}
$$

\footnotetext{
${ }^{7}$ This idea of Schölkopf et al. (1998) is based on a theorem of Mercer (1909), who proves that each kernel function $\mathfrak{K}: \mathcal{X} \times \mathcal{X} \rightarrow \mathbb{R}$ is related to a Reproducing Hilbert Space $\mathcal{H}$ with
}

$$
\mathfrak{K}\left(\mathbf{x}_{i}, \mathbf{x}_{j}\right)=\left\langle\Phi\left(\mathbf{x}_{i}\right), \Phi\left(\mathbf{x}_{j}\right)\right\rangle_{\mathcal{H}} \quad \forall \mathbf{x}_{i}, \mathbf{x}_{j} \in \mathcal{X} .
$$


An observation is called Support Vector if its Lagrange multiplier $\alpha_{i}^{*}$ is not zero. The method takes its name from these data points since only Support Vectors affect the shape of the classification function (Abe, 2005).

\subsubsection{Support Vector Regression}

In their traditional form, GPA and SVC are limited to applications in which the output variable comes from a countably finite set. Vapnik $(1995,1998)$ overcomes this constraint by introducing a method that estimates real-valued functions. The objective of Support Vector Regression (SVR) is to find a function $\mathfrak{F}: \mathcal{X} \subseteq \mathbb{R}^{m} \rightarrow \mathcal{Z} \subseteq \mathbb{R}$ whose predicted outcomes deviate at most by $\varepsilon$ from the observed labels for all observations in $\mathcal{S}=\left\{\left(\mathbf{x}_{i}, z_{i}\right) \mid i=1, \ldots, n\right\}$ :

$$
\left|\mathfrak{F}\left(\mathbf{x}_{i}\right)-z_{i}\right| \stackrel{!}{\leq} \varepsilon \quad \forall i=1, \ldots, n
$$

Let's consider first a case in which the regression function is a hyperplane:

$$
\mathfrak{F}(\mathbf{x})=\langle\mathbf{w}, \mathbf{x}\rangle+b \quad \mathbf{w} \in \mathbb{R}^{m}, b \in \mathbb{R}, \mathbf{x} \in \mathbb{R}^{m}
$$

and the norm of the slope $\mathbf{w}$ needs to be minimized. In formal terms, one solves the quadratic optimization problem

$$
\min _{\mathbf{w} \in \mathbb{R}^{m}, b \in \mathbb{R}} \frac{1}{2}\|w\|^{2} \quad \text { s.t. } \begin{cases}z_{i}-\left\langle\mathbf{w}, \mathbf{x}_{i}\right\rangle-b \leq \varepsilon \quad & \forall i \\ \left\langle\mathbf{w}, \mathbf{x}_{i}\right\rangle+b-z_{i} \leq \varepsilon & \forall i\end{cases}
$$

and uses the solution $\left(\mathbf{w}^{*}, b^{*}\right)$ to specify the regression line.

Because solving optimization problem (2.13) often turns out to be impossible, the applicability of a linear SVR is limited. Vapnik $(1995,1998)$ thus proposes - in a manner similar to SVC - the application of slack variables $\left(\xi_{i}^{+}, \xi_{i}^{-}\right) \in \mathbb{R}_{+}^{2}$ that relax the auxiliary conditions and the use of a feature map $\Phi: \mathcal{X} \rightarrow \mathcal{H}$ that allows for non-linear estimations:

$$
\min _{\mathbf{w} \in \mathcal{H}, b \in \mathbb{R},\left(\xi_{i}^{+}, \xi_{i}^{-}\right) \in \mathbb{R}_{+}^{2}} \frac{1}{2}\|w\|^{2}+C \sum_{i=1}^{n}\left(\xi_{i}^{+}+\xi_{i}^{-}\right) \text {s.t. }\left\{\begin{array}{l}
z_{i}-\left\langle\mathbf{w}, \Phi\left(\mathbf{x}_{i}\right)\right\rangle-b \leq \varepsilon+\xi_{i}^{+} \\
\left\langle\mathbf{w}, \Phi\left(\mathbf{x}_{i}\right)\right\rangle+b-z_{i} \leq \varepsilon+\xi_{i}^{-} \\
\xi_{i}^{+}, \xi_{i}^{-} \geq 0 .
\end{array}\right.
$$

To avoid computational problems in cases in which the dimension of $\mathcal{H}$ is large, the corresponding dual problem

$$
\max _{\alpha^{+}, \alpha^{-}}-\frac{1}{2} \sum_{i, j=1}^{n}\left(\alpha_{i}^{+}-\alpha_{i}^{-}\right)\left(\alpha_{j}^{+}-\alpha_{j}^{-}\right)\left\langle\Phi\left(\mathbf{x}_{i}\right), \Phi\left(\mathbf{x}_{j}\right)\right\rangle_{\mathcal{H}}-\varepsilon \sum_{i=1}^{n}\left(\alpha_{i}^{+}+\alpha_{i}^{-}\right)+\sum_{i=1}^{n} y_{i}\left(\alpha_{i}^{+}-\alpha_{i}^{-}\right)
$$




$$
\text { s.t. } \sum_{i=1}^{n}\left(\alpha_{i}^{+}-\alpha_{i}^{-}\right)=0 \quad \text { and } \quad \alpha_{i}^{+}, \alpha_{i}^{-} \in[0, C] \text {, }
$$

can be considered, where $\alpha^{+}=\left(\alpha_{1}^{+}, \ldots, \alpha_{n}^{+}\right)$and $\alpha^{-}=\left(\alpha_{1}^{-}, \ldots, \alpha_{n}^{-}\right)$denote the Lagrangian multipliers of the primal program. The dual program yields the closed form solution

$$
\mathfrak{F}(\mathbf{x})=\sum_{i=1}^{n}\left(\alpha_{i}^{+}-\alpha_{i}^{-}\right)\left\langle\Phi\left(\mathbf{x}_{i}\right), \Phi(\mathbf{x})\right\rangle_{\mathcal{H}}+b_{\mathcal{H}}^{*} .
$$

Since $\Phi: \mathcal{X} \rightarrow \mathcal{H}$ is unknown, the "kernel trick" is applied to replace the unknown inner product $\left\langle\Phi\left(\mathbf{x}_{i}\right), \Phi(\mathbf{x})\right\rangle_{\mathcal{H}}$ with a kernel $\mathfrak{K}: \mathcal{X} \times \mathcal{X} \rightarrow \mathbb{R}$. The shape of the non-linear regression function

$$
\mathfrak{F}(\mathbf{x})=\sum_{i=1}^{n}\left(\alpha_{i}-\alpha_{i}^{*}\right) \mathfrak{K}\left(\mathbf{x}_{i}, \mathbf{x}\right)+b_{\mathcal{H}}^{*},
$$

depends only on those observations - called Support Vectors - whose Lagrangian multipliers $\left(\alpha_{i}, \alpha_{i}^{*}\right)$ are different from zero (Smola and Schölkopf, 2004).

\section{$2.3 \quad$ SVM indices}

The creation of a democracy index consists of three steps (Munck and Verkuilen, 2002): first, defining the term "democracy" (conceptualization), second, compiling data that reflect the components of the concept (operationalization), and third, specifying a rule that transforms the data into an index (aggregation). In formal terms, this means that the level of democracy $(\mathrm{d})$ is a function of the observed regime characteristics $(\mathbf{x})$ :

$$
\mathrm{d}=\mathcal{A}(\mathbf{x}) \in \mathcal{D} \quad \text { with } \quad \mathbf{x}=\left(x_{1}, \ldots, x_{m}\right) \in[0,1]^{m}
$$

where $\mathcal{A}:[0,1]^{m} \rightarrow \mathcal{D}$ is the aggregation function and $m$ the number of regime characteristics. Specifying $\mathcal{A}$ entails two methodological challenges: First, we must decide whether the codomain $(\mathcal{D})$ is binary $(\mathcal{D}=\{0,1\})$ or continuous $(\mathcal{D}=[0,1])$. Second, we neither know the shape of $\mathcal{A}$ nor can we directly observe the actual level of democracy (d) for all regimes.

\subsubsection{Literature review}

The literature presents numerous democracy indicators (see e.g. Acemoglu et al. (2019), Boix et al. (2013), Bjørnskov and Rode (2018) Cheibub et al. (2010), Coppedge and Reinicke (1990), Coppedge et al. (2008), Freedom House (2018), Marshall et al. (2018), Papaioannou and Siourounis (2008), Pemstein et al. (2010), Skaaning et al. (2015), Teorell et al. (2019), Vanhanen (2000)). Below, we discuss three of them in greater detail to illustrate the major weaknesses of existing approaches. 


\subsubsection{The Polity index}

The Polity IV index by Marshall et al. (2018) is the democracy indicator that is most frequently used in applied economics and other social sciences. The Polity index has an ordinal scale that range from -10 to 10 and is determined by five subjective regime characteristics. $^{8}$ Marshall et al. (2018) weight the five regime characteristics and use an additive aggregation method to transform them into an index.

The Polity index is subject to harsh criticism (Cheibub et al., 2010, Munck and Verkuilen, 2002, Treier and Jackman, 2008). First, no theoretical justification is provided for the assumed additive relationship between the regime characteristics and the degree of democratization. Second, weighting all regime characteristics equally is problematic, especially because some of the regime characteristics are almost identical in their content. Finally, no confidence intervals exist to indicate the measurement uncertainty in the indices.

\subsubsection{The Democracy-Dictatorship index}

The Democracy-Dictatorship (DD) index by Cheibub et al. $(2010)^{9}$ is the most frequently used dichotomous indicator of democracy. The concept of democracy underlying the DD index is minimalist and Cheibub et al. (2010) use four binary regime characteristics to specify the status of a regime. A regime is classified as "democratic" if: (i) the chief executive was chosen by a popular election or by a body that was itself popularly elected, (ii) the members of the legislature were popularly elected, (iii) more than one party competed in elections, and (iv) one alternation of power under the electoral rules that brought the incumbent to office took place.

Cheibub et al. (2010) acknowledge that their democracy indicator is prone to systematic error because of the condition regarding the alternation of power. This error occurs since regimes in which incumbents have (so far) not lost an election because of their great popularity will be classified as autocratic. Recent examples for this issue are Botswana and South Africa. Cheibub et al. (2010) address this issue by marking the regimes whose classification only depends on the condition regarding the alternation of power. We argue that this coding procedure is a weak approach for indicating measurement uncertainty since it provides no information about how likely it is that a specific regime is wrongly classified.

\subsubsection{The dichotomous index by Acemoglu et al. (2019)}

Acemoglu et al. (2019) combine the information of four democracy indicator to create

\footnotetext{
${ }^{8}$ Marshall et al. (2018) refer to these five characteristics as: (i) competitiveness of political participation, (ii) regulation of political participation, (iii) openness of executive recruitment, (iv) competitiveness of executive recruitment, and (v) executive constraints.

${ }^{9}$ For the initial release of this index, see Alvarez et al. (1996). For a recent update, see Bjørnskov and Rode (2018).
} 
a new dichotomous index. The coding is as follows: Acemoglu et al. (2019) first code all regimes as "democratic" that have a Polity IV index greater than 0 and a Freedom House index smaller than $5.5,{ }^{10}$ and then classify all regimes for which only one of the two indices is available, using the same thresholds and the dichotomous indices by Boix et al. (2013) and Cheibub et al. (2010) as additional sources of information. ${ }^{11}$

Acemoglu et al. (2019) acknowledge that their coding procedure creates some regime changes that are spurious and thus must be manually corrected. Manual adjustments are problematic for several reasons. A major problem is the lack of transparency. The index developed by Acemoglu et al. (2019) has three further weak points. First, the threshold values with regard to the Polity index and the Freedom House index are arbitrary (Bogaards, 2010). Second, some conceptual inconsistencies exist. ${ }^{12}$ Third, measurement uncertainty is not indicated.

\subsubsection{Machine learning procedure}

This section presents a machine learning approach for measuring democracy. Our approach has three key features: (i) It solves a non-linear optimization problem to specify the rule that transforms the regime characteristics into an index. An advantage of the optimization approach is that we avoid simplistic assumptions about the shape of the aggregation function and arbitrary weighting schemes. ${ }^{13}$ (ii) Applying SVM allows for producing - conceptually equivalent - continuous and dichotomous indices without choosing arbitrary threshold values. (iii) The degree of measurement uncertainty can be individually indicated for each country-year observation. In Section 2.4, we exploit the second and third feature to study the empirical consequences of using a continuous democracy indicator rather than a dichotomous democracy indicator.

\subsubsection{Conceptualization and operationalization}

The definition of democracy is a much debated issue. In this paper, we assume a narrow concept that includes the three aspects: political participation, political competition, and freedom of opinion (Dahl, 1971). We choose this definition to avoid conceptual overlaps with other factors, such as the quality of the economic institutions, the rule of law, or civil liberties.

We use nine regime characteristics that are available for a large sample (186 countries, 1919 - 2016) to operationalize our definition of democracy. Following Munck and

\footnotetext{
${ }^{10}$ The Freedom House index ranges from 1 (most democratic) to 7 (least democratic) and has similar weaknesses as the Polity index.

${ }^{11}$ There are two major reasons for missing information: first, the Freedom House index is not available prior to 1973, and second, the Polity index is not available for small countries.

${ }^{12}$ Conceptual inconsistencies exist because of changes in the data availability. For example, the Freedom House index is the only index that takes civil liberties into account. Since the Freedom House index was first published in 1973 and the democracy index offered by Acemoglu et al. (2019) starts in 1960, the concept of democracy that underlies this index changes over time.

${ }^{13}$ Chapter 3 of this dissertation explains in detail why these simplistic assumptions are problematic.
} 
Verkuilen's (2002) guidelines, we use subjective as well as objective regime characteristics. $^{14}$

We define political participation as the right of citizens to elect their political representatives (Dahl, 1971). Two types of disenfranchisement are common: first, constitutional restrictions exclude citizens from the political process due to their gender, race, social class, or income; and second, the constitutionally guaranteed voting right is undermined due to war, repression, or martial law. We have two regime characteristics with regard to political participation: the turnout and the voter-population-ratio.

Political competition exists if people with different party affiliations compete in public elections for political mandates (Dahl, 1971). We exploit an expert-based measure on party pluralism and collected four objective regime characteristics to operationalize this key aspect of democracy. Our objective regime characteristics are: (i) the share of parliament seats not won by the leading party, (ii) the ratio between the number of parliament seats won by the second largest party and the number of parliament seats won by the leading party, (iii) the share of votes not won by the leading party or candidate ${ }^{15}$, and (iv) the voting share of the second strongest party or candidate divided by the voting share of the strongest party or candidate.

People enjoy the freedom of opinion if they can freely choose their source of information and can express their political views regardless of whether they are compatible with the political views of the government (United Nations, 1948). To evaluate to what extent the citizens of a country have this freedom, we exploit gender-specific ratings on the freedom of debate from the Varieties of Democracy (V-Dem) Database (Coppedge et al., 2018).

\subsubsection{Priming data}

Using SVM needs observations for which input characteristics and the outcome are observable (Steinwart and Christmann, 2008). ${ }^{16}$ We take two steps to find observations that are suited for this purpose. First, we assume that the level of democracy of the most and least democratic regimes is uncontroversial and thus observable. ${ }^{17}$ Second, we use the continuous indices by Teorell et al. (2019) and Pemstein et al. (2010) to identify some regimes that belong to either of the two categories. We label a countryyear as "autocratic" ("democratic") if it is part of the lower (upper) decile of the index

\footnotetext{
${ }^{14}$ We obtain our objective data from a different sources, including African Election Database, the InterParliamentary Union, Adam Carr's Election Archive, the International Institute for Democracy and Electoral Assistance, the International Foundation of Electoral Systems, Nohlen (2005), Nohlen et al. (2001, 1999), and Nohlen and Stöver (2010). A documentation of the collected data is available upon request. The subjective data comes from Coppedge et al. (2018).

${ }^{15}$ Parliamentary and presidential elections are weighted according to their relevance.

${ }^{16}$ Henceforth, we refer to these observations as "priming data".

${ }^{17}$ Cheibub et al. (2010) and Lindberg et al. (2014) point out that distinguishing the least democratic regimes from the most democratic regimes is a simple exercise: almost everyone agrees that Sweden is democratic, whereas Saudi Arabia is not. We exploit this consensus on the regimes at the ends of the distribution to justify the assumption that the degree of democratization of these regimes is directly observable.
} 
by Teorell et al. (2019) or Pemstein et al. (2010). ${ }^{18}$

\subsubsection{Aggregation}

We use a five-step procedure to transform our nine regime characteristics into a democracy index. First, we decide on the codomain of the index. We can choose between a continuous index $(\mathcal{D}=[0,1])$ and a dichotomous index $(\mathcal{D}=\{0,1\})$. Second, we randomly select country-years from the priming data to produce the training set $\mathcal{T}_{\zeta}$. Third, we apply SVM to estimate a classification function or a regression function:

$$
\mathcal{A}_{\mathcal{T}_{\zeta}}^{\{0,1\}}: \mathcal{X} \rightarrow\{0,1\} \quad \text { or } \quad \mathcal{A}_{\mathcal{T}_{\zeta}}^{[0,1]}: \mathcal{X} \rightarrow[0,1]
$$

Fourth, we use the estimated aggregation function to compute a dichotomous or continuous index for each country-year observation $(i, t)$ in the data set:

$$
\mathrm{d}_{i, t, \zeta}^{\{0,1\}}=\mathcal{A}_{\mathcal{T}_{\zeta}}^{\{0,1\}}\left(\mathbf{x}_{i, t}\right) \quad \text { or } \quad \mathrm{d}_{i, t, \zeta}^{\{0,1\}}=\mathcal{A}_{\mathcal{T}_{\zeta}}^{[0,1]}\left(\mathbf{x}_{i, t}\right)
$$

Finally, we repeat the steps $2-4$ for all iterations $\zeta \in\left\{0, \ldots, \zeta_{\max }\right\}$.

\subsubsection{Output}

For each country-year, we extract three types of information from the procedure described above: First, the SVM index which is the median of the distribution produced by the $\zeta_{\max }$ realizations:

$$
\mathrm{d}_{i, t}^{\{0,1\}}=\operatorname{med}_{\zeta}\left(\mathrm{d}_{i, t, \zeta}^{\{0,1\}}\right) \quad \text { or } \quad \mathrm{d}_{i, t}^{[0,1]}=\operatorname{med}_{\zeta}\left(\mathrm{d}_{i, t, \zeta}^{[0,1]}\right)
$$

The second information is a set of indices that includes all percentiles of the distribution produced by the $\zeta_{\max }$ realizations:

$$
\mathfrak{D}_{i, t}^{\{0,1\}}=\left\{\mathrm{d}_{i, t, p_{0}}^{\{0,1\}}, \ldots, \mathrm{d}_{i, t, p_{100}}^{\{0,1\}}\right\} \quad \text { or } \quad \mathfrak{D}_{i, t}^{[0,1]}=\left\{\mathrm{d}_{i, t, p_{0}}^{[0,1]}, \ldots, \mathrm{d}_{i, t, p_{100}}^{[0,1]}\right\}
$$

where subscript $p_{j}$ denotes the $j$-th percentile. Below, we refer to $\mathfrak{D}$ as the $S V M$ index set. The third information is an indicator that reflects the measurement uncertainty in each SVM index:

$$
\sigma_{i, t}=\left(\frac{1}{100} \cdot \sum_{k=0}^{100}\left(\mathrm{~d}_{i, t}-\mathrm{d}_{i, t, p_{k}}\right)^{2}\right)^{0.5}
$$

\subsubsection{Country examples}

The continuous and dichotomous SVM indices are available for 186 countries and cover the period from 1919 to 2016. This section uses two of these countries to illustrate the

\footnotetext{
${ }^{18}$ We choose the indices by Teorell et al. (2019) or Pemstein et al. (2010) because of their scaling and availability. Section 2.3.4 addresses potential concerns about our selection strategy.
} 
Figure 2.3 Democracy in Austria (1919 - 2016) - SVM indices.

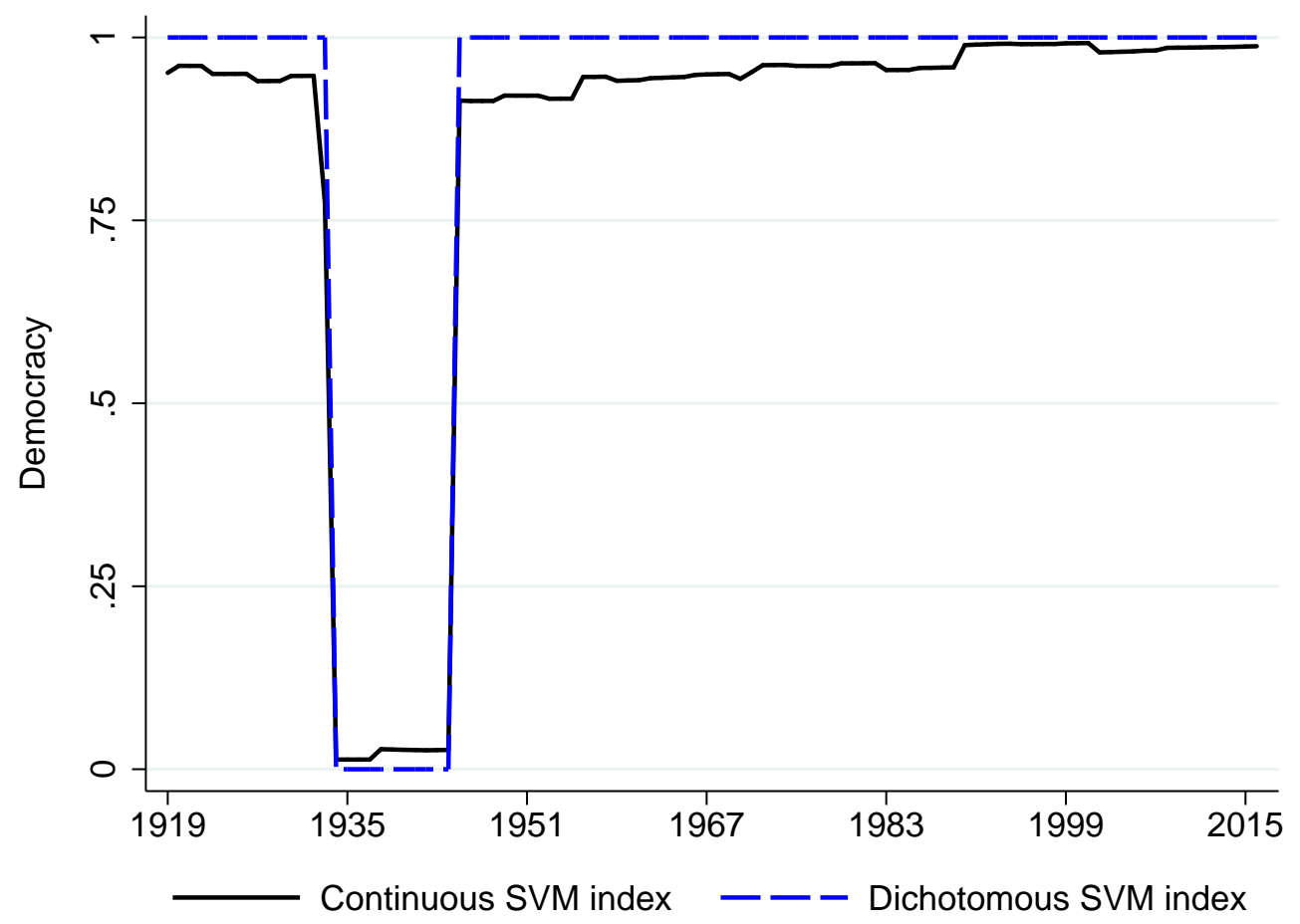

main similarities and differences of continuous and dichotomous democracy indices.

\subsubsection{Austria}

After the end of the First World War, Austria abolished the Habsburg monarchy and implemented a new constitutional law. This constitutional law established a parliamentary system with bi-cameral legislature and universal suffrage. Between 1920 and 1932, general elections were free and competitive. However, the main parties - the Christian Social Party and the Social Democratic Party - and their paramilitary forces created an atmosphere of violence (Nohlen and Stöver, 2010). After a series of armed clashes in February 1934, Chancellor Engelbert Dollfuss prohibited the Social Democratic Party and Austria became an one-party regime (Beller, 2006). From March 1938 to 1945, Austria was annexed by Nazi Germany. After the German defeat in the Second World War, Austria was divided in four occupation zones. However, unlike Germany, Austria remained a unified country and country-wide general elections were held in November 1945. Since then, all Austrian elections were free and fair (Beller, 2006, Nohlen and Stöver, 2010).

Figure 2.3 shows the degree of democratization of Austria as indicated by the continuous and dichotomous SVM indiex. We observe great similarities between these two indices. Consistent with the historical facts, both indices suggest two democratic periods $(1919$ - 1933, 1945 - 2016) and one autocratic period $(1934-1944)$. We also 
Figure 2.4 Democracy in South Africa (1919 - 2016) — SVM indices.

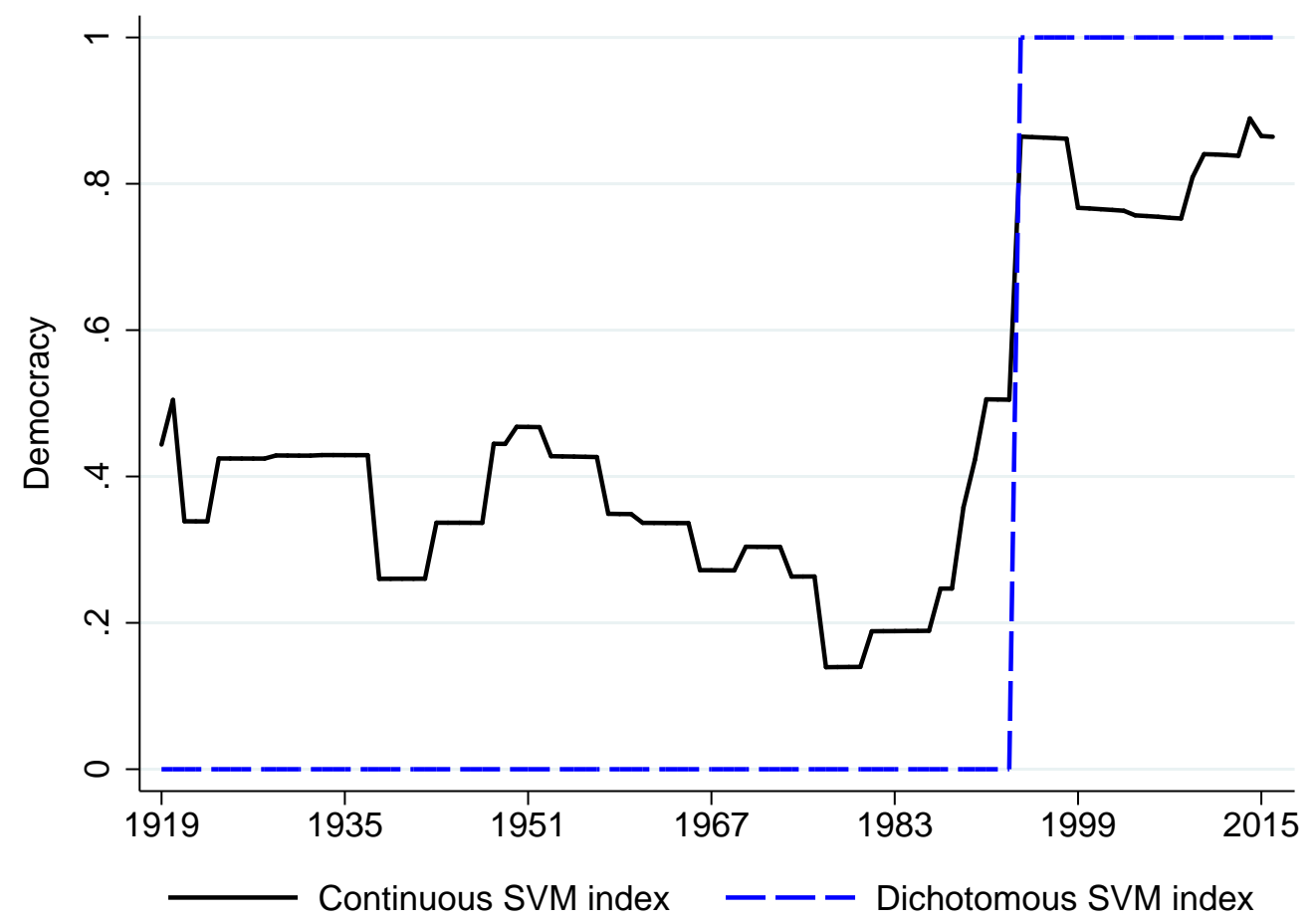

observe that the continuous SVM index differs slightly from the dichotomous SVM index for the first democratic period and the period after the Second World War. These differences nicely illustrate the greater discriminatory power of continuous index since only the continuous SVM index reveals the small democratic deficits in Austria that existed because of violent clashes and foreign occupation.

\subsubsection{South Africa}

South Africa gained independence from the United Kingdom in December 1911. Since then, all governments have been legitimized through competitive elections, although the suffrage was limited until 1994 (Nohlen et al., 1999): From 1911 to 1930, only white men could vote. White women obtained voting rights in 1930, while black citizens who constitute the majority of the South African population remained disenfranchised until 1994.

The general election in May 1948 brought the National Party (NP) into power. The new government implemented a system of racial segregation-known as the Apartheid regime - which caused a systematic repression of the non-white South Africans (Beck, 2013).

The Apartheid regime ended peacefully. After his election in 1989, President Frederik de Klerk launched a number of reforms: he lifted the ban of the African National Congress (ANC) and other black political organizations, released most political prison- 
Figure 2.5 SVM index sets of South Africa (1988, 1990, 1992, 1994).
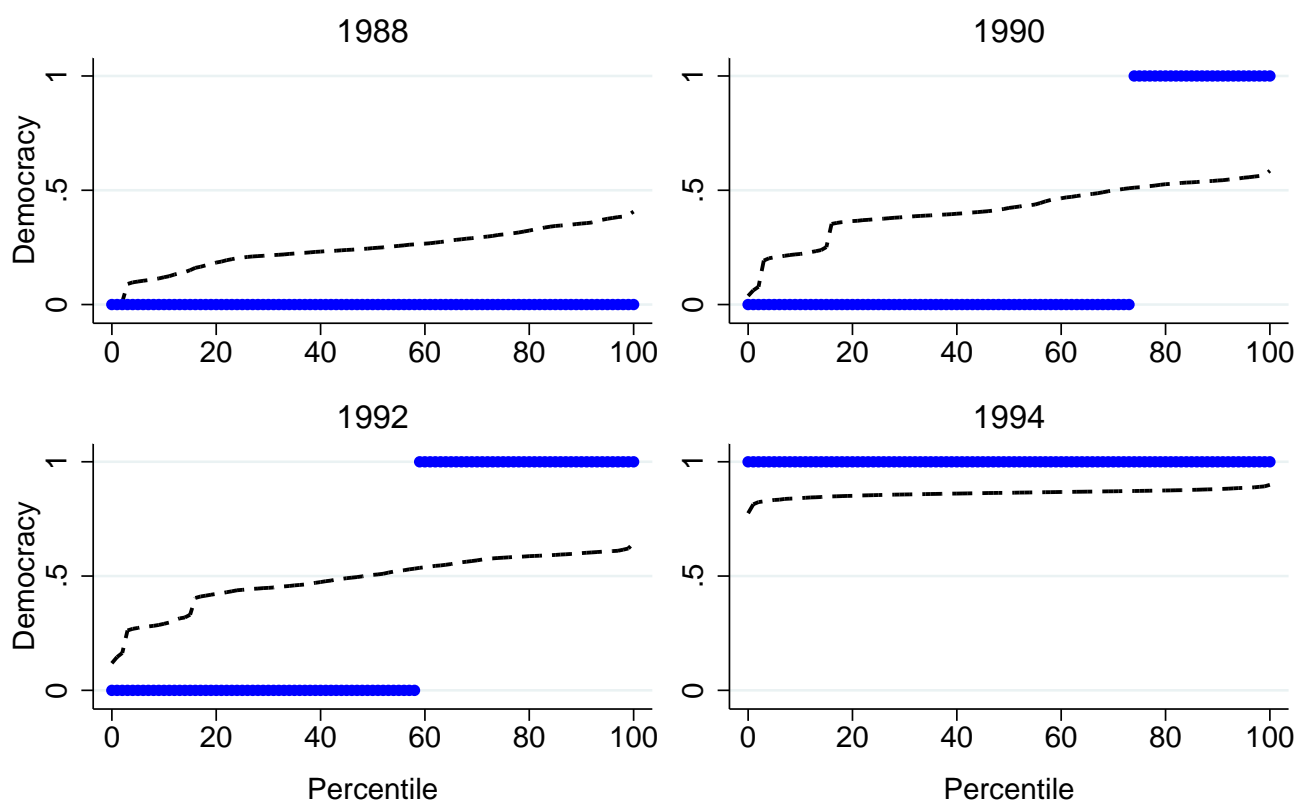

Continuous SVM index set

- Dichotomous SVM index set

ers, improved the political rights of non-white citizens, and started negotiations with the ANC on a new electoral law. The reform process led to a parliamentary election under universal suffrage in April 1994, which was clearly won by the ANC. All subsequent elections had similar results (Beck, 2013, Nohlen et al., 1999).

Figure 2.4 shows the SVM indices of South Africa. We find notable differences between our continuous and dichotomous index. A major difference concerns the period in which the black citizens of South Africa were excluded from the political process (1919 - 1989). We observe that the dichotomous SVM index is stable over this period and classifies South Africa as autocratic, which is reasonable because of the disenfranchisement of black South Africans. The continuous index differs in two aspects from the dichotomous index: First, it reports an intermediate level of democracy and thus captures the hybrid nature of South Africa's political system at this time. Second, the continuous index reflects the increasing repression of the non-white South Africans during the Apartheid period (1948 - 1989).

Another period in which the continuous and dichotomous index differ from each other is the transition period $(1989-1994)$. While the continuous SVM index indicates a gradual transition towards democratic system, the dichotomous SVM index suggests a sudden change in the political institutions. We think that the description given by our continuous index is more consistent with the historical events.

A major feature of our machine learning procedure is that it creates multiple indices for each country-year observations and provides some information about measurement 
Table 2.1 Measurement uncertainty in SVM indices of South Africa (1988, 1990, 1992, 1994).

\begin{tabular}{lllll}
\hline & $\mathbf{1 9 8 8}$ & $\mathbf{1 9 9 0}$ & $\mathbf{1 9 9 2}$ & $\mathbf{1 9 9 4}$ \\
\cline { 2 - 5 } Continuous SVM Index & 0.088 & 0.119 & 0.116 & 0.018 \\
Dichotomous SVM Index & 0.000 & 0.445 & 0.495 & 0.000 \\
\hline
\end{tabular}

uncertainty. Figure 2.5 presents the SVM index sets of four South African observations (1988, 1990, 1992, 1994). Table 2.1 shows the corresponding indicators of measurement uncertainty. Two results are especially notable. First, if we consider the dichotomous SVM index set rather than the dichotomous SVM index, the impression of a sudden change in the political system of South Africa disappears. Second, the continuous and dichotomous index suffer from different types of measurement uncertainty: measurement uncertainty is relatively low for continuous indices and exists permanently, while it is only temporary but considerably larger when occurring in the dichotomous indices.

\subsubsection{Discussion}

Before we turn to the empirical part of this paper in which we investigate the consequences of a change in the scale of the index, we discuss some concerns that may exist with regard to our machine learning procedure.

\subsubsection{Priming data - Adequacy}

The priming data consists of 2.728 country-year observations: 1.308 democracies and 1.420 autocracies (for a list, see Appendix Table A.1). We used the election handbooks published by Dieter Nohlen $(1999,2001,2005,2010)$ and many other sources to examine whether the selected observations are correctly labeled. We detected only four controversial observations: The first two are the country-years for Switzerland in 1952/1970 because women could not vote in national elections. The third is the observation for Israel in 1999 because Palestinians living in the Gaza Strip and the West Bank were not allowed to participate in elections of the Israeli parliament. The last case is the observation for Uganda in 1980, which is labeled as autocratic. This label is reasonable given that a coup occurred in May 1980. However, in December 1980, a multiparty election was hold, which speaks against the adequacy of the label.

In Section 2.3.2, we claimed that the degrees of democratization of the regimes included in the priming data are uncontroversial. To substantiate this claim, we checked how popular democracy indices evaluate the selected observations. Table A.2 reports the results of our analysis and suggests that there is broad consensus about the labeled country-years. For example, we find that 99.84 percent of the democratically labeled observations belong to the highest category of the Lexical Index of Electoral Democracy (LIED) by Skaaning et al. (2015). 


\subsubsection{Priming data - Representativeness}

Autocratic and democratic regimes take different forms. The priming data must reflect this institutional heterogeneity, because otherwise we may produce SVM indices that discriminate in favor of regime types. Below, we illustrate that this condition is satisfied.

Cheibub et al. (2010) distinguish four types of dictatorship: civil dictatorship, communist dictatorship, military dictatorship, and royal dictatorship. The first column of Table A.3 shows that the priming data includes autocracies of each of these four types.

Schedler (2002) discerns between electoral autocracies and closed autocracies: while the former category refers to autocracies in which non-competitive elections take place, the second category consists of regimes in which the government does not organize national elections. The second and third column of Table A.3 show that the priming data includes both electoral and closed autocracies.

The theories developed by Olson (1993) and Wintrobe (1990) imply that the durability of a regime can serve as a classification criterion for autocracies. We distinguish between three types: (i) autocracies that exist for less than six years, (ii) autocracies that exist for more than 6 years and less than 26 years, and (iii) autocracies that exist for at least 26 years. The last three columns of Table A.3 show that the durations of the autocratic regimes included in the priming data differ considerably.

Cheibub et al. (2010) distinguish democracies according to the power balance between the parliament and the head of government. Their classification scheme consists of three categories: parliamentary regimes, semi-presidential regimes, and presidential regimes. The first column of Table A.4 shows that our priming data includes democratic regimes of all three types.

Persson and Tabellini (2005) suggest that legislative authorities are established through different voting procedures (proportional vs. majoritarian systems) and have different structures (unicameral vs. bicameral systems). Columns $2-5$ of Table A.4 show that the priming data reflects this institutional heterogeneity.

\subsubsection{Priming data - Alternative selection procedures}

We exploit the Electoral Democracy (ED) index by Teorell et al. (2019) and the Unified Democracy Score (UDS) index by Pemstein et al. (2010) to specify the priming data. We label country-year observations as "autocratic" ("democratic") when they belong to the lower (upper) decile of the ED or the UDS index. We choose these two indices because of their scaling and availability. Table A.5 shows that the SVM indices remain almost unchanged when using alternative selection criteria.

\subsubsection{Falsification tests}

We also investigate the consequences of having country-year observations in the priming 
data that are incorrectly labeled. We distinguish between two types of mislabeling: (i) an actually autocratic regime is labeled as democratic, and (ii) an actually democratic regime is labeled as autocratic.

To create a situation in which our machine learning procedure faces incorrect labels, we first falsify the 35 Finish and the 31 Omani observations in the priming data and then compare the original SVM indices with the SVM indices that we obtain when using the priming data in which the Finish/Omani observations are mislabeled. We find that the average change in the continuous SVM indices is negligible (Finland: 0.029; Oman 0.040) and that the corresponding dichotomous SVM indices do not change at all. These findings are notable since they indicate that our machine learning procedure autonomously corrects errors in the priming data.

\subsubsection{Out-of-sample prediction}

The priming data only includes observations from 1950 or later. We do not use earlier observations because we exploit them for an out-of-sample validation. We proceed in the following way: first, we identify the "last selected" country-years ${ }^{19}$ and then select those observations from the 1919 - 1949 period whose ED/UDS index is larger (smaller) than the ED/UDS index of the last selected democratic (autocratic) country-year. ${ }^{20}$ This approach creates a list of 545 country-year observations. Below, we refer to them as "validation data".

If our aggregation procedure works adequately, we should not find systematic differences when we compare the average of the SVM indices of the autocratic/ democratic observations in the priming data with the average of the SVM indices of the autocratic/democratic observations in the validation data. Table A.6 shows that the differences in the mean values are negligibly small. ${ }^{21}$

\subsubsection{Measurement error in the regime characteristics}

When selecting regime characteristics, a trade-off exists between data quality and data availability. We give high priority to data quality and follow Munck and Verkuilen's (2002) guidelines, recommending the use of disaggregated data from subjective and objective sources. However, despite our best efforts, measurement errors in the regime characteristics are an issue because of interpolated data and inconsistent information.

Our aggregation procedure provides a tool kit for capturing the measurement uncertainty that comes from measurement errors in the regime characteristics. To illustrate

\footnotetext{
${ }^{19}$ For example, the last selected democratic country-year with regard to the ED index by Teorell et al. (2019) is the observation for Luxembourg in 2016 (ED index $=0.8627)$. The last selected autocratic country-year is the observation from Venezuela in 1958 (ED index =0.0985). An observation belongs to the priming data and is labeled as autocratic (democratic) if its ED index is smaller (greater) than 0.0985 (0.8627).

${ }^{20}$ With regard to the UDS, we use the extended version published by Márquez (2016) to get indices for the 1919 - 1949 period.

${ }^{21}$ Systematic differences in the mean SVM indices would indicate an overfitting problem in favor of the priming data.
} 
this feature, we proceed in three steps. First, we create biased regime characteristics:

$$
\hat{x}_{i, t_{j}}=x_{i, t_{j}}+\eta_{j} \quad \text { with } \quad \eta_{j} \sim \mathcal{U}\left(-\lambda \cdot \sigma_{x_{j}}, \lambda \cdot \sigma_{x_{j}}\right)
$$

where $\lambda$ specifies the degree of distortion and $\sigma_{x_{j}}$ denotes the sample standard deviation of the $j$-th regime characteristic. ${ }^{22}$ Second, we use the biased regime characteristics to produce biased SVM indices. Finally, we examine whether the biased SVM indices lie between the lower and upper bound of the unbiased SVM index sets. The coverage rates reported in Table A.7 show that this is indeed the case. We therefore believe that the SVM index sets can be used to indicate the measurement uncertainty in the SVM indices.

\subsubsection{Numerical robustness}

A key feature of our aggregation method is that we do not have to specify the aggregation rule manually and thus avoid simplistic/arbitrary assumptions about the functional relationship between the regime characteristics and the degree of democratization. Our approach only requires the setting of two parameters: the maximum number of iterations $\left(\zeta_{\max }\right)$ and a cost parameter $(C)$ that determines how strong misclassifications with regard to the priming data will be penalized when estimating the aggregation function. In our basic setup, we set $\zeta_{\max }=2000$ and $C=1$. Table A.8 shows that the SVM indices change only marginally if we use other parameterizations.

\subsubsection{Spurious and redundant regime characteristics}

Our definition of democracy consists of three dimensions (political competition, political participation, freedom of opinions) and we operationalize each of these aspects through multiple regime characteristics (see Section 2.3.2). Munck and Verkuilen (2002) recommend this approach, but also explain that using multiple regime characteristics can lead to biased indices if the used aggregation method cannot identify redundant regime characteristics. ${ }^{23}$ We proceed in two steps to illustrate how our machine learning method reacts to redundancy in the regime characteristics. First, we create a regime characteristic that is almost perfectly correlated with voter turnout:

$$
x_{i, t_{\text {red }}}=x_{i, t_{\text {turnout }}}+\xi_{i, t} \quad \text { with } \quad \xi_{i, t} \sim \mathcal{U}(-0.01,0.01)
$$

\footnotetext{
${ }^{22}$ For example, $\lambda=0.1$ implies that the turnout can be biased up to \pm 3.4 percentage points and that the share of votes of the leading party can be biased up to \pm 2.8 percentage points.

${ }^{23}$ Munck and Verkuilen (2002) use the Polity index by Marshall et al. (2018) to illustrate the problems that may result from redundant regime characteristics. Munck and Verkuilen (2002) first explain that the regime characteristics competitiveness of political participation and regulation of political participation capture the same aspect of democracy. They then argue that the additive aggregation rule of the Polity index does not take this redundancy into account since all regime characteristics are equally weighted. The consequence is an unintentionally strong emphasis on political participation.
} 
Second, we extend the list of regime characteristics by the redundant variable and apply our machine learning method. Columns 1 and 3 of Table A.9 show that the resulting SVM indices differ only marginally from the original SVM indices. ${ }^{24}$

Furthermore, we examine the consequence of adding a random variable

$$
x_{i, t_{\text {rand }}} \sim \mathcal{U}(0,1)
$$

to the list of regime characteristics. Columns 2 and 4 of Table A.9 show that the resulting chances in the SVM indices are minor.

\subsection{Empirical analysis}

In this section, we examine the empirical consequences of replacing a continuous index with a conceptually equivalent dichotomous index. Our main application example is the relationship between democracy and economic growth.

\subsubsection{Literature review}

The question of how democracy affects economic growth is the subject of many studies in economics and political sciences. Theoretical studies suggest different mechanisms: Democratic transitions may accelerate economic growth because of higher public investments in education and better economic institutions. On the other hand, democratization may decrease economic growth because of efficiency loses and higher tax burden (Knutsen, 2012, Przeworski and Limongi, 1993).

Early empirical studies on the effect of democracy on economic growth produce diverse results. Doucouliagos and Ulubaşoğlu (2008) who compiled the results of more than 80 studies find that:

"15 percent of the estimates are negative and statistically significant, 21 percent of the estimates are negative and statistically insignificant, 37 percent of the estimates are positive and statistically insignificant, and 27 percent of the estimates are positive and statistically significant."

The results of more recent - and econometrically more sophisticated studies - are less diverse, but still not unambiguous. Acemoglu et al. (2019), Flachaire et al. (2014), Gründler and Krieger (2016), Persson and Tabellini (2008, 2009), Knutsen (2015), Madsen et al. (2015), and Papaioannou and Siourounis (2008) find that democracy positively affects economic growth, whereas Apolte (2011), Aisen and Veiga (2013), and Murtin and Wacziarg (2014) find that political regimes do not affect economic growth.

\footnotetext{
${ }^{24}$ We obtain similar results when using another regime characteristic to generate a redundant variable. These results are available upon request.
} 
Although a controversial debate exists on whether continuous or dichotomous indices are more suited for measuring democracy, only little is known about the consequences of replacing a continuous index with a dichotomous index. In their meta-analysis, Doucouliagos and Ulubaşoğlu (2008) find that estimated effect of democracy on economic growth decreases when using a dichotomous index. The main problem with this study is that it compares indices that differ not only with regard to their scale but also with regard to their concept of democracy. Elkins (2000) who investigates the effect of democracy on international conflict provides the only study that compares conceptually equivalent continuous and dichotomous indices. His results also suggest that continuous indices produce larger regression coefficients than dichotomous indices. However, since Elkins (2000) runs only one regression, it remains unclear whether his result generally applies or whether the consequence of switching from one type of scaling to the other type is context-specific.

\subsubsection{Identification strategies}

Acemoglu et al. (2019) and Persson and Tabellini (2008) explain that identifying the effect of democracy on economic growth is challenging for three key reasons: first, the causality running from economic growth to democracy, second, the non-observable differences between autocracies and democracies, and third, the dips in economic growth that often precede democratic transitions. ${ }^{25}$

We address these three endogeneity issues in two ways. First, we estimate the dynamic fixed effect model:

$$
Y_{i, t}=\sum_{l=1}^{4} \beta_{l} \cdot Y_{i, t-l}+\gamma \cdot D_{i, t}+\xi_{i}+\eta_{t}+\varepsilon_{i, t}
$$

where $D_{i, t}$ is the degree of democratization of country $i$ in year $t, Y_{i, t}$ the log of GDP per capita, $\xi_{i}$ the country fixed effect, $\eta_{t}$ the year fixed effect, and $\varepsilon_{i, t}$ the error term. Following Acemoglu et al. (2019), we add four lags of the dependent variable to the regression model.

Since a dynamic fixed effect model may produce biased estimates of $\gamma$ due to omitted time-varying factors, we also apply a two-stage least squares procedure. We exploit the first lag of the regional (jack-knifed) degree of democratization to create exogenous variation in the domestic degree of democratization (Acemoglu et al., 2019, Giuliano et al., 2013, Persson and Tabellini, 2009). The motivation for our instrumentation strategy is that political transitions often occur in regional waves, and thus a strong correlation exist between the regional and the domestic degree of democratization (Huntington,

\footnotetext{
${ }^{25}$ These dips are problematic from econometric perspective because they constitute a violation of the parallel trends assumption that are required by conventional diff-in-diff and dynamic panel data estimators.
} 
1993, Teorell, 2010). Put differently, we estimate the first-stage model:

$$
D_{i, t}=\sum_{l=1}^{L} \delta_{l} \cdot Y_{i, t-l}+\alpha \cdot Z_{i, t-1}+\zeta_{i}+\tau_{t}+\iota_{i, t}
$$

with

$$
Z_{i, t}=\frac{1}{|\mathcal{R}|} \sum_{j \in \mathcal{R}} D_{j, t} \quad \text { and } \quad \mathcal{R}=\left\{j: j \neq i, r_{j}=r_{i}\right\} .
$$

where $r_{i}$ denotes the region in which country $i$ is located. ${ }^{26}$

\subsubsection{Estimation results}

Column 1 of Table 2.2 shows results from estimating (2.26) using the continuous SVM democracy index. The underlying sample is unbalanced, covers the period from 1919 to 2016 and includes data of 163 countries. The standard errors are clustered at the country level and robust to heteroscedasticity. The data on GDP per capita comes from the Maddison Project Database 2018 (Bolt et al., 2018).

The OLS coefficient presented in Column 1 suggests that democracy positively affects economic growth. The estimate is statistically significant at the 1 percent level and implies that a democratic transition increases GDP per capita by about 1.7 percent.

Column 3 of Table 2.2 shows how the OLS estimate changes if we replace the continuous SVM index with the dichotomous SVM index. We observe that the point estimate decreases from 0.017 to 0.011. The difference between these OLS coefficients is statistically significant at the one percent level. ${ }^{27}$

Columns 2 and 4 of Table 2.2 present our 2SLS estimates. ${ }^{28}$ Two findings are particularly relevant. First, compared to the OLS estimates shown in Columns 1 and 3, the size of the coefficients increase considerably. Second, and even more important for the purpose of our study, replacing the continuous SVM index with the dichotomous SVM index has no significant consequence anymore.

Appendix A.1 reports the results of several robustness checks. Appendix Table A.12 uses five-year averaged data rather than annual data to examine the effect of democracy on economic growth. Appendix Tables A.13 and A.14 show results from sub-sample analyses. Appendix Table A.15 illustrates how the estimation results change when adding time-variant control variables to the regression model. ${ }^{29}$ All estimates reported

\footnotetext{
${ }^{26}$ We use the classification of the United Nations to divide the world into 19 regions. For details, see Appendix Table A.10.

${ }^{27}$ The OLS estimate that we obtain when using the dichotomous index closely resembles the figure reported by Acemoglu et al. (2019).

${ }^{28}$ Appendix Table A.11 reports the first-stage estimates. These estimates suggest that the correlation between the regional and the domestic degree of democratization is strong. In Table 2.2, we report several first-stage diagnostics. We present the Sanderson and Windmeijer (2016) F-statistic and find that it exceeds the Stock and Yogo (2005) critical value. We also report the p-values of the weak instrument tests by Anderson and Rubin (1949) and Stock and Wright (2000). Neither of these tests suggests a weak instrument problem.

${ }^{29}$ The list of control variable includes: an expert-based index of high court independence, population growth, a
} 
Table 2.2 Democracy and economic growth - Baseline results.

\begin{tabular}{lcccc}
\hline & \multicolumn{2}{c}{ Continuous SVM index } & \multicolumn{2}{c}{ Dichotomous SVM index } \\
\hline & \multicolumn{1}{c}{$(1)$} & $(2)$ & $(3)$ & $(4)$ \\
\cline { 2 - 5 } & $O L S$ & $2 S L S$ & $O L S$ & $2 S L S$ \\
\hline Democracy & $0.017^{* * *}$ & $0.029^{* * *}$ & $0.011^{* * *}$ & $0.026^{* * *}$ \\
& $(0.0028)$ & $(0.0047)$ & $(0.0019)$ & $(0.0044)$ \\
\hline Observations & 10,733 & 10,708 & 10,733 & 10,708 \\
Countries & 163 & 163 & 163 & 163 \\
Equal. (p-val.) & - & - & 0.002 & 0.497 \\
SaWi (F.stat.) & - & 167.79 & - & 136.44 \\
AR (p-val.) & - & 0.000 & - & 0.000 \\
StWr (p-val.) & - & 0.000 & - & 0.000 \\
KP (p-val.) & - & 0.000 & & 0.000 \\
\hline
\end{tabular}

Notes: This table presents OLS and 2SLS estimates. The dependent variable is the log of GDP per capita. All regressions include four lags of the dependent variable, country fixed effects, and year fixed effects. The first lag of the regional (jack-knifed) degree of democratization serves as the instrument for the domestic degree of democratization. We report the results a Wald test to show whether the estimate reported in Column 3 (4) is statistically significant from the estimate reported in Column 1 (2). Standard errors are clustered at the country level and reported in parentheses. The following notation is used to highlight coefficients that are significantly different from zero: ${ }^{*}$ p-value $<0.10,{ }^{* *}$ p-value $<0.05,{ }^{* * *}$ p-value $<0.01$.

in these tables imply that democracy has a positive effect on economic growth. In addition, the OLS estimates that we obtain when using the continuous SVM are always considerably larger than the OLS estimates that we receive from using the dichotomous SVM index. This difference vanishes if we consider the 2SLS estimates.

Economic theory indicates two main channels through which democracy fuels economic growth: human capital and quality of economic institutions. We test these predictions by estimating the model (Acemoglu et al., 2019):

$$
C_{i, t}=\sum_{l=1}^{L} \alpha_{l} \cdot C_{i, t-l}+\sum_{l=1}^{L} \beta_{l} \cdot Y_{i, t-l}+\gamma \cdot D_{i, t}+\xi_{i}+\eta_{t}+\varepsilon_{i, t}
$$

where $C$ is either our measure of human capital (average years of schooling) or institutional quality (high court independence). Appendix Tables A.16 and A.17 show that the estimates of the effect of democracy on institutional quality/human capital are positive and statistically significant at conventional levels. In line with our former results, we also find that replacing the continuous SVM index with the dichotomous SVM index causes a decrease in the OLS estimates, while the 2SLS estimates remain almost unchanged.

binary measure of civil conflict, and a standard measure of human capital (average years of schooling). The data comes from Barro and Lee (2013), Bolt et al. (2018), Brecke (1999), Cohen and Soto (2007), Coppedge et al. (2018), the Cross-National Time Series Data Archive, the World Bank, the Uppsala Conflict Data Program, and the web page www.populstat.info. 


\subsubsection{Explanation}

We draw two conclusions from the results shown in the previous section: first, a continuous index creates larger OLS estimates than a dichotomous index, and second, the 2SLS estimates created by a continuous index do not differ from the 2SLS created by a dichotomous index. We can explain this result with standard econometric theory (Angrist and Pischke, 2009, Wooldridge, 2010).

Classical measurement error in an explanatory variable biases an OLS estimate towards zero. This bias - known as attenuation bias - increases in the size of the classical measurement error and disappears when using an instrumental variable approach. Differences in the extent of classical measurement error can therefore serve as explanation for our results, if the dichotomous index suffers, on average, more from classical measurement error than the continuous index. Our machine learning procedure allows for testing this issue because it produces indicators of measurement uncertainty. We find that the mean uncertainty in the dichotomous index (0.043) exceeds the mean uncertainty in the continuous index (0.026).

\subsection{Conclusion}

We present a new aggregation method and uses this technique to produce novel measures of democracy (186 countries, 1919 - 2016). Our method is based on a machine learning technique of pattern recognition, known as Support Vector Machine (SVM). An advantage of using SVM is that we do not have to specify the aggregation rule in a manual way and thus avoid simplistic assumption about the relationship between the regime characteristics and the level of democracy. Our machine learning procedure has two further features: first, it creates conceptually equivalent continuous and dichotomous indices, and second, it produces indicators of measurement uncertainty. We use these features to study the consequences of applying a continuous index rather than a dichotomous index. We observe that a dichotomous index creates significantly smaller OLS estimates than a continuous index. We also show that this difference disappears when using a two-stage least approach. Our explanation for this result is that a dichotomous democracy index suffers more from classical measurement error than a continuous index and thus creates a greater attenuation bias in OLS estimates.

The two main lessons to be learned from our paper are the following: First, the differences in the scale of the index partly explain why studies on the economic consequences of political transition differ with regard to the estimated effect of democracy. Second, the attenuation bias that arises when using a dichotomous democracy index in an OLS analysis is substantial and scholars who use this type of index must seriously address this endogeneity issue. 


\section{A.1 Additional tables}

Table A.1 Priming data - Selected country-years.

\begin{tabular}{|c|c|c|}
\hline Country & Observations & Years \\
\hline \multicolumn{3}{|c|}{ Democratic regimes (1308 observations) } \\
\hline Australia & 51 & $1964,1966-67,1969-2016$ \\
\hline Austria & 63 & $1950-59,1961,1963-65,1967-2015$ \\
\hline Barbados & 2 & $1981-82$ \\
\hline Belgium & 55 & $1955,1963-2016$ \\
\hline Brazil & 19 & $1995-98,2000-14$ \\
\hline Canada & 42 & $1972-81,1983-2013,2016$ \\
\hline Chile & 15 & $2002-16$ \\
\hline Costa Rica & 41 & $1975-80,1982-2016$ \\
\hline Cyprus & 22 & $1989-2010$ \\
\hline Czech Republic & 23 & $1991-2013$ \\
\hline Denmark & 67 & $1950-2016$ \\
\hline Estonia & 24 & $1993-2016$ \\
\hline Finland & 35 & $1967-1971,1987-2016$ \\
\hline France & 47 & $1970-2016$ \\
\hline Germany & 48 & $1950-52,1972-2016$ \\
\hline Greece & 28 & $1984-2011$ \\
\hline Hungary & 8 & 1994-1997, 2004-05, 2007, 2009 \\
\hline Iceland & 47 & $1967-2013$ \\
\hline Ireland & 40 & $1968,1976-81,1983-2015$ \\
\hline Israel & 1 & 1999 \\
\hline Italy & 48 & $1960-61,1963-1976,1983-1992,1994-2012,2014-16$ \\
\hline Japan & 14 & $1980-90,2010-14$ \\
\hline Latvia & 2 & $2013-14$ \\
\hline Luxembourg & 60 & $1951-53,1960-2016$ \\
\hline Malta & 27 & $1973-75,1989-2012$ \\
\hline Mauritius & 1 & 2004 \\
\hline Netherlands & 65 & $1952-2016$ \\
\hline New Zealand & 54 & $1963-2016$ \\
\hline Norway & 49 & $1968-2016$ \\
\hline Poland & 24 & $1991-2014$ \\
\hline Portugal & 33 & $1984-2016$ \\
\hline Slovakia & 12 & 1999-2012 \\
\hline Slovenia & 12 & $1997,2002-11,2013-15$ \\
\hline Spain & 29 & $1980-82,1987-2012$ \\
\hline St. Kitts and Nevis & 1 & 2010 \\
\hline Sweden & 50 & $1967-2016$ \\
\hline Switzerland & 48 & $1952,1970-2016$ \\
\hline Taiwan & 1 & 2005 \\
\hline United Kingdom & 35 & $1961,1964,1975-89,1999-2016$ \\
\hline United States & 37 & $1968-69,1976-77,1983-86,1988-2016$ \\
\hline Uruguay & 28 & $1989-2016$ \\
\hline \multicolumn{3}{|c|}{ Autocratic regimes (1420 observations) } \\
\hline Afghanistan & 34 & $1950-63,1978-91,1996-2001$ \\
\hline Albania & 29 & $1951-53,1955,1957-61,1965,1970,1981-89$ \\
\hline Algeria & 14 & $1965-76,1985,1994$ \\
\hline Angola & 18 & $1975-92$ \\
\hline Argentina & 12 & $1966-71,1977-82$ \\
\hline Bahrain & 28 & $1971-73,1976-2000$ \\
\hline Benin & 10 & $1974-79,1984,1986-87,1989$ \\
\hline Bhutan & 57 & $1950-2006$ \\
\hline Bolivia & 7 & $1972-77,1980$ \\
\hline Brazil & 2 & $1968-69$ \\
\hline Bulgaria & 8 & $1980,1983-89$ \\
\hline Burkina Faso & 1 & 1965 \\
\hline Burma (Myanmar) & 39 & $1963-1974,1983-2008,2010$ \\
\hline Burundi & 16 & $1967-81,1988$ \\
\hline Cambodia & 16 & $1953,1966-67,1979-91$ \\
\hline Cameroon & 1 & 1988 \\
\hline Central African Rep. & 15 & $1967-1980,1988$ \\
\hline Chad & 17 & $1962,1970,1972-74,1976-77,1980-89$ \\
\hline Chile & 14 & $1975-88$ \\
\hline China & 44 & $1950-78,1985,1989-97,2000,2013-16$ \\
\hline Democratic Rep. of Congo & 16 & $1965-76,1983-87,1989$ \\
\hline Rep. of Congo & 7 & $1968-1972,1978-79$ \\
\hline Cuba & 48 & $1958,1960-2005,2007$ \\
\hline Czech Republic & 5 & $1950-1954$ \\
\hline Dominican Rep. & 10 & $1950-1953,1955-1960$ \\
\hline ; & : & : \\
\hline
\end{tabular}


Table A.1 Priming data — Selected country-years (continued).

\begin{tabular}{|c|c|c|}
\hline Country & Observations & Years \\
\hline : & $\vdots$ & $\vdots$ \\
\hline Egypt & 3 & $1954-56$ \\
\hline Equatorial Guinea & 17 & $1973-82,1985-91$ \\
\hline Eritrea & 15 & $2002-16$ \\
\hline Ethiopia & 32 & $1950-59,1961-62,1965,1970-72,1974-86,1988-90$ \\
\hline Gabon & 1 & 1968 \\
\hline Germany (East) & 25 & $1953,1960-66,1969,1972-88$ \\
\hline Ghana & 1 & 1965 \\
\hline Greece & 6 & $1968-73$ \\
\hline Guatemala & 3 & $1956,1964-54$ \\
\hline Guinea & 18 & $1958-60,1967-68,1972-84$ \\
\hline Guinea-Bissau & 2 & 1980,1985 \\
\hline Haiti & 20 & $1950,1963-64,1967,1971-84,1992-93$ \\
\hline Indonesia & 1 & 1965 \\
\hline Iran & 19 & $1953-64,1966-1974,1976$ \\
\hline Iraq & 40 & $1963-2002$ \\
\hline Ivory Coast & 1 & 1966 \\
\hline Jordan & 22 & $1950,1957-59,1961-64,1967-68,1970,1974-83$ \\
\hline Korea (North) & 59 & $1958-2016$ \\
\hline Kuwait & 10 & $1965-66,1976,1979-80,1986-1990$ \\
\hline Laos & 40 & $1976-89,1991-2016$ \\
\hline Lesotho & 2 & $1970-71$ \\
\hline Liberia & 2 & $1980-81$ \\
\hline Libya & 45 & $1952-55,1970-2010$ \\
\hline Malawi & 22 & $1964,1966,1972-87,1989-92$ \\
\hline Maldives & 4 & $1965-68$ \\
\hline Mali & 7 & $1975-78,1980-81,1985$ \\
\hline Mauritania & 4 & $1979-82$ \\
\hline Mongolia & 9 & $1950-51,1980,1983-88$ \\
\hline Morocco & 12 & 1956-1962, 1965-69 \\
\hline Mozambique & 15 & $1976-1990$ \\
\hline Nepal & 10 & $1950-51,1960-65,1967-68$ \\
\hline Niger & 4 & $1979-82$ \\
\hline Nigeria & 1 & 1966 \\
\hline Oman & 31 & $1970-2000$ \\
\hline Pakistan & 1 & 1980 \\
\hline Panama & 3 & $1969-71$ \\
\hline Paraguay & 5 & $1954,1956-57,1960-61$ \\
\hline Peru & 1 & 1969 \\
\hline Philippines & 5 & $1973-77$ \\
\hline Portugal & 16 & $1951-54,1956-59,1961-64,1966-68,1970$ \\
\hline Qatar & 47 & $1970-2016$ \\
\hline Romania & 6 & $1983-88$ \\
\hline Russia (Soviet Union) & 9 & $1950-52,1967-69,1984-86$ \\
\hline Rwanda & 5 & $1974-1977,1980$ \\
\hline Saudi Arabia & 67 & $1950-2016$ \\
\hline Serbia (Yugoslavia) & 10 & $1950,1954-57,1975-79$ \\
\hline Somalia & 19 & $1970-80,1983-90$ \\
\hline Spain & 18 & $1950-67$ \\
\hline Sudan & 16 & $1959-63,1989-97,1999,2001$ \\
\hline Swaziland & 11 & $1974-77,1984,1986-87,1989-92$ \\
\hline Syria & 28 & $1961,1965,1970-73,1983-2002,2011-12$ \\
\hline Taiwan & 20 & $1950-69$ \\
\hline Togo & 14 & $1967-79,1985$ \\
\hline Tunisia & 5 & $1956-1959,1962$ \\
\hline Turkmenistan & 20 & $1992-2012$ \\
\hline Uganda & 9 & $1972-1980$ \\
\hline United Arab Emirates & 41 & $1971-2011$ \\
\hline Uruguay & 3 & $1976-78$ \\
\hline Uzbekistan & 16 & $1995-06,2008,2010-12$ \\
\hline Venezuela & 3 & $1954-56$ \\
\hline Vietnam & 20 & $1954-59,1985-86,1989-2000$ \\
\hline Yemen (Yemen North) & 31 & $1950-70,1978-1987$ \\
\hline
\end{tabular}

Notes: This table reports the country-years that are part of the priming data. The selection is based on the indicies developed by Pemstein et al. (2010) and Teorell et al. (2019). 
Table A.2 Priming data - Agreement rates.

\begin{tabular}{lccccc}
\hline & \multicolumn{5}{c}{ Democratic regimes } \\
\cline { 2 - 6 } Overlap & Polity $(\geq 7)$ & LIED $(=6)$ & ANRR $(=1)$ & BMR $(=1)$ & BR $(=1)$ \\
\cline { 2 - 6 } & 0.9943 & 0.9984 & 1.0000 & 1.0000 & 1.0000 \\
\hline \multirow{3}{*}{ Overlap } & Autocratic regimes \\
\cline { 2 - 6 } & Polity $(\leq-7)$ & LIED $(\leq 1)$ & ANRR $(=0)$ & BMR $(=0)$ & BR $(=0)$ \\
\cline { 2 - 6 } & 0.9511 & 0.9441 & 0.9993 & 0.9993 & 1.0000 \\
\hline
\end{tabular}

Notes: This table shows agreement rates, i.e. the share of country-year observations in the priming data that are labeled as "autocratic" ("democratic") and are classified as autocracy (democracy) by an alternative index. The list of alternative indices includes: the Polity IV index (Marshall et al., 2018), the Lexical index of electoral democracy (Skaaning et al., 2015), and the dichotomous indices by Acemoglu et al. (2019), Boix et al. (2013), and Bjørnskov and Rode (2018).

Table A.3 Priming data - Representativeness of autocratic regimes.

\begin{tabular}{|c|c|c|c|c|c|c|}
\hline & \multirow{2}{*}{$\frac{\text { Regime }}{\Sigma}$} & \multicolumn{2}{|c|}{ Elections } & \multicolumn{3}{|c|}{ Duration } \\
\hline & & Yes & No & $\leq 5$ years & $6-25$ years & $>25$ years \\
\hline Civil dictator. & 199 & 141 & 58 & 64 & 115 & 20 \\
\hline Communist dictator. & 386 & 269 & 117 & 49 & 153 & 184 \\
\hline Military dictator. & 429 & 119 & 310 & 154 & 229 & 46 \\
\hline \multirow[t]{2}{*}{ Royal dictator. } & 406 & 84 & 322 & 37 & 128 & 241 \\
\hline & 1,420 & 613 & 807 & 304 & 625 & 491 \\
\hline
\end{tabular}

Notes: Our machine learning approach requires that the priming data reflects the institutional heterogeneity among autocracies and democracies. This table presents how the autocratically labeled country-year observations are distributed over different categories. The data comes from Bjørnskov and Rode (2018) and Geddes et al. (2014).

Table A.4 Priming data - Representativeness of democratic regimes.

\begin{tabular}{lccccc}
\hline & Regime & \multicolumn{2}{c}{ Legislature } & \multicolumn{2}{c}{ Voting system } \\
\cline { 2 - 6 } & $\Sigma$ & Unicameral & Bicameral & Proportional & Majoritarian \\
\cline { 2 - 6 } Parliamentary demo. & 792 & 366 & 426 & 606 & 186 \\
Semi-presidential demo. & 306 & 102 & 204 & 260 & 46 \\
Presidential demo. & 210 & 63 & 147 & 173 & 37 \\
\cline { 2 - 6 } & 1,308 & 531 & 7777 & 269 & 269 \\
\hline
\end{tabular}

Notes: Our machine learning approach requires that the priming data reflects the institutional heterogeneity among autocracies and democracies. This table presents how the democratically labeled country-year observations are distributed over different categories. The data comes from Bjørnskov and Rode (2018). 
Table A.5 Alternative selection criteria for priming data.

\begin{tabular}{lccccc}
\hline & $\begin{array}{c}\text { Only ED } \\
\text { index }\end{array}$ & $\begin{array}{c}\text { Only UDS } \\
\text { index }\end{array}$ & $\begin{array}{c}\text { Add Polity } \\
\text { index }\end{array}$ & $\begin{array}{c}\text { Add Lib-Dem } \\
\text { index }\end{array}$ & $\begin{array}{c}\text { Add Polity \& } \\
\text { Lib-Dem index }\end{array}$ \\
\cline { 2 - 5 } Mean deviation & 0.0147 & 0.0104 & 0.0109 & 0.0133 & 0.0041 \\
Coverage rate & 1.0000 & 1.0000 & 1.0000 & 1.0000 & 1.0000 \\
\cline { 2 - 6 } & \multicolumn{7}{c}{ Panel A: Continuous SVM index } \\
Mean deviation & 0.0142 & 0.0046 & 0.0070 & 0.0072 & 0.0019 \\
Coverage rate & 1.0000 & 1.0000 & 1.0000 & 1.0000 & 1.0000 \\
\hline
\end{tabular}

Notes: This table shows how the SVM indices change when using alternative criteria for the creation of the priming data. We report two summary statistics: (i) the mean deviation between the original SVM indices and the SVM indices that arise when using the alternative selection criterion, and (ii) the coverage rate, i.e. the share of country-year observations for which the alternative SVM index is between the lower and upper bound of the original SVM index set. The original SVM indices use the upper/lower deciles of the Electoral Democracy (ED) index by Teorell et al. (2019) and the Unified Democracy Score (UDS) by Pemstein et al. (2010) to create the priming data. In Column 1 (2), the selection is only based on the upper/lower decile of the ED (UDS) index. In Column 3 - 5, we also use the upper/lower deciles of the Polity index (Marshall et al., 2018) and the Liberal Democracy index by Coppedge et al. (2018).

Table A.6 Out of sample predictions.

\begin{tabular}{lcccc}
\hline & \multicolumn{2}{c}{ Continuous SVM index } & \multicolumn{2}{c}{ Dichotomous SVM index } \\
\hline & Priming & Validation & Priming & Validation \\
\cline { 2 - 5 } Autocratic observations & 0.0245 & 0.0396 & 0.0021 & 0.0000 \\
Democratic observations & 0.9751 & 0.9527 & 1.0000 & 1.0000 \\
\hline
\end{tabular}

Notes: This table reports the average SVM index of the country-year observations in the priming data and the validation data.

Table A.7 Measurement error in the regime characteristics.

\begin{tabular}{lccccc}
\hline & $\lambda=0.01$ & $\lambda=0.025$ & $\lambda=0.05$ & $\lambda=0.10$ & $\lambda=0.20$ \\
\cline { 2 - 5 } & \multicolumn{5}{c}{ Panel A: Continuous SVM index } \\
\cline { 2 - 6 } Mean deviation & 0.0009 & 0.0018 & 0.0034 & 0.0065 & 0.0121 \\
Coverage rate & 1.0000 & 0.9996 & 0.9994 & 0.9925 & 0.9620 \\
\cline { 2 - 6 } & \multicolumn{5}{c}{ Panel B: Dichotomous SVM index } \\
\cline { 2 - 6 } Mean deviation & 0.0002 & 0.0009 & 0.0014 & 0.0030 & 0.0050 \\
Coverage rate & 1.0000 & 1.0000 & 1.0000 & 1.0000 & 1.0000 \\
\hline
\end{tabular}

Notes: This table shows how the SVM indices react to random measurement error in the regime characteristics. The parameter $\lambda$ specifies the degree of distortion: for example, $\lambda=0.1$ implies that voter turnout can be biased up to \pm 3.4 percentage points. We report two summary statistics: (i) the mean deviation between the original SVM indices $(\lambda=0)$ and the biased SVM indices $(\lambda>0)$, and (ii) the coverage rate, i.e. the share of country-year observations for which the biased SVM index is between the lower and upper bound of the original SVM index set. 
Table A.8 Numerical stability — Parameter choice.

\begin{tabular}{|c|c|c|c|c|c|c|}
\hline & \multicolumn{3}{|c|}{ Number of iterations $\left(\zeta_{\max }\right)$} & \multicolumn{3}{|c|}{ Cost parameter $(C)$} \\
\hline & 500 & 1000 & 5000 & 0.5 & 2 & 5 \\
\hline & \multicolumn{6}{|c|}{ Panel A: Continuous SVM index } \\
\hline Mean deviation & 0.0009 & 0.0007 & 0.0003 & 0.0058 & 0.0060 & 0.0161 \\
\hline \multirow[t]{2}{*}{ Coverage rate } & 1.0000 & 1.0000 & 1.0000 & 1.0000 & 1.0000 & 1.0000 \\
\hline & \multicolumn{6}{|c|}{ Panel B: Dichotomous SVM index } \\
\hline Mean deviation & 0.0004 & 0.0005 & 0.0001 & 0.0058 & 0.0092 & 0.0136 \\
\hline Coverage rate & 1.0000 & 1.0000 & 1.0000 & 1.0000 & 1.0000 & 1.0000 \\
\hline
\end{tabular}

Notes: This table shows how the SVM indices react to changes in the computational parameters. We report two summary statistics: (i) the mean deviation between the original SVM indices and the SVM indices that arise when using the alternative parameter choice, and (ii) the coverage rate, i.e. the share of country-year observations for which the alternative SVM index is between the lower and upper bound of the original SVM index set. The original parameter choices are $\zeta_{\max }=2000$ and $C=1$.

Table A.9 Spurious and redundant regime characteristics.

\begin{tabular}{lcccc}
\hline & \multicolumn{2}{c}{ Continuous SVM index } & \multicolumn{2}{c}{ Dichotomous SVM index } \\
\hline & Redundant & Random & Redundant & Random \\
\cline { 2 - 5 } Mean deviation & 0.0030 & 0.0070 & 0.0023 & 0.0045 \\
Coverage rate & 1.0000 & 0.9842 & 1.0000 & 1.0000 \\
\hline
\end{tabular}

Notes: This table shows how the SVM indices react if the set of regime characteristics includes unnecessary information. We report two summary statistics: (i) the mean deviation between the original SVM indices and the SVM indices that arise when adding a redundant/random variable to the list of regime characteristics, and (ii) the coverage rate, i.e. the share of country-year observations for which the alternative SVM index is between the lower and upper bound of the original SVM index set. 
Table A.10 List of countries (by region).

\begin{tabular}{|c|c|}
\hline Region & Countries \\
\hline Eastern Africa & $\begin{array}{l}\text { Burundi, Comoros, Djibouti, Eritrea, Ethiopia, Kenya, Madagascar, } \\
\text { Malawi, Mauritius, Mozambique, Rwanda, Seychelles, Somalia, South } \\
\text { Sudan, Tanzania, Uganda, Zambia, Zimbabwe }\end{array}$ \\
\hline Middle Africa & $\begin{array}{l}\text { Angola, Cameroon, Central African Republic, Chad, Democratic } \\
\text { Republic of Congo, Republic of Congo, Equatorial Guinea, Gabon, Sao } \\
\text { Tome and Principe }\end{array}$ \\
\hline Northern Africa & Algeria, Egypt, Libya, Morocco, Sudan, Tunisia \\
\hline Southern Africa & Botswana, Lesotho, Namibia, South Africa, Swaziland \\
\hline Western Africa & $\begin{array}{l}\text { Benin, Burkina Faso, Cape Verde, Gambia, Ghana, Guinea, } \\
\text { Guinea-Bissau, Ivory Coast, Liberia, Mali, Mauritania, Niger, Nigeria, } \\
\text { Senegal, Sierra Leone, Togo }\end{array}$ \\
\hline Caribbean & $\begin{array}{l}\text { Antigua and Barbuda, Bahamas, Barbados, Cuba, Dominica, Dominican } \\
\text { Republic, Grenada, Haiti, Jamaica, Saint Kitts and Nevis, Saint Lucia, } \\
\text { Saint Vincent and the Grenadines, Trinidad and Tobago }\end{array}$ \\
\hline Central America & $\begin{array}{l}\text { Belize, Costa Rica, El Salvador, Guatemala, Honduras, Mexico, } \\
\text { Nicaragua, Panama }\end{array}$ \\
\hline Northern America & Canada, United States \\
\hline South America & $\begin{array}{l}\text { Argentina, Bolivia, Brazil, Chile, Columbia, Ecuador, Guyana, } \\
\text { Paraguay, Peru, Suriname, Uruguay, Venezuela }\end{array}$ \\
\hline Central Asia & Kazakhstan, Kyrgyzstan, Tajikistan, Turkmenistan, Uzbekistan \\
\hline Eastern Asia & China, Japan, Mongolia, North Korea, South Korea, Taiwan \\
\hline Oceania & $\begin{array}{l}\text { Australia, Fiji, New Zealand, Papua New Guinea, Samoa, Solomon } \\
\text { Island, Tonga, Vanuatu }\end{array}$ \\
\hline South Eastern Asia & $\begin{array}{l}\text { Brunei, Cambodia, East Timor, Indonesia, Laos, Malaysia, Myanmar, } \\
\text { Philippines, Singapore, Thailand, Vietnam }\end{array}$ \\
\hline Southern Asia & $\begin{array}{l}\text { Afghanistan, Bangladesh, Bhutan, India, Iran, Maldives, Nepal, } \\
\text { Pakistan, Sri Lanka }\end{array}$ \\
\hline Western Asia & $\begin{array}{l}\text { Armenia, Azerbaijan, Bahrain, Cyprus, Georgia, Iraq, Israel, Jordan, } \\
\text { Kuwait, Lebanon, Oman, Qatar, Saudi Arabia, Syria, Turkey, United } \\
\text { Arab Emirates, Yemen }\end{array}$ \\
\hline Eastern Europe & $\begin{array}{l}\text { Belarus, Bulgaria, Czech Republic, Hungary, Moldova, Poland, } \\
\text { Romania, Russia, Slovakia, Ukraine }\end{array}$ \\
\hline Northern Europe & $\begin{array}{l}\text { Denmark, Estonia, Finland, Iceland, Ireland, Latvia, Lithuania, Norway, } \\
\text { Sweden, United Kingdom }\end{array}$ \\
\hline Southern Europe & $\begin{array}{l}\text { Albania, Bosnia and Herzegovina, Croatia, Greece, Italy, Kosovo, } \\
\text { Macedonia, Malta, Montenegro, Portugal, Serbia, Slovenia, Spain }\end{array}$ \\
\hline Western Europe & $\begin{array}{l}\text { Austria, Belgium, France, Germany, Luxembourg, Netherlands, } \\
\text { Switzerland }\end{array}$ \\
\hline
\end{tabular}

Notes: This table shows how we assign countries to geographical regions. Our classification scheme is identical with the classification scheme proposed by the United Nations. 
Table A.11 Democracy and economic growth — First-stage estimates.

\begin{tabular}{lcc}
\hline & Continuous SVM index & Dichotomous SVM index \\
\hline Democracy (regional) & $(1)$ & $(2)$ \\
& $0.789^{* * *}$ & $0.757^{* * *}$ \\
& $(0.0609)$ & $(0.0648)$ \\
\hline Observations & 10,708 & 10,708 \\
Countries & 163 & 163 \\
\hline
\end{tabular}

Notes: This table presents first-stage estimates. For the corresponding second-stage estimates, see Columns 2 and 4 of Table 2.2. Standard errors are clustered at the country level and reported in parentheses. The following notation is used to highlight coefficients that are significantly different from zero: ${ }^{*}$ p-value $<0.10,{ }^{* *} \mathrm{p}$-value $<0.05,{ }^{* * *}$ p-value $<0.01$.

Table A.12 Democracy and economic growth — Five-year data

\begin{tabular}{|c|c|c|c|c|}
\hline & \multicolumn{2}{|c|}{ Continuous SVM index } & \multicolumn{2}{|c|}{ Dichotomous SVM index } \\
\hline & (1) & $(2)$ & (3) & (4) \\
\hline & $O L S$ & $2 S L S$ & $O L S$ & $2 S L S$ \\
\hline Democracy & $\begin{array}{c}0.055^{* * *} \\
(0.0144)\end{array}$ & $\begin{array}{c}0.135^{* * *} \\
()\end{array}$ & $\begin{array}{c}0.0413^{* * *} \\
(0.0109)\end{array}$ & $\begin{array}{c}0.124^{* * *} \\
(0.0238)\end{array}$ \\
\hline Observations & 2,250 & 2,244 & 2,250 & 2,244 \\
\hline Countries & 163 & 163 & 163 & 163 \\
\hline Equal. (p-val.) & - & - & 0.196 & 0.658 \\
\hline SaWi (F.stat.) & - & 151.44 & - & 121.52 \\
\hline AR (p-val.) & - & 0.000 & - & 0.000 \\
\hline StWr (p-val.) & - & 0.000 & - & 0.000 \\
\hline KP (p-val.) & - & 0.000 & - & 0.000 \\
\hline
\end{tabular}

Notes: This table presents OLS and 2SLS estimates. All variables are averaged over five-year periods. The dependent variable is the log of GDP per capita. All regressions include the first lag of the dependent variable, country fixed effects, and year fixed effects. The first lag of the regional (jack-knifed) degree of democratization serves as the instrument for the domestic degree of democratization. We report the results a Wald test to show whether the estimate reported in Column $3(4)$ is statistically significant from the estimate reported in Column 1 (2). Standard errors are clustered at the country level and reported in parentheses. The following notation is used to highlight coefficients that are significantly different from zero: ${ }^{*} \mathrm{p}$-value $<0.10,{ }^{* *} \mathrm{p}$-value $<0.05,{ }^{* * *} \mathrm{p}$-value $<0.01$. 
Table A.13 Democracy and economic growth — Sub-sample analyses (continents).

\begin{tabular}{|c|c|c|c|c|}
\hline & \multicolumn{2}{|c|}{ Continuous SVM index } & \multicolumn{2}{|c|}{ Dichotomous SVM index } \\
\hline & (1) & $(2)$ & $(3)$ & $(4)$ \\
\hline & $O L S$ & $2 S L S$ & $O L S$ & $2 S L S$ \\
\hline \multirow[b]{2}{*}{ Democracy } & \multicolumn{4}{|c|}{ Panel A: Africa } \\
\hline & $\begin{array}{c}0.019 * * * \\
(0.0045)\end{array}$ & $\begin{array}{c}0.028^{* * *} \\
(0.0065)\end{array}$ & $\begin{array}{c}0.013^{* * *} \\
(0.0030)\end{array}$ & $\begin{array}{c}0.026^{* * *} \\
(0.0059)\end{array}$ \\
\hline Observations & 3,194 & 3,194 & 3,194 & \\
\hline Countries & 51 & 51 & 51 & \\
\hline Equal. (p-val.) & - & - & 0.047 & 0.726 \\
\hline \multirow[t]{2}{*}{ SaWi (F.stat.) } & - & 138.10 & - & 74.04 \\
\hline & \multicolumn{4}{|c|}{ Panel B: America and Europe } \\
\hline Democracy & $\begin{array}{c}0.007 * * \\
(0.0033)\end{array}$ & $\begin{array}{c}0.015^{* * *} \\
(0.0047)\end{array}$ & $\begin{array}{c}0.004^{*} \\
(0.0024)\end{array}$ & $\begin{array}{c}0.014^{* * * *} \\
(0.0045)\end{array}$ \\
\hline Observations & 4,867 & 4,853 & 4.867 & 4,853 \\
\hline Countries & 67 & 67 & 67 & 67 \\
\hline Equal. (p-val.) & - & - & 0.195 & 0.877 \\
\hline SaWi (F.stat.) & - & 68.84 & - & 64.13 \\
\hline \multirow[b]{2}{*}{ Democracy } & \multicolumn{4}{|c|}{ Panel C: Asia } \\
\hline & $\begin{array}{c}0.035^{* * *} \\
(0.0080)\end{array}$ & $\begin{array}{c}0.114^{* * *} \\
(0.0330)\end{array}$ & $\begin{array}{c}0.021 * * * \\
(0.0049)\end{array}$ & $\begin{array}{c}0.106^{* * *} \\
(0.0322)\end{array}$ \\
\hline Observations & 2,484 & 2,473 & 2,484 & 2,473 \\
\hline Countries & 43 & 43 & 43 & 43 \\
\hline Equal. (p-val.) & - & - & 0.009 & 0.804 \\
\hline SaWi (F.stat.) & - & 17.24 & - & 14.22 \\
\hline
\end{tabular}

Notes: This table presents OLS and 2SLS estimates. The dependent variable is the log of GDP per capita. All regressions include four lags of the dependent variable, country fixed effects, and year fixed effects. The first lag of the regional (jack-knifed) degree of democratization serves as the instrument for the domestic degree of democratization. We report the results a Wald test to show whether the estimate reported in Column 3 (4) is statistically significant from the estimate reported in Column 1 (2). Standard errors are clustered at the country level and reported in parentheses. The following notation is used to highlight coefficients that are significantly different from zero: ${ }^{*}$ p-value $<0.10,{ }^{* *}$ p-value $<0.05,{ }^{* * *}$ p-value $<0.01$. 
Table A.14 Democracy and economic growth — Sub-sample analyses (periods).

\begin{tabular}{|c|c|c|c|c|}
\hline & \multicolumn{2}{|c|}{ Continuous SVM index } & \multicolumn{2}{|c|}{ Dichotomous SVM index } \\
\hline & (1) & $(2)$ & $(3)$ & (4) \\
\hline & $O L S$ & $2 S L S$ & $O L S$ & $2 S L S$ \\
\hline \multirow[b]{2}{*}{ Democracy } & \multicolumn{4}{|c|}{ Panel A: 1946 - 2016} \\
\hline & $\begin{array}{c}0.015 \\
(0.0026)\end{array}$ & $\begin{array}{c}0.027 * * * \\
(0.0047)\end{array}$ & $\begin{array}{c}0.009 * * * \\
(0.0018)\end{array}$ & $\begin{array}{c}0.024^{* * * *} \\
(0.0043)\end{array}$ \\
\hline Observations & 9,679 & 9,656 & 9,679 & 9,656 \\
\hline Countries & 163 & 163 & 163 & 163 \\
\hline Equal. (p-val.) & - & - & 0.002 & 0.416 \\
\hline \multirow[t]{2}{*}{ SaWi (F.stat.) } & - & 202.64 & - & 157.21 \\
\hline & \multicolumn{4}{|c|}{ Panel B: $1970-2016$} \\
\hline Democracy & $\begin{array}{c}0.020^{* * *} \\
(0.0029)\end{array}$ & $\begin{array}{c}0.039 * * * \\
(0.0054)\end{array}$ & $\begin{array}{c}0.012^{* * *} \\
(0.0170)\end{array}$ & $\begin{array}{c}0.033^{* * *} \\
(0.0048)\end{array}$ \\
\hline Observations & 7,176 & 7,155 & 7,176 & 7,155 \\
\hline Countries & 163 & 163 & 163 & 163 \\
\hline Equal. (p-val.) & - & - & 0.000 & 0.220 \\
\hline SaWi (F.stat.) & - & 252.37 & - & 193.25 \\
\hline
\end{tabular}

Notes: This table presents OLS and 2SLS estimates. The dependent variable is the log of GDP per capita. All regressions include four lags of the dependent variable, country fixed effects, and year fixed effects. The first lag of the regional (jack-knifed) degree of democratization serves as the instrument for the domestic degree of democratization. We report the results a Wald test to show whether the estimate reported in Column 3 (4) is statistically significant from the estimate reported in Column 1 (2). Standard errors are clustered at the country level and reported in parentheses. The following notation is used to highlight coefficients that are significantly different from zero: ${ }^{*}$ p-value $<0.10,{ }^{* *}$ p-value $<0.05,{ }^{* * *}$ p-value $<0.01$.

Table A.15 Democracy and economic growth — Additional control variables.

\begin{tabular}{lcccc}
\hline & \multicolumn{2}{c}{ Continuous SVM index } & \multicolumn{2}{c}{ Dichotomous SVM index } \\
\cline { 2 - 5 } & $(1)$ & $(2)$ & $(3)$ & $(4)$ \\
& $O L S$ & $2 S L S$ & $0 L S$ & $2 S L S$ \\
\hline Democracy & $0.009^{* * *}$ & $0.021^{* * *}$ & $0.005^{* *}$ & $0.021^{* *}$ \\
& $(0.0037)$ & $(0.0089)$ & $(0.0023)$ & $(0.0085)$ \\
\hline Observations & 8,908 & 8,908 & 8,908 & 8,908 \\
Countries & 140 & 140 & 140 & 140 \\
Equal. (p-val.) & - & - & 0.147 & 0.928 \\
SaWi (F.stat.) & - & 54.33 & - & 37.10 \\
\hline
\end{tabular}

Notes: This table presents OLS and 2SLS estimates. The dependent variable is the log of GDP per capita. All regressions include four lags of the dependent variable, country fixed effects, year fixed effects, and four timevarying controls: population growth, average years of schooling (linearly interpolated), an index of high court independence, and a measure of civil conflict. The first lag of the regional (jack-knifed) degree of democratization serves as the instrument for the domestic degree of democratization. We report the results a Wald test to show whether the estimate reported in Column 3 (4) is statistically significant from the estimate reported in Column 1 (2). Standard errors are clustered at the country level and reported in parentheses. The following notation is used to highlight coefficients that are significantly different from zero: ${ }^{*}$ p-value $<0.10,{ }^{* *}$ p-value $<0.05,{ }^{* * *}$ p-value $<0.01$. 
Table A.16 Democracy and economic institutions (annual data).

\begin{tabular}{lcccc}
\hline & \multicolumn{2}{c}{ Continuous SVM index } & \multicolumn{2}{c}{ Dichotomous SVM index } \\
\hline & $(1)$ & $(2)$ & $(3)$ & $(4)$ \\
\cline { 2 - 5 } & $O L S$ & $2 S L S$ & $O L S$ & $2 S L S$ \\
\hline Democracy & $0.045^{* * *}$ & $0.024^{* * *}$ & $0.028^{* * *}$ & $0.021^{* * *}$ \\
& $(0.0064)$ & $(0.0077)$ & $(0.0046)$ & $(0.0070)$ \\
\hline Observations & 10,394 & 10,391 & 10,394 & 160,391 \\
Countries & 160 & 160 & 0.000 & 160 \\
Equal. (p-val.) & - & - & - & 0.608 \\
SaWi (F.stat.) & - & 113.30 & - & 83.60 \\
AR (p-val.) & - & 0.000 & - & 0.000 \\
StWr (p-val.) & - & 0.000 & - & 0.000 \\
KP (p-val.) & - & 0.000 & 0.000 \\
\hline
\end{tabular}

Notes: This table presents OLS and 2SLS estimates. The dependent variable is an expert-based index of high court independence. All regressions include four lags of the dependent variable, four lags of the log of GDP per capita, country fixed effects, and year fixed effects. The first lag of the regional (jack-knifed) degree of democratization serves as the instrument for the domestic degree of democratization. We report the results a Wald test to show whether the estimate reported in Column $3(4)$ is statistically significant from the estimate reported in Column 1 (2). Standard errors are clustered at the country level and reported in parentheses. The following notation is used to highlight coefficients that are significantly different from zero: ${ }^{*}$ p-value $<0.10,{ }^{* *}$ p-value $<0.05,{ }^{* * *} \mathrm{p}$-value $<0.01$.

Table A.17 Democracy and years of schooling (five-year data).

\begin{tabular}{lcccc}
\hline & \multicolumn{2}{c}{ Continuous SVM index } & \multicolumn{2}{c}{ Dichotomous SVM index } \\
\hline & $(1)$ & $(2)$ & $(3)$ & $(4)$ \\
\cline { 2 - 5 } & $O L S$ & $2 S L S$ & $O L S$ & $2 S L S$ \\
\hline Democracy & $0.212^{* * *}$ & $0.337^{* * *}$ & $0.155^{* * *}$ & $(0.0316)$ \\
& $(0.0441)$ & $(0.1282)$ & 1,979 & $(0.1103)$ \\
\hline Observations & 1,979 & 1,976 & 141 & 1,976 \\
Countries & 141 & 141 & 0.074 & 141 \\
Equal. (p-val.) & - & - & - & 0.510 \\
SaWi (F.stat.) & - & 81.15 & - & 59.02 \\
AR (p-val.) & - & 0.011 & - & 0.025 \\
StWr (p-val.) & - & 0.008 & - & 0.021 \\
KP (p-val.) & - & 0.000 & 0.000 \\
\hline
\end{tabular}

Notes: This table presents OLS and 2SLS estimates. The dependent variable is the average years of schooling. All regressions include the first lag of the dependent variable, the first lag of the log of GDP per capita, country fixed effects, and year fixed effects. The first lag of the regional (jack-knifed) degree of democratization serves as the instrument for the domestic degree of democratization. We report the results a Wald test to show whether the estimate reported in Column 3 (4) is statistically significant from the estimate reported in Column 1 (2). Standard errors are clustered at the country level and reported in parentheses. The following notation is used to highlight coefficients that are significantly different from zero: ${ }^{*}$ p-value $<0.10,{ }^{* *}$ p-value $<0.05,{ }^{* * *}$ p-value $<0.01$. 


\title{
Chapter 3
}

\section{Should we care (more) about data aggregation? Evidence from the democracy-growth-nexus.}

with KLAUs GrüNDLER (LMU Munich, ifo Institute)

\begin{abstract}
We observe that most of the available aggregation techniques produce indices that are often too favorable for autocratic regimes and too unfavorable for democratic regimes. The sole exception is a machine learning technique. Using a stylized model, we show that applying an index with implausibly low (high) scores for democracies (autocracies) in a regression analysis produces upward-biased OLS and 2SLS estimates. The results of an analysis of the effect of democracy on economic growth show that the distortions in the OLS and 2SLS estimates are substantial. Our findings imply that commonly used indices are not well suited for empirical purposes.
\end{abstract}




\subsection{Introduction}

The view that authoritarian institutions are more conducive to economic growth than liberal-democratic institutions has recently gained popularity among some voters and politicians (Plattner, 2015, Wike et al., 2017). The Hungarian Prime Minister, Victor Orbán, for example, argued in his speech on July 26, 2014, that:

"The defining aspect of today's world can be articulated as a race to figure out a way of organizing communities and to find the state that is most capable of making a nation competitive. This is why, [...] a trending topic in thinking is understanding systems that are not Western, not liberal, not liberal democracies, maybe not even democracies, and yet making nations successful."

and attracted global attention by concluding that:

"What all this exactly means [...] we have to abandon liberal methods and principles of organizing a society, as well as the liberal way to look at the world." 1

Early empirical studies on the effect of democracy on economic growth support the notion that autocratic regimes grow faster than democratic regimes and explain their result with differences in tax policies (Barro, 1996, Tavares and Wacziarg, 2001). Some recent empirical studies challenge this pessimistic view and report results showing that democracy causes long-run growth by increasing human capital and the quality of the economic institutions (Acemoglu et al., 2019, Gründler and Krieger, 2016, Papaioannou and Siourounis, 2008, Persson and Tabellini, 2006, 2008). Knutsen (2012) argues that these recent studies are more sophisticated because of their empirical methods. This paper shows that only improving the identification strategy does not suffice to allay all endogeneity concerns, and thereby raises doubts about the precision of the estimates reported in these studies.

Any empirical study that examines the consequences of a transition from autocracy towards democracy (or vice versa) needs an index that measures the degree to which a regime satisfies democratic principles. Since the literature provides multiple democracy indices, we examined in an earlier study whether the estimated effect of democracy on economic growth depends on the measure of democracy (Gründler and Krieger, 2016). Our results show that replacing a democracy indicator with another indicator creates notable changes in the size of the regression coefficient. However, because of a lack of data, exploring where these differences in the effect size come from was impossible. ${ }^{2}$

\footnotetext{
${ }^{1}$ For an English version of the speech, see https://hungarianspectrum . wordpress . com/2014/07/31/.

${ }^{2}$ In advance, it is unclear whether the differences in the effect size pose a problem. If, for example, the differences in the effect size are caused by differences in the concept of democracy, we do not have to worry because we can develop an economic theory explaining why using different concepts leads to different results about the effect of democracy on economic growth. If, however, some indices are just more error-prone than other indices, we must be concerned about the different effect sizes because then they may only exist since some indices are unsuited for empirical purposes. Below, we argue that the second case applies.
} 
To address this question, we compile novel data on political participation, political competition, and the freedom of speech (186 countries, 1919 - 2016) and ask how these regime characteristics can be transformed into an index. Since generally acknowledged guidelines for data aggregation do not exist, we apply different aggregation techniques and compare their performance. ${ }^{3}$ We observe that most of the available aggregation methods create indices that are often too favorable for autocracies and too unfavorable for democracies. The sole aggregation method that does not produce these malfunctions is a machine learning technique.

We develop a theoretical model to examine the empirical consequences of using an aggregation method that produces implausibly low (high) indices for pure democracies (autocracies). We find that applying a biased index in a regression analysis causes an upward bias in the ordinary least squares (OLS) estimator. Our model also shows that having an instrument for the degree of democratization does not suffice to correct this upward bias. This result is important because many scholars working on the effects of political transitions claim that their instrumental variable approach allays any concern about measurement error in the democracy index.

Using our new democracy indices, we estimate the effect of democracy on economic growth to investigate whether the overestimation biases predicted by our model are of practical relevance. We report results from OLS fixed effect and instrumental variable regressions showing that democracy positively affects economic growth. In line with the prediction of our stylized model, we observe that applying an index that is biased for clearly autocratic regimes or clearly democratic regimes causes a significant increase in the estimated effect of democracy on economic growth.

This paper addresses economists and political scientists interested in the causes and consequences of political transitions. ${ }^{4}$ Our results suggest that widely used democracy indicators - such as the Polity index, the Freedom House indices, the Vanhanen (2000) index, or the indices proposed by Pemstein et al. (2010) and Márquez (2016) - are not well suited for empirical analyses. The reason is that the aggregation methods used for the creation of these indices cause non-random measurement errors. We also present a machine learning index that is not prone to non-random measurement errors and thus more suitable for research purposes.

Our results are also relevant for other applied economists and social scientists since indices belong to the standard tool kit in all humanities. We are convinced that most problems caused by the application of simple data aggregation methods arise in various situations and that scholars should thus be cautious in using simple indices for causal

\footnotetext{
${ }^{3}$ Our list of aggregation techniques includes: an additive method, a multiplicative method, an additivemultiplicative method, a Bayesian latent variable method, and a machine learning method. We select these five techniques because other scholars used them to create measures of democracy.

${ }^{4}$ For studies examining how economic development and economic shocks influence democratization, see Acemoglu et al. (2008), Aidt and Franck (2015), Aidt and Leon (2016), Brückner and Ciccone (2011), Cervellati et al. (2014), Gundlach and Paldam (2009), Lipset (1959), Murtin and Wacziarg (2014), and Przeworski (2000).
} 
identification.

We organize the paper in the following way. Section 3.2 presents the basic ingredients of democracy indices and compares the performance of different aggregation methods. Sections 3.3 and 3.4 show why data aggregation matters for identifying the influence of political regimes. Section 3.5 concludes.

\subsection{Measuring democracy}

We use the standard three-stage procedure to measure democracy (Munck and Verkuilen, 2002): first, we define the term "democracy" (conceptualization), then collect the data reflecting the components of the definition (operationalization), and finally specify the rule that transforms the raw data into an index (aggregation).

\subsubsection{Conceptualization}

The literature distinguishes between narrow (thin, minimalist), realistic (balanced), and broad (thick, maximalist) definitions of democracy (O'Donnell, 2001). Narrow concepts are focused on whether public elections for political mandates are competitive. Realistic concepts also require universal suffrage and basic political rights, while broad concepts also incorporate a wide range of socioeconomic conditions.

Munck and Verkuilen (2002) explain why neither a narrow nor a broad definition of democracy is well suited for analytical purposes. Broad concepts are difficult to operationalize because of insufficient data availability and overlap with other economic concepts (e.g. corruption, economic freedom, inequality), whereas narrow concepts do not sufficiently differentiate between autocratic, democratic, and hybrid regimes.

We share Munck and Verkuilen's (2002) concerns and assume a realistic concept of democracy. Our concept resembles the concept of Dahl (1971) and includes three core aspects of democracy: political competition, political participation, and freedom of opinion.

\subsubsection{Operationalization}

We collected data on nine regime characteristics that are available for a comprehensive sample of country-years. Our data meets Munck and Verkuilen's (2002) guidelines that recommend the use of non-aggregated data from objective and subjective sources.

Political participation is defined as the right of citizens to elect their political leaders and representatives (Dahl, 1971). Suffrage may be limited, either through constitutional restrictions that exclude citizens because of their gender, race, or income, or by non-constitutional restrictions that result from martial law or repression. We collected data on voter turnout and calculated the voter-population-ratio to capture the two types of disenfranchisement. ${ }^{5}$

\footnotetext{
${ }^{5}$ We obtain our data from a number of sources, including African Election Database, the Inter-Parliamentary
} 
The political process is competitive if individuals with different party affiliations compete in elections for political support (Przeworski, 1991). We use data on five regime characteristics to capture this core aspect of democracy: (i) an expert-based measure of party pluralism ${ }^{6}$, (ii) the share of seats in parliament not won by the leading party, (iii) the number of seats won by the second strongest party divided by the number of seats won by the leading party, (iv) the share of votes not won by the leading party (or its presidential candidate), and (v) the share of votes won by the second strongest party (candidate) divided by the share of votes won by the leading party (candidate). ${ }^{7}$

Freedom of opinion means that citizens can freely choose their sources of information and can express their political views even if these views are not compatible with the political views of the government. To evaluate whether the citizens of a country enjoy these human rights, we use gender-specific ratings on the freedom of debate from the Varieties of Democracy (V-Dem) database (Coppedge et al., 2018).

\subsubsection{Aggregation}

Formally, the degree of democratization (d) is a function of a set of observable regime characteristics $(\mathbf{x})$ :

$$
\mathrm{d}=\mathcal{A}(\mathbf{x}) \in[0,1] \quad \text { with } \quad \mathbf{x}=\left(x_{1}, \ldots, x_{m}\right) \in[0,1]^{m}
$$

where $\mathcal{A}:[0,1]^{m} \rightarrow[0,1]$ is the aggregation function and $m$ the number of regime characteristics. Specifying $\mathcal{A}$ is difficult because we neither observe the shape of $\mathcal{A}$ nor can we directly observe the actual level of democracy (d) for all regimes.

The literature suggests two ways of meeting this challenge. The standard procedure is to weight the regime characteristics and then to apply a multiplicative or additive aggregation function (Goertz, 2006):

$$
\mathrm{d}=\prod_{j=1}^{m} x_{j}^{\omega_{j}} \quad \text { or } \quad \mathrm{d}=\sum_{j=1}^{m} \omega_{j} \cdot x_{j} \quad \text { with } \quad \sum_{j=1}^{m} \omega_{j}=1
$$

where $\omega_{j} \geq 0$ denotes the weight of regime characteristic $x_{j}{ }^{8}$

Union, Adam Carr's Election Archive, the International Institute for Democracy and Electoral Assistance, the International Foundation of Electoral Systems, Nohlen (2005), Nohlen et al. (2001, 1999), and Nohlen and Stöver (2010). A documentation of the collected data is available upon request.

${ }^{6}$ This ordinal index of party pluralism has five categories: (i) there are no political parties, (ii) one legal party exists, (iii) there are multiple parties but opposition parties are faced with significant obstacles, (iv) there are multiple parties but opposition parties are faced with small obstacles, and (v) there are multiple parties and virtually no obstacles for opposition parties. The core data come from Coppedge et al. (2018). Supplementary information come from the African Election Database, the Inter-Parliamentary Union, Nohlen (2005), Nohlen et al. (2001, 1999), and Nohlen and Stöver (2010).

${ }^{7} \mathrm{We}$ weight parliamentary and presidential elections according to their relevance for the political decision making process. We obtained the data needed for the calculation of the four latter characteristics from multiple sources (for a list, see Footnote 5).

${ }^{8}$ Skaaning et al. (2015) and Teorell et al. (2019) refine the conventional approach by combining additive and multiplicative measures of democracy. 
Pemstein et al. (2010) and Gründler and Krieger (2016) deviate from this standard procedure: Pemstein et al. (2010) propose a Bayesian latent variable (LV) method and Gründler and Krieger (2016) a machine learning technique for pattern recognition. A major advantage of these two approaches is that they relax the assumptions about the functional relationship $(\mathcal{A})$ between the regime characteristics $(\mathbf{x})$ and the degree of democratization (d). A disadvantage is, however, that the aggregation process is fully data driven rather than founded in preconceived rules.

\subsubsection{Comparing aggregation methods}

In this section, we compare the performance of five aggregation methods: an additive method, a multiplicative method, a method that combines additive and multiplicative elements, a Bayesian latent variable approach, and a machine learning technique. We proceed in two steps: first, we apply these aggregation techniques to our nine regime characteristics, and then consider multiple country examples to identify the similarities and the differences between the resulting democracy indices (for computational details, see Appendix B.1).

\subsubsection{Germany}

After its defeat in the First World War, Germany adopted a novel constitution and replaced the constitutional monarchy with a semi-presidential system. This constitution introduced universal suffrage and ensured freedom of opinion for all male and female citizens. Competitive multiparty elections were regularly held between 1919 and 1932, bringing politicians from different parties into power (Nohlen and Stöver, 2010). The parliamentary election in March 1933 was won by the Nazi Party and its leader, Adolf Hitler, became chancellor of Germany. In July 1933, Hitler enacted a law banning all political parties apart from the Nazi Party. The elections in December 1933, March 1936, and April 1938 were one-party elections and the Nazi Party punished any form of opposition (Shirer, 1991). After the victory of the Allied Forces in 1945, Germany was divided into four occupation zones. The occupation of the Western Allies ended in May 1949 when the Federal Republic of Germany was founded. Since then, free multiparty elections were regularly held in the Federal Republic of Germany (Nohlen and Stöver, 2010). ${ }^{9}$

Figure 3.1 shows the level of democracy in Germany, depending on the aggregation method. All measures of democracy indicate three periods: two are democratic (1919 - 1932, 1949 - 2016) and one is non-democratic (1933 - 1948). This classification seems plausible given the historical facts. Having a closer look at Figure 3.1, we observe two notable differences. The first difference concerns the Nazi period (1933-

\footnotetext{
${ }^{9}$ The occupation of the Soviet Union ended in October 1949 as the German Democratic Republic was founded. The reunification of the Federal Republic of Germany and the German Democratic Republic took place in October 1990.
} 
Figure 3.1 Democracy in Germany $(1919-2016)$.
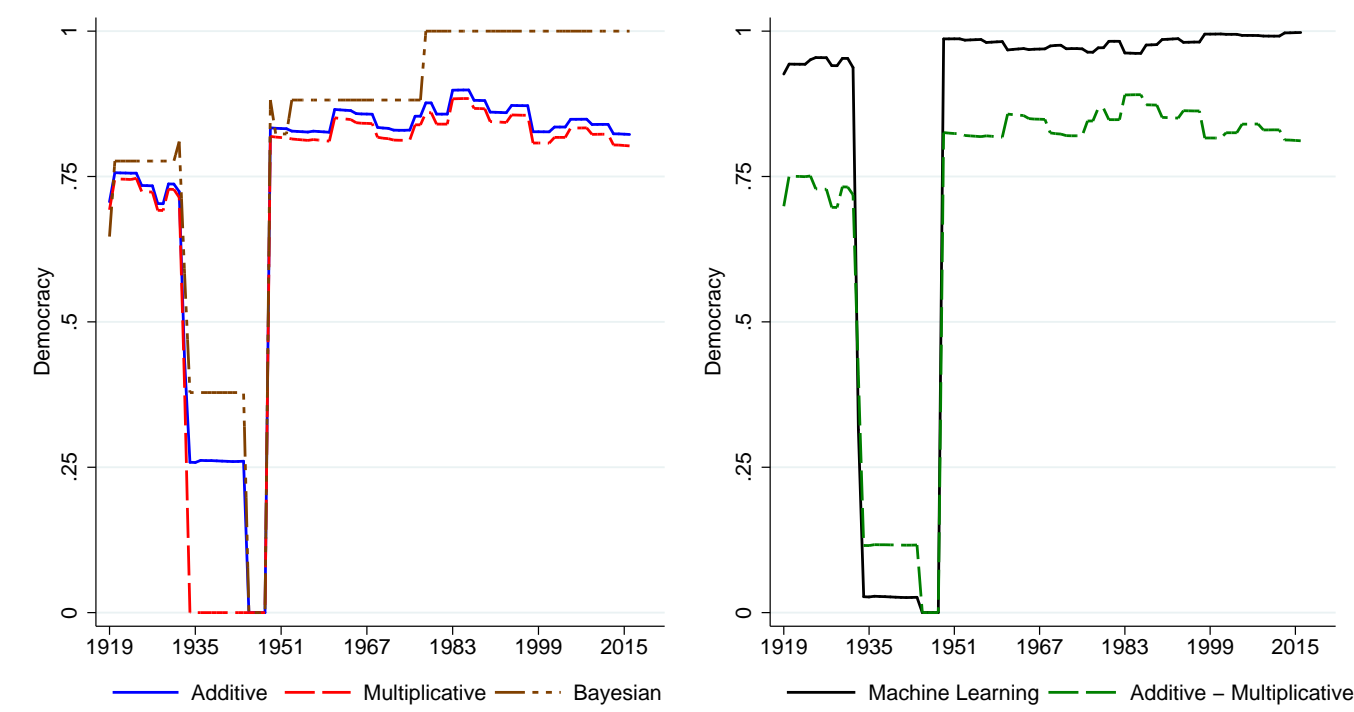

Notes: The figures show the level of democracy of Germany, depending on how we aggregate our nine regime characteristics. For the period from 1949 to 1989, the measures of democracy refer to the Federal Republic of Germany.

1945). While the machine learning indicator and the multiplicative indicator suggest the absence of democracy, the other indices indicate the existence of some democratic structures. The latter assessment is incompatible with our concept of democracy since the Nazi party persecuted opponents and restricted the freedom of opinion (Shirer, 1991). The second striking difference exists for the recent past. The additive indicator, the multiplicative indicator, and the additive-multiplicative indicator suggest a democratic deficit, whereas the other indicators do not point to a lack of democracy. Because we are not aware of any policy report or qualitative study indicating a lack of political competition, political participation, or freedom of opinion, we doubt whether the former indicators correctly reflect what is usually considered as the prevailing level of democracy.

\subsubsection{Russia (Soviet Union)}

After the abdication of the Russian czar in March 1917, the October Revolution, and the Russian Civil War, the Soviet Union was founded in December 1922. The constitution enacted in December 1936 introduced universal direct suffrage. One year later, the first general election took place. However, no political parties except the ruling Communist Party was permitted to participate. Subsequent elections were also singleparty elections. In 1986, Mikhail Gorbachev, the General Secretary of the Communist Party, launched two new policies - Glasnost and Perestroika ${ }^{10}$ — thereby initiating an

\footnotetext{
${ }^{10}$ Perestroika was introduced to modernize the economy of the Soviet Union. Glasnost comprised several political reforms that were implemented to lift restrictions on the freedom of speech and information (Sakwa, 1990).
} 
Figure 3.2 Democracy in Russia (1919 - 2016).
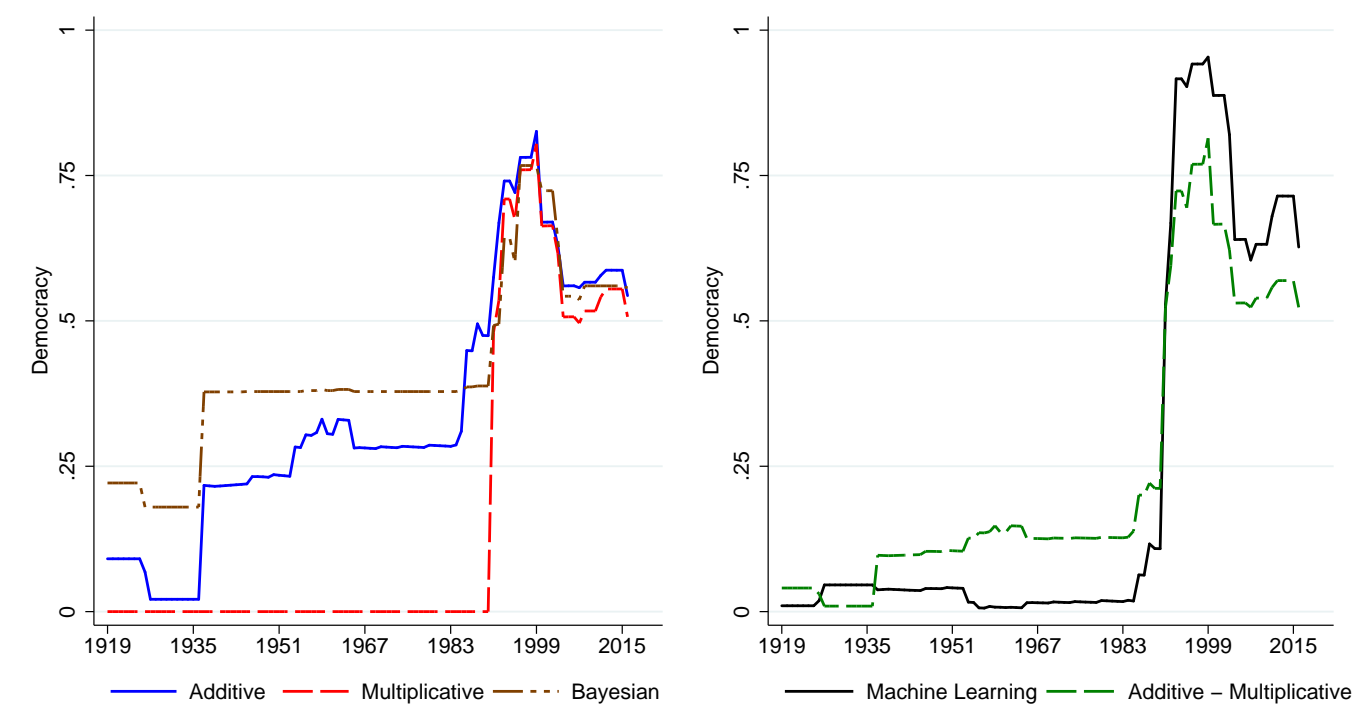

Notes: The figures show the level of democracy of Russia, depending on how we aggregate our nine regime characteristics. For the period from 1922 to 1990, the measures of democracy refer to the Soviet Union.

institutional change (Sakwa, 2005). The democratization process accelerated after the collapse of the Soviet Union. In 1991, Boris Yeltsin became the first freely elected president of the Russian Federation. President Yeltsin was narrowly reelected in July 1996 and stepped down in December 1999. Under his successors, Vladimir Putin and Dmitry Medvedev, party competition decreased and constraints on the freedom of opinion became more frequent (Nohlen and Stöver, 2010, Sakwa, 2014).

Figure 3.2 shows the level of democracy of the Russian Federation (Soviet Union) for different aggregation methods. We observe great similarities for the post-Cold War era and significant differences for the Soviet era. After the fall of the Iron Curtain, all five indices indicate a distinct increase in the Russian degree of democratization. We think this increase is plausible since free multi-party elections took place in the early years of the Russian Federation, while single-party elections were held in the Soviet period. We also observe that all five indices decrease after the inauguration of Vladimir Putin and find several expert reports that justify this result (Hale et al., 2004, Sakwa, 2010).

The measurement differences in the Soviet period resemble the differences for the Nazi period in Germany. The additive index, the Bayesian index, and the additivemultiplicative index indicate that the Soviet Union partly respected basic democratic principles, while the multiplicative indicator and the machine learning indicator suggest that the Soviet Union had a highly autocratic government. Only the latter assessment is consistent with a realistic concept of democracy because of the absence of political pluralism and freedom of opinion in the Soviet Union. 
Figure 3.3 Democracy in Myanmar (1948 - 2016).
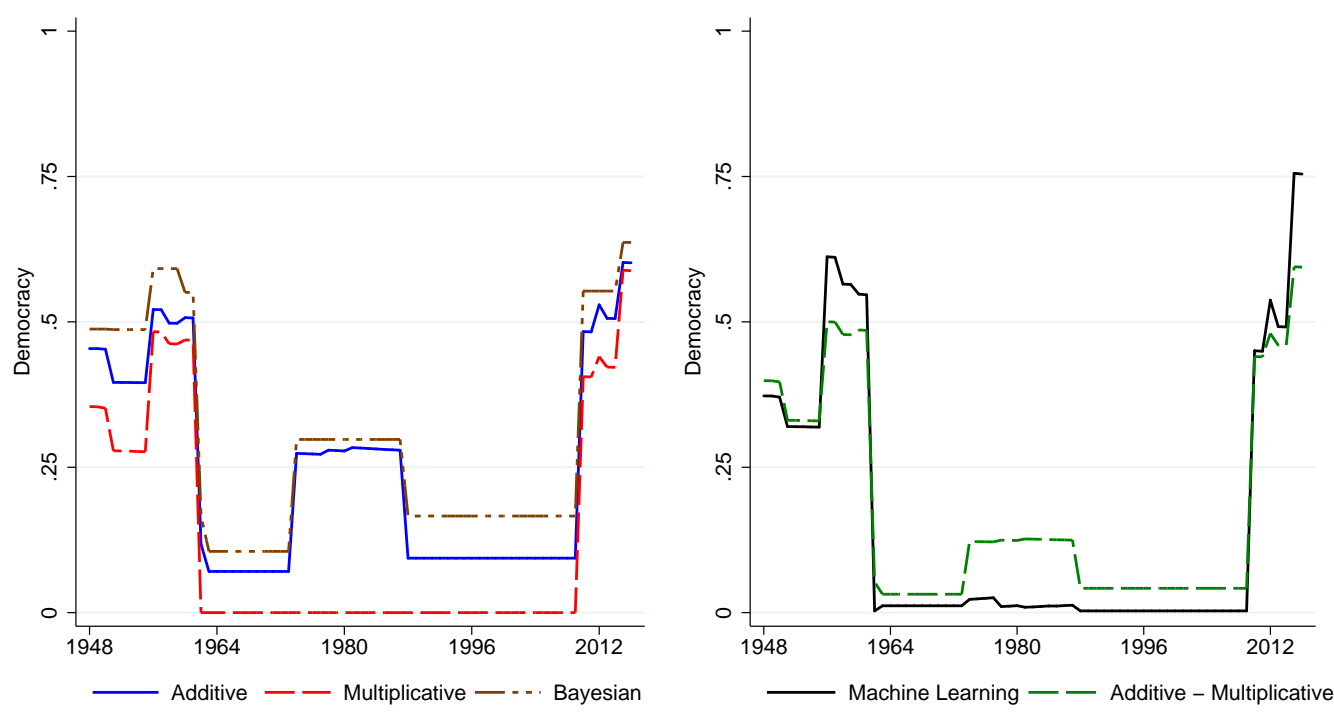

Notes: The figures show the level of democracy of Myanmar, depending on how we aggregate our nine regime characteristics. The country was renamed from Burma to Myanmar in 1989.

\subsubsection{Myanmar (Burma)}

After gaining independence from the United Kingdom in 1948, Burmese politics was mainly shaped by the Anti-Fascist People's Freedom League (AFPFL), which won the elections in 1951/52, 1956, and 1960. Dissatisfied with the performance of the AFPFL, General Ne Win overthrew the civilian government in March 1962 and established a military-dominated regime (Nohlen et al., 2001). In 1974, the military government organized elections for the first time since 1960. However, the Burma Socialist Program Party - led by General Ne Win - did not allow for electoral competition (Devi, 2014). In 1988, General Ne Win resigned from office and the interim government announced a multiparty election for 1990. This election was clearly won by the National League for Democracy (NLD), the main opposition force. The military prevented, however, the democratic takeover and military governments stayed in power for another 21 years. In 2010, the military withdrew and thus paved the way for an institutional change (Barany, 2016, Rieffel, 2013).

Figure 3.3 presents how the five democracy indicators evaluate Myanmar (Burma). We observe that the indicators differ only slightly from each other for the periods in which multiparty elections took place $\left(1948\right.$ - 1961, 2010 - 2016). ${ }^{11}$ Furthermore, we find two striking differences for the period of military dictatorship. First, the additive

\footnotetext{
${ }^{11}$ Even though multiparty elections were held in these two periods, all five measures indicate democratic deficits. We think this result is compatible with our concept of democracy for two reasons: first, some ethnic groups (e.g. Rohingya) were excluded from the political process and did not enjoy the freedom of opinion, and second, the great influence of the military on the political decision making process. For example, only 168 out of 224 seats in the parliament were up for election in 2010 and 2015 . The other seats were reserved for members of the armed forces (Barany, 2016).
} 
Figure 3.4 Kernel densities.
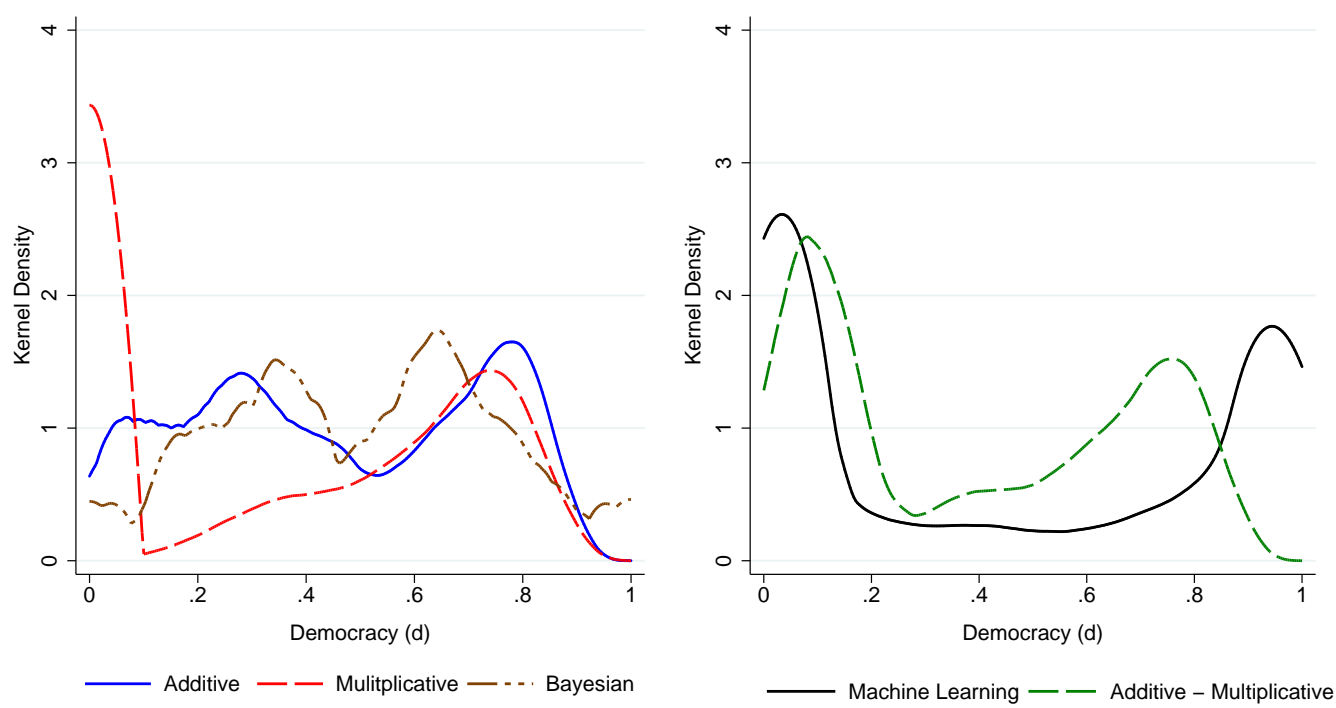

Notes: The figure shows the kernel densities of our five measures of democracy. We use the Epanechnikov kernel to estimate the density functions. Colonies are excluded from the estimation sample.

index, the Bayesian index, and, to a lesser extent, the additive-multiplicative index indicate a step towards democracy in 1974, whereas the machine learning index and the multiplicative index remain unchanged. We argue that the latter assessment is more consistent with a realistic concept of democracy because political competition did not exist in the single-party regime established in 1974. Second, the additive index and the Bayesian index suggest some democratic structures in the two periods in which the government was not elected $(1962$ - 1973, 1988 - 2009). We believe that these figures are incompatible with the concept of democracy because electoral legitimacy constitutes a necessary condition for democracy.

\subsubsection{Discussion}

We draw three conclusions from Section 3.2.4. First, the question of how we transform the regime characteristics into an index matters because the degree of democratization significantly change when we replace an aggregation method with another aggregation method. Second, the additive method and the Bayesian method are likely to produce indicators that are too favorable for highly autocratic regimes to be consistent with the concept of democracy. Finally, the machine learning method is least likely to create an indices that underestimate the level of democracy of a highly democratic regime. ${ }^{12}$

\footnotetext{
${ }^{12}$ Our analysis leaves open the question of which aggregation technique produces the "best" indicies for hybrid (partial, semi-democratic) regimes. We think that answering this question is impossible because the true degree of democratization of a hybrid regime cannot be observed (Diamond, 2002, Lindberg et al., 2014). Excluding hybrid regimes from our analysis is not problematic for two reasons: first, the number of hybrid regimes is relatively low, and second, the differences between the five indicators are much smaller for hybrid regimes than for autocracies and democracies.
} 
Table 3.1 Average changes in the level of democracy — Democratization events.

\begin{tabular}{cccccc}
\hline & Machine Learning & Additive & Multiplicative & Add. / Multi. & Bayesian \\
\hline$\Delta$ & 0.522 & 0.276 & 0.399 & 0.344 & 0.284 \\
\hline
\end{tabular}

Notes: This table reports results from estimating (3.3). The figures show how much the democracy indices change, on average, when Papaioannou and Siourounis (2008) indicate a transition from autocracy towards democracy.

An potential objection to our evaluation is that the three country examples cannot provide sufficient evidence for the second and third conclusion. This objection is not farfetched, especially because our most favored aggregation method, the machine learning method, is our brainchild (Gründler and Krieger, 2016). ${ }^{13}$ Below, we present additional results that support our conclusions and, hopefully, fully alleviate the suspicion that we strategically selected our three country examples to give an advantage to our preferred aggregation method. Another concern might be that the regime characteristics could be strategically chosen. Appendix B.2.2 shows that our conclusions remain unchanged if we use the regime characteristics proposed by Teorell et al. (2019).

Appendix B.2.1 presents additional country examples (Bhutan, Kenya, and Spain) to support the conclusions drawn from Section 3.2.4. We also examined many other country examples (not reported, but available upon request) and find strong evidence for our conjectures. ${ }^{14}$

Figure 3.4 presents the results from kernel density estimations. We observe that the density functions of all five indicators have a local maximum in the lower part of the spectrum $(\mathrm{d}<0.5)$ and another local maximum in the upper part of the spectrum $(\mathrm{d}>0.5)$. However, the exact locations of the local maxima differ between the five density functions. While the density functions of the multiplicative index, the machine learning index, and the additive-multiplicative index have a lower maximum at $\mathrm{d} \approx 0$, the density functions of the additive index and the Bayesian index have a lower local maximum at $\mathrm{d} \approx 0.3$. This result is reassuring since it is consistent with the view that the additive method and the Bayesian method are likely to produce implausibly high indices for autocratic regimes. Furthermore, the upper local maximum of the density function of the machine learning index is closer to $\mathrm{d}=1$ than the other upper local maxima, showing that the machine learning method is least likely to create implausibly low indicators for highly democratic regimes.

Papaioannou and Siourounis (2008) report a list of countries in which an autocratic regime was replaced with a democratic regime in the 1960 - 2005 period. If the conclusions drawn from the case studies generally apply, we should find that the machine learning index indicates, on average, greater changes in the degree of democratization

\footnotetext{
${ }^{13}$ In Gründler and Krieger (2016), we use the machine learning method to synthesize existing democracy indicators. For data availability reasons, the resulting index only covers the period from 1981 to 2011. Another problem is that combining different measures of democracy leads to conceptual vagueness.

${ }^{14}$ We can explain the performance differences with the assumptions that the aggregation methods make about the functional relationship between the regime characteristics and the level of democracy (for details, see Appendix B.2.3).
} 
than the other four indices. We expect such a difference because the machine learning index is least likely to underestimate (overestimate) the degree of democratization of a clearly democratic (autocratic) regime. To test this hypothesis, we calculate a measure reflecting the average change in the level of democracy:

$$
\Delta^{j}=\frac{1}{|\mathcal{D}|} \sum_{(i, t) \in \mathcal{D}}\left|\mathrm{d}_{i, t}^{j}-\mathrm{d}_{i, t-1}^{j}\right|
$$

where $\mathrm{d}_{i, t}^{j}$ denotes the level of democracy of country $i$ in year $t$ indicated by index $j$. The set $\mathcal{D}$ includes all country-year observations for which Papaioannou and Siourounis (2008) report a transition from autocracy to democracy. The results shown in Table 3.1 confirm that the machine learning index increases more than the other indices when a country becomes democratic. ${ }^{15}$

\subsection{Econometric model}

In the previous section, we showed that most aggregation methods are likely to create implausibly low (high) indices for democratic (autocratic) regimes. In this section, we present an econometric model that shows how these malfunctions affect the result of a regression in which the degree of democratization serves as the explanatory variable.

\subsubsection{Ordinary least squares estimator}

Consider a model in which the degree of democratization (d) influences an outcome variable $(y)$ in the following manner:

$$
\mathrm{y}_{i}=\alpha+\beta \cdot \mathrm{d}_{i}+\varepsilon_{i}
$$

where $\alpha>0$ and $\beta>0$ denote unknown parameters and $\varepsilon$ a randomly distributed error term. For analytical convenience, we also assume that $m$ of the $n$ independent observations have a degree of democratization of $\mathrm{d}_{\text {low }}$ and that the remaining $n-m$ observations have a degree of democratization of $\mathrm{d}_{\text {high }}>\mathrm{d}_{\text {low }}$. We consider two indices: the first index $\left(\mathrm{d}_{1, .}\right)$ correctly indicates the true degree of democratization, while the second index $\left(\mathrm{d}_{2, .}\right)$ is biased:

$$
\mathrm{d}_{1, j}=\mathrm{d}_{j} \quad \text { and } \quad \mathrm{d}_{2, j}=\mathrm{d}_{j}+\mathcal{E}\left(\mathrm{d}_{j}\right) \quad \text { for } \quad j \in\{\text { low, high }\}
$$

where $\mathcal{E}(\cdot)$ indicates the measurement error of the second index. The results presented in Section 3.2 suggest that most of the available aggregation techniques produce too

\footnotetext{
${ }^{15}$ Appendix Table B.1 shows that we obtain similar results if we use the Boix et al. (2013) database to identify major regime changes. The Boix et al. (2013) database has two advantages compared to the Papaioannou and Siourounis (2008) list: first, it has a greater coverage (1800-2007), and second, it indicates transitions from democracy to autocracy. The disadvantage of the Boix et al. (2013) data is that it does not distinguish between autocratic, hybrid, and democratic regimes.
} 
high (low) indices for autocratic (democratic) regimes. We portray these biases by specifying:

$$
\mathcal{E}\left(\mathrm{d}_{j}\right)=\left\{\begin{array}{cc}
-\eta & \text { for } \quad \mathrm{d}_{j}=\mathrm{d}_{\text {high }} \\
\gamma & \text { for } \quad \mathrm{d}_{j}=\mathrm{d}_{\text {low }}
\end{array} \quad \text { with } \quad \eta>0 \quad \text { and } \quad \gamma>0 .{ }^{16}\right.
$$

In this simple model, the ordinary least squares (OLS) estimators have the following form:

$$
\beta^{k, \text { ols }}=\frac{\operatorname{cov}\left(\mathrm{y}, \mathrm{d}_{k, \cdot}\right)}{\operatorname{var}\left(\mathrm{d}_{k, \cdot}\right)}=\frac{m \cdot \sum_{i=m+1}^{n}\left(y_{i}-\bar{y}\right)-(n-m) \cdot \sum_{i=1}^{m}\left(y_{i}-\bar{y}\right)}{\left(\mathrm{d}_{k, \text { high }}-\mathrm{d}_{k, \text { low }}\right) \cdot m \cdot(n-m)}
$$

where $k$ indicates whether we use the unbiased democracy indicator $(k=1)$ or the biased democracy indicator $(k=2)$.

Equation (3.7) implies that the OLS estimator of the paramter $\beta$ increases when we replace the unbiased index $\left(d_{1,}\right)$ with the biased index $\left(d_{2,},\right)$. The reason is that the biased index underestimates the difference between $\mathrm{d}_{\text {high }}$ and $\mathrm{d}_{\text {low }}$ :

$$
\mathrm{d}_{2, \text { high }}-\mathrm{d}_{2, \text { low }}<\mathrm{d}_{1, \text { high }}-\mathrm{d}_{1, \text { low }}=\mathrm{d}_{\text {high }}-\mathrm{d}_{\text {low }} \Rightarrow \beta^{2, \text { ols }}>\beta^{1, \text { ols }} .
$$

\subsubsection{Two-stage least squares estimator}

Many economists and political scientists who investigate the consequences of political transitions use an instrumental variable (IV) strategy to alleviate concerns related to measurement errors in the democracy index. This approach works if the measurement error is random, i.e. when it does not depend on the level of democracy (Angrist and Pischke, 2009). In Sections 3.2.4 and 3.2.5, we showed, however, that the measurement errors caused by most of the available aggregation methods are not random. We thus doubt whether an IV approach suffices to fully compensate for the biases in democracy indicators.

To justify our concerns, we extend the model specified in (3.4) - (3.6) by the assumption that we observe a variable $\mathrm{z} \geq 0$ which positively correlates with the true degree of democratization (d) and does not affect the outcome variable (y). Put differently, the variable $z$ can serve as an instrumental variable in a two-stage least squares (2SLS) regression. The 2SLS estimator then has the form:

$$
\beta^{k, i v}=\frac{\operatorname{cov}(\mathrm{y}, \mathrm{z})}{\operatorname{cov}\left(\mathrm{d}_{k, \cdot,}, \mathrm{z}\right)}=\frac{\delta^{o l s}}{\rho^{k, o l s}},
$$

where $\rho^{k, o l s}$ is the OLS estimator of the first-stage model:

$$
\mathrm{d}_{i}=\pi+\rho \cdot \mathrm{z}_{i}+\xi_{i} \text { with } \rho>0,
$$

$\overline{16}^{16}$ Below, we only consider cases in which $d_{2, \text { high }}=\mathrm{d}_{\text {high }}-\eta>\mathrm{d}_{\text {low }}+\gamma=d_{2, \text { low }}$. 
and $\delta^{\text {ols }}$ denotes the OLS estimator of the reduced-form model:

$$
\mathrm{y}_{i}=\zeta+\delta \cdot \mathrm{z}_{i}+\iota_{i} \text { with } \delta>0
$$

From

$$
\begin{aligned}
\rho^{k, o l s} & =\frac{\operatorname{cov}\left(\mathrm{z}, \mathrm{d}_{k, .}\right)}{\operatorname{var}(\mathrm{z})} \\
& =\frac{\frac{1}{n} \cdot\left(\mathrm{d}_{k, h i g h}-\mathrm{d}_{k, \text { low }}\right) \cdot\left(m \cdot \sum_{i=m+1}^{n}\left(z_{i}-\bar{z}\right)-(n-m) \cdot \sum_{i=1}^{m}\left(z_{i}-\bar{z}\right)\right)}{\operatorname{var}(\mathrm{z})}
\end{aligned}
$$

we can infer that the estimate of the first-stage parameter $\rho$ decreases if we replace the unbiased index with the biased index, because the biased index underestimates the difference between $\mathrm{d}_{\text {high }}$ and $\mathrm{d}_{\text {low }}$. The main consequence of using the biased index is that we overestimate the parameter $\beta$ :

$$
\mathrm{d}_{2, \text { high }}-\mathrm{d}_{2, \text { low }}<\mathrm{d}_{1, \text { high }}-\mathrm{d}_{1, \text { low }} \Rightarrow \rho^{2, \text { ols }}<\rho^{1, \text { ols }} \Rightarrow \beta^{2, i v}>\beta^{1, i v} .
$$

\subsection{Democracy and economic growth}

We now turn to the empirical part of the paper, in which we use our new indices to estimate the effect of democracy on economic growth. The motivation for this study is twofold: first, confirming the key predictions of our stylized model, and second, showing that the overestimation biases predicted by our model are of practical relevance.

The question of whether democracy cause economic growth is the subject of many studies. Some theories argue that a democracy grows faster than an autocracy since it has better economic institutions and spends more on education. Other theories suggest, however, that economic growth decreases if a democratic system replaces an autocratic system due to higher taxation and efficiency loses (Acemoglu, 2008, Besley and Coate, 1998, Saint-Paul and Verdier, 1993).

A number of recent empirical studies show that the positive aspects of democracy outweigh the negative aspects (Acemoglu et al., 2019, Flachaire et al., 2014, Gründler and Krieger, 2016, Madsen et al., 2015, Papaioannou and Siourounis, 2008, Persson and Tabellini, 2006, Rodrik and Wacziarg, 2005). Below, we present results confirming the view that democracy positively affects economic growth. The focus of our analysis is, however, on the question of whether the size of the effect depends on the aggregation method used for the creation of the measure of democracy.

\subsubsection{Identification strategies}

Three endogeneity problems complicate any empirical study that examines the effect of democracy on economic growth. First, autocracies may differ from democracies in non-observable factors that also affect economic growth. Second, causality may run from economic development to democracy. Finally, democratization is often preceded 
by a temporal decline in GDP per capita (Acemoglu et al., 2019).

Most empirical studies address these endogeneity issues with a dynamic fixed effect model:

$$
Y_{i, t}=\sum_{l=1}^{L} \beta_{l} \cdot Y_{i, t-l}+\gamma \cdot D_{i, t}+\xi_{i}+\eta_{t}+\varepsilon_{i, t}
$$

where $D$ denotes the level of democracy of country $i$ in year $t, Y$ the $\log$ of GDP per capita, $\xi$ the country fixed effect, $\eta$ the year fixed effect, and $\varepsilon$ the error term. ${ }^{17}$

The effect of democracy on economic growth $(\gamma)$ can be identified with the dynamic fixed effect model if the error term is uncorrelated with the past, current, and future realizations of the degree of democratization. Since this condition may not be satisfied because of omitted time-varying factors, several studies use a two-stage least squares approach in which the average level of democracy in neighboring countries serves as the instrument for the domestic degree of democratization (Acemoglu et al., 2019, Persson and Tabellini, 2009): ${ }^{18}$

$$
D_{i, t}=\sum_{l=1}^{L} \delta_{l} \cdot Y_{i, t-l}+\alpha \cdot Z_{i, t-1}+\zeta_{i}+\tau_{t}+\iota_{i, t}
$$

with

$$
Z_{i, t}=\frac{1}{|\mathcal{R}|} \sum_{j \in \mathcal{R}} D_{j, t} \quad \text { and } \quad \mathcal{R}=\left\{j: j \neq i, r_{j}=r_{i}\right\}
$$

where $r_{i}$ denotes the region in which country $i$ is located. ${ }^{19}$

\subsubsection{Results from ordinary least squares regressions}

Column 1 of Table 3.2 shows the results from estimating (3.13) when using the machine learning indicator to measure the degree of democratization. In line with other recent studies, we find a positive and statistically significant effect of democracy on economic growth. The OLS coefficient implies that a transition from autocracy $(d=0)$ towards democracy $(\mathrm{d}=1)$ causes an increase in GDP per capita by about 1.7 percent. ${ }^{20}$

The results presented in Section 3.2 suggest that the additive index is more likely to underestimate changes in the true degree of democratization than the machine learning index. The reason is that the additive aggregation approach often produces too large (small) indicies for autocratic (democratic) regimes. In Section 3.3.1, we argue that the estimate obtained from an OLS regression increases and becomes inconsistent when we

\footnotetext{
${ }^{17}$ The data on GDP per capita comes from the Maddison Project Database 2018 (Bolt et al., 2018).

${ }^{18}$ The motivation for this instrumentation strategy is that transitions from autocracy to democracy (or vice versa) often occurred in regional waves (Huntington, 1993, Teorell, 2010).

${ }^{19}$ In our baseline analysis, we use the classification of the United Nations to divide the world into 19 regions. Results for other classification schemes look similar and are available upon request.

${ }^{20}$ Compared with other studies that present OLS results from a dynamic fixed effect model, the main advantage of our analysis is the comprehensive sample which includes 163 countries and covers the period from 1919 to 2016. Just for comparison, most previous studies use data from 1960 onward (Acemoglu et al., 2019, Gründler and Krieger, 2016, Papaioannou and Siourounis, 2008, Persson and Tabellini, 2006).
} 
Table 3.2 Democracy and economic growth — OLS estimates.

\begin{tabular}{lccccc}
\hline & Machine Learning & Additive & Multiplicative & Add./ Multi. & Bayesian \\
\cline { 2 - 6 } & $(1)$ & $(2)$ & $(3)$ & $(4)$ & $(5)$ \\
\hline Democracy & $0.017^{* * *}$ & $0.027^{* * *}$ & $0.023^{* * *}$ & $0.026^{* * *}$ & $0.025^{* * *}$ \\
& $(0.0028)$ & $(0.0044)$ & $(0.0037)$ & $(0.0041)$ & $(0.0042)$ \\
\hline Observations & 10,733 & 10,733 & 10,733 & 10,733 & 10,733 \\
Countries & 163 & 163 & 163 & 163 & 163 \\
$\mathrm{R}^{2}$ & 0.997 & 0.997 & 0.997 & 0.997 & 0.997 \\
Equal. (p-val.) & - & 0.017 & 0.090 & 0.025 & 0.041 \\
\hline
\end{tabular}

Notes: The table presents OLS estimates. The dependent variable is the log of GDP per capita. All regressions include four lags of the dependent variable, country fixed effects, and year fixed effects. All democracy indicators are continuous and range from 0 to 1 . Standard errors clustered by country are reported in parentheses. We report results from a Wald test to show whether the estimates reported in Columns $2-5$ are significantly different from the estimates reported in Column 1. The following notation is used to highlight coefficients that are significantly different from zero: ${ }^{*} \mathrm{p}$-value $<0.10,{ }^{* *}$ $\mathrm{p}$-value $<0.05,{ }^{* * *} \mathrm{p}$-value $<0.01$.

apply a democracy index that suffers from these malfunctions. Column 2 of Table 3.2 supports this argument since it shows that the estimate of the effect of democracy on economic growth increase from 1.7 percent to 2.7 percent when we replace the machine learning index with the additive index. The difference between these two estimates is statistically significant at the five percent level.

In Columns $3-5$, we show the results for the multiplicative index, the additivemultiplicative index, and the Bayesian index. Again. we find that the OLS estimates of the effect of democracy on economic growth significantly increase compared with the estimate reported in Column 1. This result was to be expected because the machine learning method is less likely than the other aggregation methods to produce measures of democracy that underestimate the changes in the true degree of democratization (see Section 3.2).

\subsubsection{Results from two-stage least squares regressions}

Table 3.3 reports results from two-stage least squares regressions in which the regional (jack-knifed) degree of democratization serves as the instrument for the domestic degree of democratization. Column 1 presents the results for the machine learning index. We find a positive and statistically significant 2SLS estimate of the effect of democracy on economic growth (see Panel A).

In Panel B, we report the first-stage result. The estimate suggests that the regional level of democracy positively correlates with the domestic level of democracy. We also present results from three weak instrument tests. We report the first-stage F-statistic as suggested by Sanderson and Windmeijer (2016) and find that it exceeds the Stock and Yogo (2005) critical value. Furthermore, we present the p-values of the Anderson and Rubin (1949) test and the Stock and Wright (2000) test. None of these tests points to a weak instrument problem.

Section 3.3.2 suggests that the first-stage (second-stage) estimate becomes too small 
Table 3.3 Democracy and economic growth - 2SLS estimates.

\begin{tabular}{lccccc}
\hline & Machine Learning & Additive & Multiplicative & Add./ Multi. & Bayesian \\
\cline { 2 - 5 } & $(1)$ & $(2)$ & $(3)$ & $(4)$ & $(5)$ \\
\cline { 2 - 5 } Democracy & $0.029^{* * *}$ & $0.048^{* * *}$ & $0.037^{* * *}$ & $0.042^{* * *}$ & $0.052^{* * *}$ \\
& $(0.0047)$ & $(0.0073)$ & $(0.0060)$ & $(0.0065)$ & $(0.0080)$ \\
\cline { 2 - 6 } Equal. (p-val.) & - & 0.011 & 0.178 & 0.005 \\
\hline & \multicolumn{2}{c}{ Panel B: First-stage estimates } \\
nemo. (reg.) & $0.789^{* * *}$ & $0.482^{* * *}$ & $0.618^{* * *}$ & $0.557^{* * *}$ & $0.446^{* * *}$ \\
& $(0.0609)$ & $(0.0365)$ & $(0.0476)$ & $(0.0416)$ & $(0.0351)$ \\
Equal. (p-val.) & - & 0.000 & 0.001 & 0.000 & 0.000 \\
\hline Observations & 10,708 & 10,708 & 10,708 & 10,708 & 10,708 \\
Countries & 163 & 163 & 163 & 163 & 163 \\
SaWi (F.stat.) & 167.79 & 174.43 & 168.88 & 179.00 & 161.44 \\
AR (p-val.) & 0.000 & 0.000 & 0.000 & 0.000 & 0.000 \\
StWr (p-val.) & 0.000 & 0.000 & 0.000 & 0.000 & 0.000 \\
KP (p-val.) & 0.000 & 0.000 & 0.000 & 0.000 & 0.000 \\
\hline
\end{tabular}

Notes: The table presents 2SLS estimates. The dependent variable is the log of GDP per capita. All regressions include four lags of the dependent variable, country fixed effects, and year fixed effects. All democracy indicators are continuous and range from 0 to 1 . The first lag of the regional (jack-knifed) degree of democratization serves as the instrument for the domestic degree of democratization. We report different first-stage diagnostics to indicate the strength and validity of our instrumental variable. Standard errors clustered by country are reported in parentheses. We report results from a Wald test to show whether the estimates reported in Columns $2-5$ are significantly different from the estimates reported in Column 1. The following notation is used to highlight coefficients that are significantly different from zero: ${ }^{*}$ p-value $<0.10,{ }^{* *}$ p-value $<0.05,{ }^{* * *}$ p-value $<0.01$.

(large) when using an indicator that underestimates the changes in the true degree of democratization. Columns $2-5$ of Table 3.3 support these predictions. We observe that the first-stage estimate decreases and that the second-stage estimate increases when we replace the machine learning indicator with an alternative measure of democracy. The differences in the first-stage estimates are statistically significant at the one percent level and the differences in the second-stage estimates are - with one exception - statistically significant at conventional levels.

\subsubsection{Robustness}

We draw two conclusions from the regression results presented in Tables 3.2 and 3.3: first, democracy positively affects economic growth, and second, we overestimate the positive effect of democracy on economic growth if we use an additive, multiplicative, additive-multiplicative, or Bayesian index. The latter result is particularly noteworthy because almost all studies that examine the economic consequences of political transitions use these types of indicies. Below, we present the results of several robustness checks.

Some economists argue that annual data is inappropriate for studying the causes of economic growth. These scholars prefer data that is averaged over multiple years since data averaging filters out the business cycle fluctuations and mitigates the impact of measurement error in the variables (Durlauf et al., 2005). In Appendix Tables B.2 
and B.3, we show that the estimates of the effect of democracy on economic growth remain positive and statistically significant when we use five-year data rather than annual data. These two tables also show that using averaged data does not suffice to eliminate the differences in the effect size caused by a replacement of the machine learning index.

We conduct several subsample analyses to rule out that our results are driven by a particular group of countries or a specific period. Appendix Tables B.4 and B.5 show that our results hold when we drop all countries from either Africa, America, Asia, or Europa. Appendix Tables B.6 and B.7 suggest that our results also remain unchanged when we restrict the analysis to specific periods (1946 - 2016, 1970 - 2016).

In Appendix Tables B.8 and B.9, we extend the regression model by several control variables (civil conflict, population growth, institutional quality, education, investment, trade openness, government consumption). We find that the estimates of the effect of democracy on economic growth slightly decrease and are statistically significant at the five percent level. We also observe that the machine learning indicator still suggests a smaller effect than the other indicators. ${ }^{21}$

Finally, Appendix Tables B.10 and B.11 show results from regressions in which the average years of schooling serves as the outcome variable. In line with other empirical studies, we find that education increases in the degree of democratization (Acemoglu et al., 2019, Baum and Lake, 2003, Harding and Stasavage, 2013). We also observe that the positive effect of democracy on education increases when we replace the machine learning index with another index. This result is notable because it suggests that our conclusions about how changes in the aggregation technique affect the OLS and 2SLS estimates have at least some external validity.

\subsection{Conclusion}

Dissatisfied with the quality of standard measures of democracy, we compiled data on political participation, political competition, and the freedom of opinion (186 countries, 1919 - 2016) to create a new indicator. Since the literature does not provide generally acknowledged guidelines for aggregation, we use different methods and compare their performance. We observe that four out of five well-established aggregation techniques produce indices that underestimate changes in the true degree of democratization. The sole exception is a machine learning method.

We present a model that assumes a linear relationship between democracy and an outcome variable to illustrate the empirical consequence of applying error-prone data

\footnotetext{
${ }^{21}$ We use data from Brecke (1999) and the Uppsala Conflict Data Program to create an index of civil conflict. The measure of institutional quality comes form Coppedge et al. (2018) and reflects the extent to which courts operate independently. We use the Barro and Lee (2013) data on on years of schooling to measure education. The data on population growth is obtained from different sources, including: Bolt et al. (2018), the Cross-National Time Series Data Archive, the World Bank, and the web page www.populstat.info. The data on trade openness, government consumption, and investment comes from Feenstra et al. (2015).
} 
aggregation methods. We show that estimating such a model creates excessively large OLS estimates if the democracy indicator underestimates changes in the true degree of democratization. We also explain why having an instrument for the level of democracy does not suffice to correct this upward bias. The results of an analysis of the effect of democracy on economic growth demonstrate that the bias is significant.

Our paper has two main implications: First, data aggregation matters and all social scientists should be careful in drawing causal inferences from regressions in which the variables of interests are measured by an index. Second, researchers interested in the consequences of political transitions should discontinue using simple democracy indices, such as the Polity IV index or the Freedom House indices, because their underlying aggregation methods produce non-random measurement errors. 


\section{B.1 Supplementary material for Section 3.2.4}

A key objective of our study is to figure out which of the available aggregation methods are suited for the creation of democracy indices. In this section, we provide some methodological details about the five aggregation techniques that we compare in our analysis.

\section{B.1.1 Additive approach}

The main difficulty in creating an additive index

$$
\mathrm{d}^{\text {ad }}=\omega_{1} \cdot x_{1}+\ldots+\omega_{m} \cdot x_{m} \quad \text { with } \sum_{j=1}^{m} \omega_{j}=1 \quad \text { and } \quad\left(x_{1}, \ldots, x_{m}\right) \in[0,1]^{m}
$$

is to select the weights $\left(\omega_{1}, \ldots, \omega_{m}\right)$ for the regime characteristics $\left(x_{1}, \ldots, x_{m}\right)$. The related literature suggests two weighting method: (i) assigning the same weight to all regime characteristics, or (ii) extracting the weights from a principle component analysis (PCA). We use the second approach because our regime characteristics are unequally distributed between our three dimensions of democracy (political competition, political participation, and freedom of opinion).

\section{B.1.2 Multiplicative approach}

Creating a multiplicative index

$$
\mathrm{d}^{\mathrm{mu}}=x_{1}^{\omega_{1}} \cdot \ldots \cdot x_{m}^{\omega_{m}} \quad \text { with } \quad \sum_{j=1}^{m} \omega_{j}=1 \quad \text { and } \quad\left(x_{1}, \ldots, x_{m}\right) \in[0,1]^{m}
$$

also requires the selection of weights $\left(\omega_{1}, \ldots, \omega_{m}\right)$. For the sake of consistency, we use the same weighting scheme as for the additive index.

\section{B.1.3 Combining the additive and the multiplicative approach}

Teorell et al. (2019) argue that combining an additive approach with a multiplicative approach is the best solution for the aggregation problem:

$$
\mathrm{d}^{\mathrm{am}}=\lambda \cdot \sum_{j=1}^{m} \omega_{j} \cdot x_{j}+(1-\lambda) \cdot \prod_{j=1}^{m} x_{j}^{\omega_{j}}
$$

where $\lambda \in(0,1)$ is the weight of the additive component. We use a PCA to calculate this weighting factor. 


\section{B.1.4 Bayesian latent variable approach}

We use the R package provided by Márquez (2016) to implement the Bayesian latent variable approach. This approach requires ordinal regime characteristics. We therefore transform all continuous variables in five point scale variables.

\section{B.1.5 Machine learning approach}

In a previous study, we proposed an aggregation method that is based on a machine learning technique for pattern recognition, known as Support Vector Machines (SVM) (Gründler and Krieger, 2016). Our major objective was to avoid simple assumptions about the functional relationship between the regime characteristics and the degree of democratization. To achieve this objective, we put the aggregation problem into a non-linear optimization problem.

To use SVM for the measurement of democracy, we need some observations - called priming data - with a generally acknowledged level of democracy, based on which the machine learning algorithm can estimate the aggregation function. We argue that the degree of democratization of the most democratic and the most autocratic regimes are uncontroversial $^{1}$ and that these regimes can thus be used as priming data. ${ }^{2}$ To find suitable regimes, we use the democracy indicies developed by Teorell et al. (2019) and Pemstein et al. (2010). ${ }^{3}$ We label a country-year as a highly autocratic (democratic) regime if it belongs to the lower (upper) decile of either of the two indicies. Appendix Table A.1 (Chapter 2) lists all labeled observations. ${ }^{4}$

\section{B.2 Supplementary material for Section 3.2.5}

The three case studies presented in Section 3.2.4 suggest that replacing an aggregation method with another method can cause significant changes in the indicated degree of democratization. We find in particular that the additive approach and the Bayesian approach often produce too optimistic indices for autocratic regimes, while the additive-

\footnotetext{
${ }^{1}$ According to Cheibub et al. (2010) and Lindberg et al. (2014), distinguishing the least democratic from the most democratic regimes is a simple exercise: most scholars agree that Sweden is a democracy and Saudi Arabia is not. We use the consensus on the regimes at the ends of the spectrum to justify the assumption that their degree of democratization is directly observable.

${ }^{2}$ A potential concern is whether learning from "extreme" cases leads to reliable democracy indicies for "intermediate" cases. The case studies presented in Section 3.2.4 and Appendix B.2.1 allay this concern because they show that all aggregation methods produce similar indicies for hybrid regimes.

${ }^{3}$ These indicators are most suited because of their continuous scale and their availability. The machine learning indices hardly change when we use alternative measures of democracy for labeling.

${ }^{4}$ The priming data include 2728 country-years: 1308 are democratic and 1420 are autocratic. We use the election handbooks prepared by Dieter Nohlen (1999, 2001, 2005, 2010) and historical records to check whether the assigned labels are consistent with our concept of democracy. We found only three observations for which the classification may be controversial: The first two are the observation for Switzerland in 1952 and 1970, since women were not entitled to vote in national elections. The last is the observation for Israel in 1999, since Palestinians living in the Gaza Strip and the West Bank were not allowed to participate in the general election for the Israeli parliament. The machine learning indices remain virtually unchanged when we exclude these three country-years from the priming data.
} 
multiplicative approach and the multiplicative approach often produce too pessimistic indices for democratic regimes. Furthermore, we find that the machine learning index suffers from none of these malfunctions.

\section{B.2.1 Additional country examples}

One legitimate concern is that three country examples do not suffice to draw general conclusions about the performance of different aggregation methods. To partly address this concern, we present below three additional country examples (Bhutan, Kenya, and Spain).

\section{B.2.1.1 Bhutan}

Bhutan has been an independent country since August 1949. In 1953, Bhutan's king, Jigme Dorji Wangchuk, established a parliament consisting of 150 nominated members. Even though several kings tried to democratize the regime, it took more than 50 years until the era of authoritarian rule ended (Nohlen et al., 2001, Turner et al., 2011). The first general election was held in 2008 and was won by the Bhutan Peace and Prosperity Party (DPT). In the next election, the DPT lost support and was replaced by the main opposition party (Turner and Tshering, 2014).

Figure B.1 shows the degree of democratization of Bhutan for different aggregation methods. We observe that all five indicators significantly increase in 2008, the year in which the first general election was held. We also observe that the indices differ widely from each other in the 1949 - 2007 period. The additive index, the Bayesian index, and, to a lesser extent, the additive-multiplicative index suggest that Bhtuan partly met democratic standards, whereas the multiplicative index and the machine learning index indicate that Bhutan was a non-democratic state. We argue that only the latter indices are compatible with a realistic concept of democracy because no federal elections were held in Bhutan before 2008.

\section{B.2.1.2 Kenya}

Kenya gained independence from the United Kingdom in December 1963. At this time, Kenyan politics was shaped by the rivalry between the Kenyan African National Union (KANU) - the winning party of the parliamentary election in Mai 1963 - and the Kenya African Democratic Union (KADU). After the forced unification of the KANU and the KADU in December 1964 and the ban of the Kenya People's Union (KPU) in October 1969, the KANU was the only legal political party until December 1991 (Nohlen et al., 1999). Against all exceptions, KANU won the multi-party election in December 1992. Elklit and Svensson (1997) and Nohlen et al. (1999) explain this victory with electoral fraud. The dominance of the KANU lasted for another ten years and ended after the general election in December 2002. 
Figure B.2 illustrates the Kenyan level of democracy, depending on the aggregation method. All measures of democracy indicate a significant decrease in the degree of democratization in 1969 and a significant increase in 1992. We observe, however, some differences in the size of the changes because the indicators suggest different levels of democracy for the period from 1969 to 1991. The multiplicative index and the machine learning index suggest the absence of democracy, whereas the other indices suggest the existence of weak democratic structures. The latter indices are not consistent with the concept of democracy because Kenya was a single-party regime at this time.

\section{B.2.1.3 Spain}

After years of restricted political competition, political patronage, and electoral fraud, General Miguel Primo de Rivera seized power in September 1923 and established - with support from the Spanish king - a military regime. Triggered by great social unrest, General Rivera stepped down in January 1930. About one year later, the Spanish king withdrew as well and thus paved the way for the proclamation of the Second Spanish Republic in April 1931 (Nohlen and Stöver, 2010). The Republican era lasted until the end of the Spanish Civil War and the establishment of a military regime led by General Franco in 1939. Under Franco's rule, which ended with his death in 1975, no general elections were held and all political parties were banned. After a short transition period, Spain established a parliamentary monarchy in 1977. Since then, all governments were legitimated through free and fair elections (Nohlen and Stöver, 2010).

Figure B.3 shows how the Spanish level of democracy depends on the aggregation method. Two differences are notable. First, the additive indicator and the Bayesian indicator suggest that democratic principles were partly met under the rule of General Rivera (1923 - 1930), whereas the multiplicative index and the machine learning index indicate the absence of democratic structures. Because no elections took place under Rivera's rule, we think that the former indices are incompatible with our concept of democracy. Second, some indices indicate a lack of democracy in the post-Franco era $(1977$ - 2016). We doubt whether this assessment is reasonable given that multi-party elections were regularly held and no remarkable restrictions on the freedom of opinion existed during this period (Nohlen and Stöver, 2010).

\section{B.2.2 Alternative regime characteristics}

Another legitimate concern is that we strategically selected our regime characteristics to favor the machine learning technique. To allay this concern, we replace our regimes characteristics with the regime characteristics used by Teorell et al. (2019) and repeat our analysis. ${ }^{5}$ We chose the Teorell et al. (2019) data for two reasons: first, the concept

\footnotetext{
${ }^{5}$ Teorell et al. (2019) use five expert-based ratings, capturing information on: suffrage, the procedure to select government officials, electoral fairness, freedom of expression, and freedom of association.
} 
of democracy assumed by Teorell et al. (2019) resembles our concept of democracy, and second, Teorell et al. (2019) provide an additive index, a multiplicative index, and an additive-multiplicative index.

Appendix Figures B.4 - B.6 illustrate that our results about the performance of the aggregation methods are robust to a change in the regime characteristics. We find that the additive index and the Bayesian index overestimate the true level of democracy of autocratic regimes, such as the Nazi regime in Germany, the communist regime in the Soviet Union, and the military regime in Myanmar (Burma). We also observe that the multiplicative index and the additive-multiplicative index underestimate the true degree of democratization of democratic regimes, such as present-day Germany. None of these malfunctions appear when we use the machine learning index.

\section{B.2.3 Methodological explanations}

How can we explain that most of the available aggregation methods produce indicators that are too unfavorable (favorable) for democratic (autocratic) regimes? Below, we will show that the answer to this open question lies in the assumptions about the functional relationship between the regime characteristics and the level of democracy. Since the crucial arguments are similar for all concerned aggregation techniques and to keep our explanation as short and simple as possible, we restrict our attention to the additive index in the remainder of this section.

\section{B.2.3.1 Implausibly low indices for democratic regimes}

An additive index is based on the assumption that the level of democracy is equal to 1 only if all regime characteristics reach their maximum:

$$
\mathrm{d}^{\mathrm{ad}}=1 \quad \Leftrightarrow \quad x_{1}=\ldots=x_{m}=1
$$

In our case, this assumption implies, for example, that voter turnout must be $100 \%$ and that the number of votes won by the leading party must be equal to the number of votes won by the second strongest party. Put differently, the additive index indicates a lack of democracy if eligible voters voluntarily abstain from voting, or if the leading party is simply more popular than the second strongest party. We argue that these conditions are too demanding to be compatible with a standard definition of democracy and that additive indices thus often underestimate the true level of democracy of democratic regimes.

\section{B.2.3.2 Implausibly high indices for autocratic regimes}

An additive index also assumes that the degree of democratization is only 0 when all 
regime characteristics reach their minimum:

$$
\mathrm{d}^{\mathrm{ad}}=0 \quad \Leftrightarrow \quad x_{1}=\ldots=x_{m}=0
$$

In our case, this assumptions implies, for example, that a regime in which single-party election are regularly held (e.g. Soviet Union, 1937 - 1990) or a regime in which no elections take place but limited freedom of opinion exist (e.g. Bhutan, 1949 - 2007) obtain a democracy score that is greater than 0. Because any definition of democracy includes electoral competition as necessary conditions, we argue that additive indicators often overestimate the true level of democracy of autocratic regimes. 


\section{B.3 Additional figures}

Figure B.1 Democracy in Bhutan (1949 - 2016).
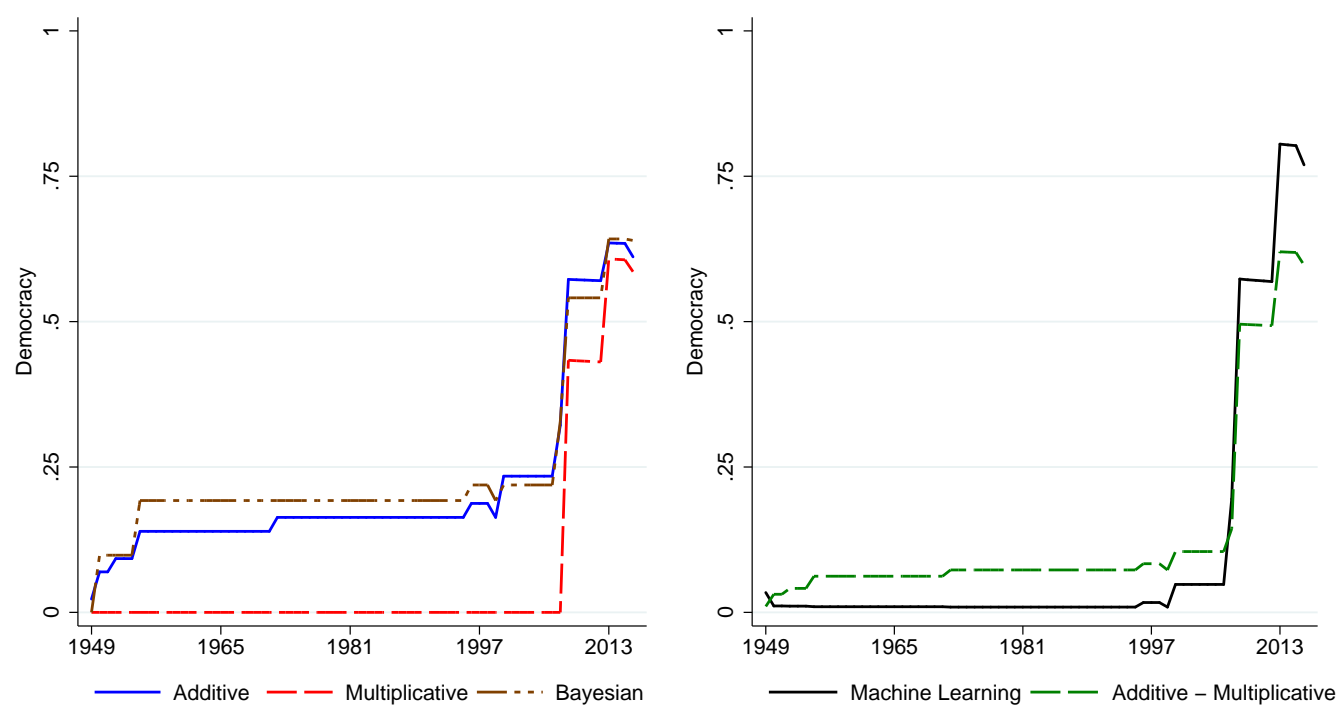

Notes: The figures show the level of democracy of Bhutan, depending on how we aggregate our nine regime characteristics.

Figure B.2 Democracy in Kenya (1963 - 2016).
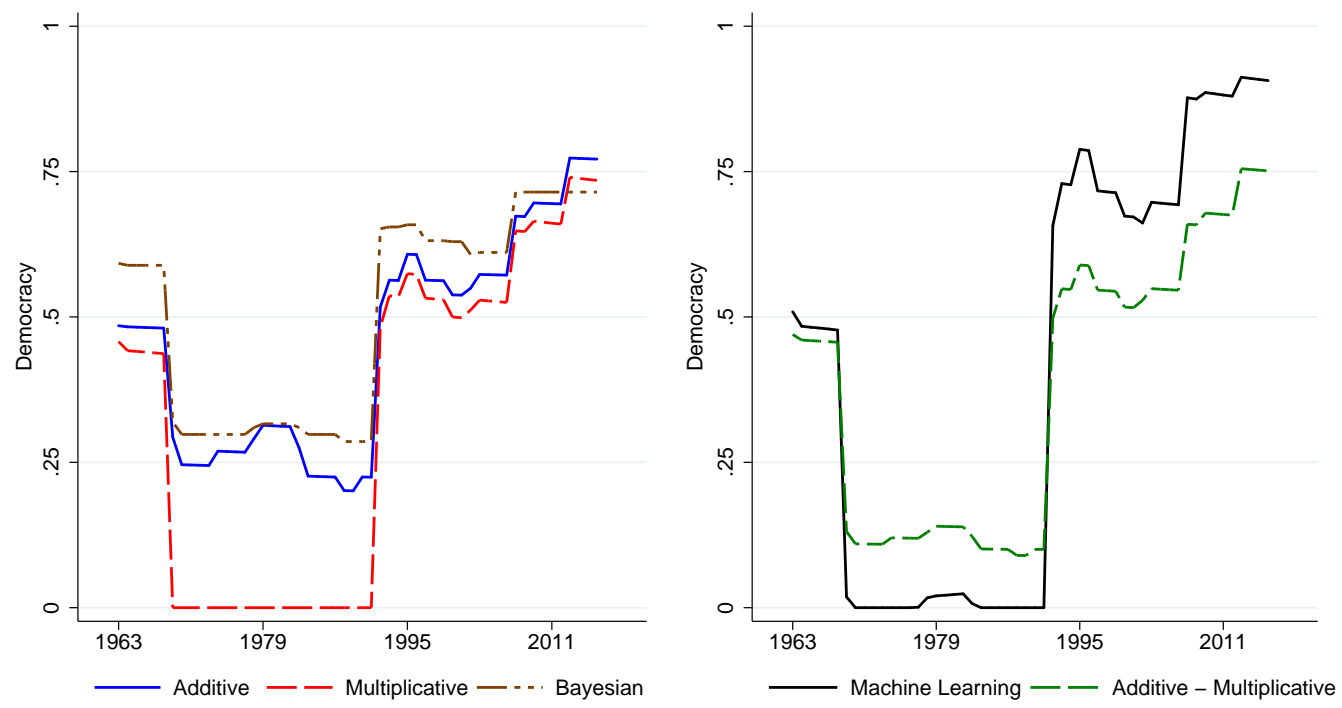

Notes: The figures show the level of democracy of Kenya, depending on how we aggregate our nine regime characteristics. 
Figure B.3 Democracy in Spain $(1919-2016)$.
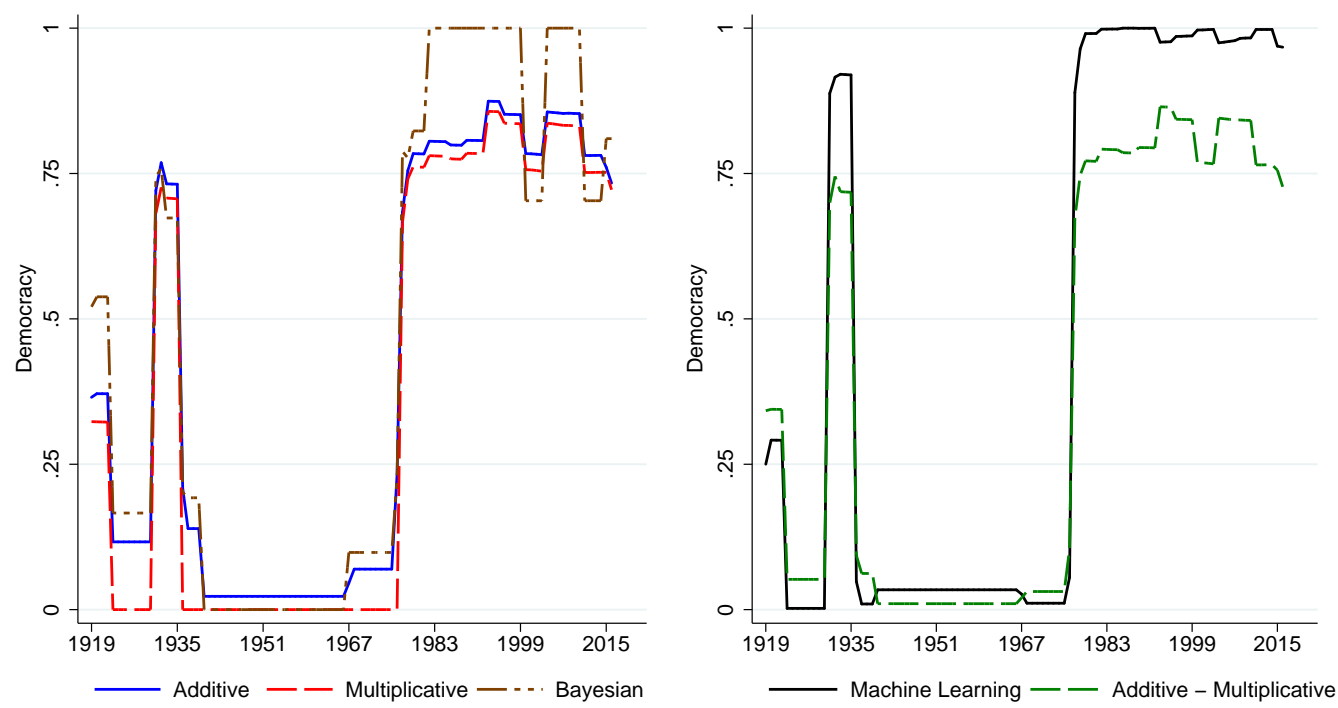

Notes: The figures show the level of democracy of Spain, depending on how we aggregate our nine regime characteristics.

Figure B.4 Democracy in Germany (1919 - 2016) - Alternative regime characteristics.
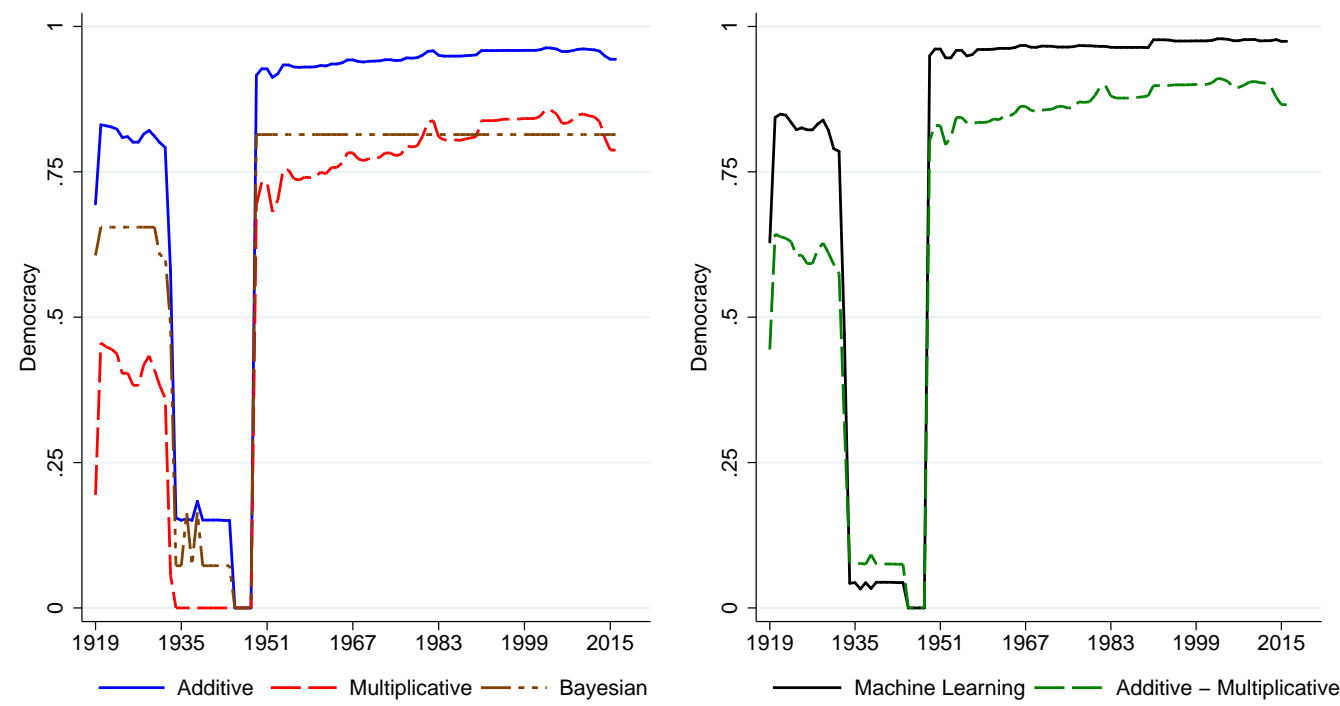

Notes: The figures show the level of democracy of Germany, depending on how we aggregate the five regime characteristics used by Teorell et al. (2019). For the period from 1949 to 1989, the measures of democracy refer to the Federal Republic of Germany. 
Figure B.5 Democracy in Russia (1919 - 2016) - Alternative regime characteristics.
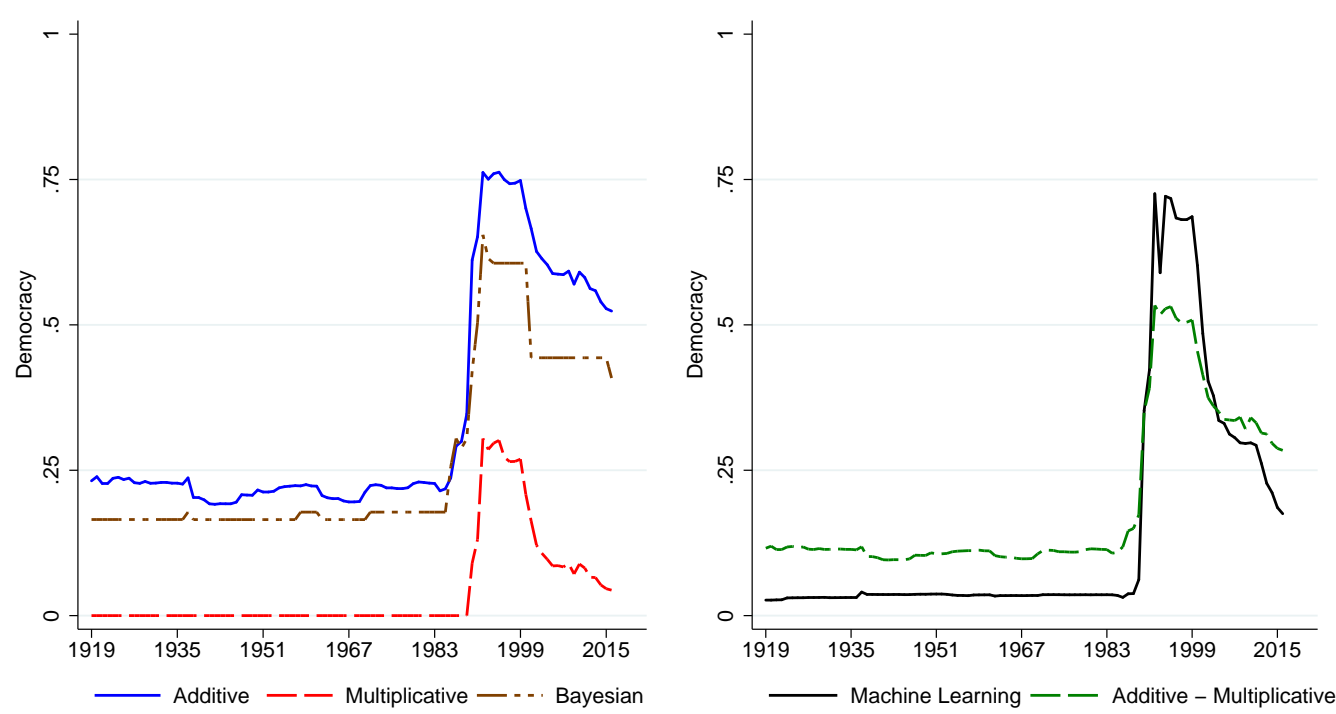

Notes: The figures show the level of democracy of Russia, depending on how we aggregate the five regime characteristics used by Teorell et al. (2019). For the period from 1922 to 1990, the measures of democracy refer to the Soviet Union.

Figure B.6 Democracy in Myanmar (1948 - 2016) - Alternative regime characteristics.
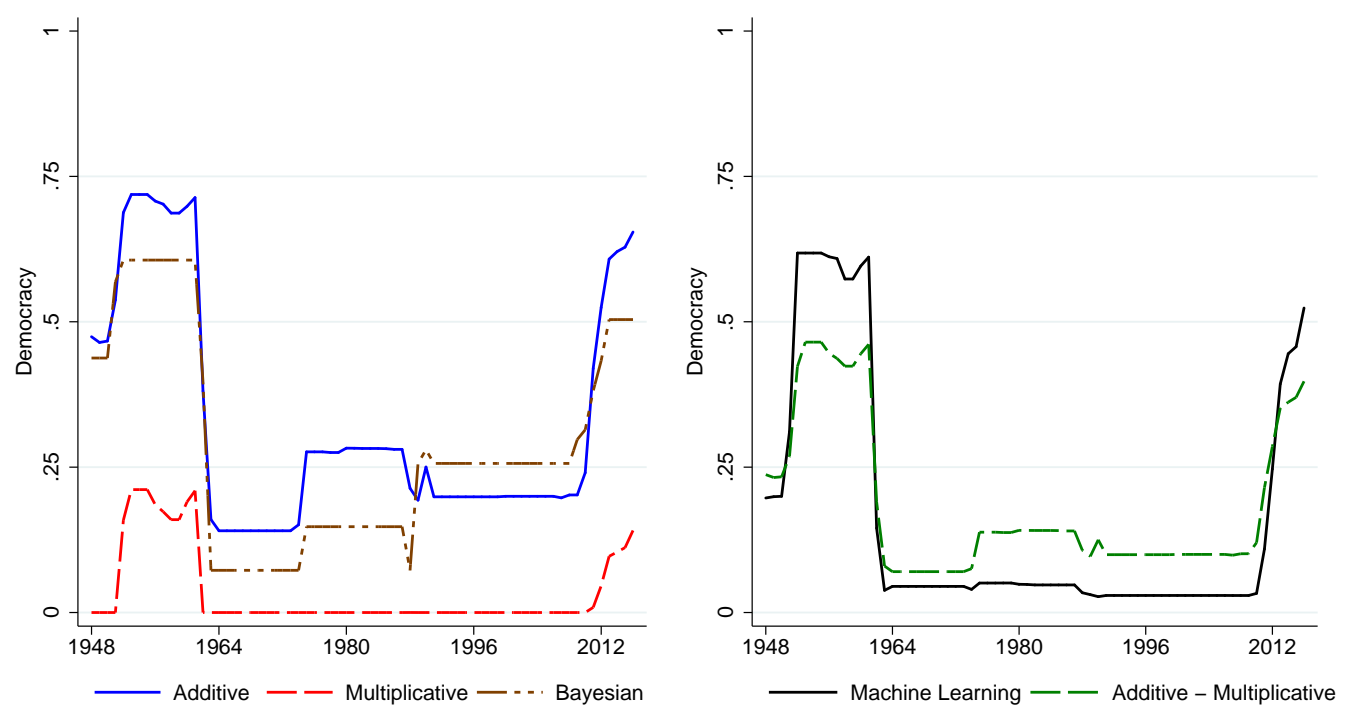

Notes: The figures show the level of democracy of Myanmar, depending on how we aggregate the five regime characteristics used by Teorell et al. (2019). The country was renamed from Burma to Myanmar in 1989. 


\section{B.4 Additional tables}

Table B.1 Average changes in the level of democracy - Regime changes.

\begin{tabular}{cccccc}
\hline & Machine Learning & Additive & Multiplicative & Add. / Multi. & Bayesian \\
\hline$\Delta^{j}$ & 0.437 & 0.287 & 0.350 & 0.322 & 0.305 \\
\hline
\end{tabular}

Notes: The table reports results from estimating

$$
\Delta^{j}=\frac{1}{|\mathcal{D}|} \sum_{(i, t) \in \mathcal{D}}\left|\mathrm{d}_{i, t}^{j}-\mathrm{d}_{i, t-1}^{j}\right|
$$

where $\mathrm{d}_{i, t}^{j}$ denotes the level of democracy of country $i$ in year $t$ indicated by index $j$. The set $\mathcal{D}$ includes all country-year observations for which Boix et al. (2013) report a political transition.

Table B.2 Democracy and economic growth - OLS estimates, five-year data.

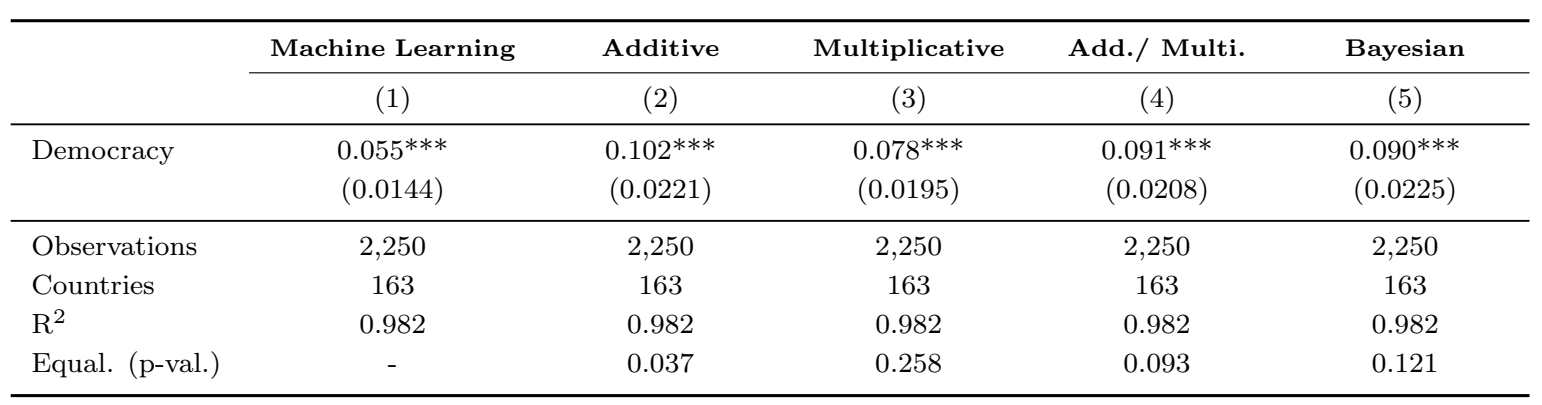

Notes: The table presents OLS estimates. The dependent variable is the log of GDP per capita. All regressions include the first lag of the dependent variable, country fixed effects, and period fixed effects. All democracy indicators are continuous and range from 0 to 1 . The data is averaged over five-year periods $(1920-24,1925-29, \ldots)$. Standard errors clustered by country are reported in parentheses. We report results from a Wald test to show whether the estimates reported in Columns $2-5$ are significantly different from the estimates reported in Column 1 . The following notation is used to highlight coefficients that are significantly different from zero: ${ }^{*}$ p-value $<0.10,{ }^{* *}$ p-value $<0.05,{ }^{* * *} \mathrm{p}$-value $<0.01 .$. 
Table B.3 Democracy and economic growth - 2SLS estimates.

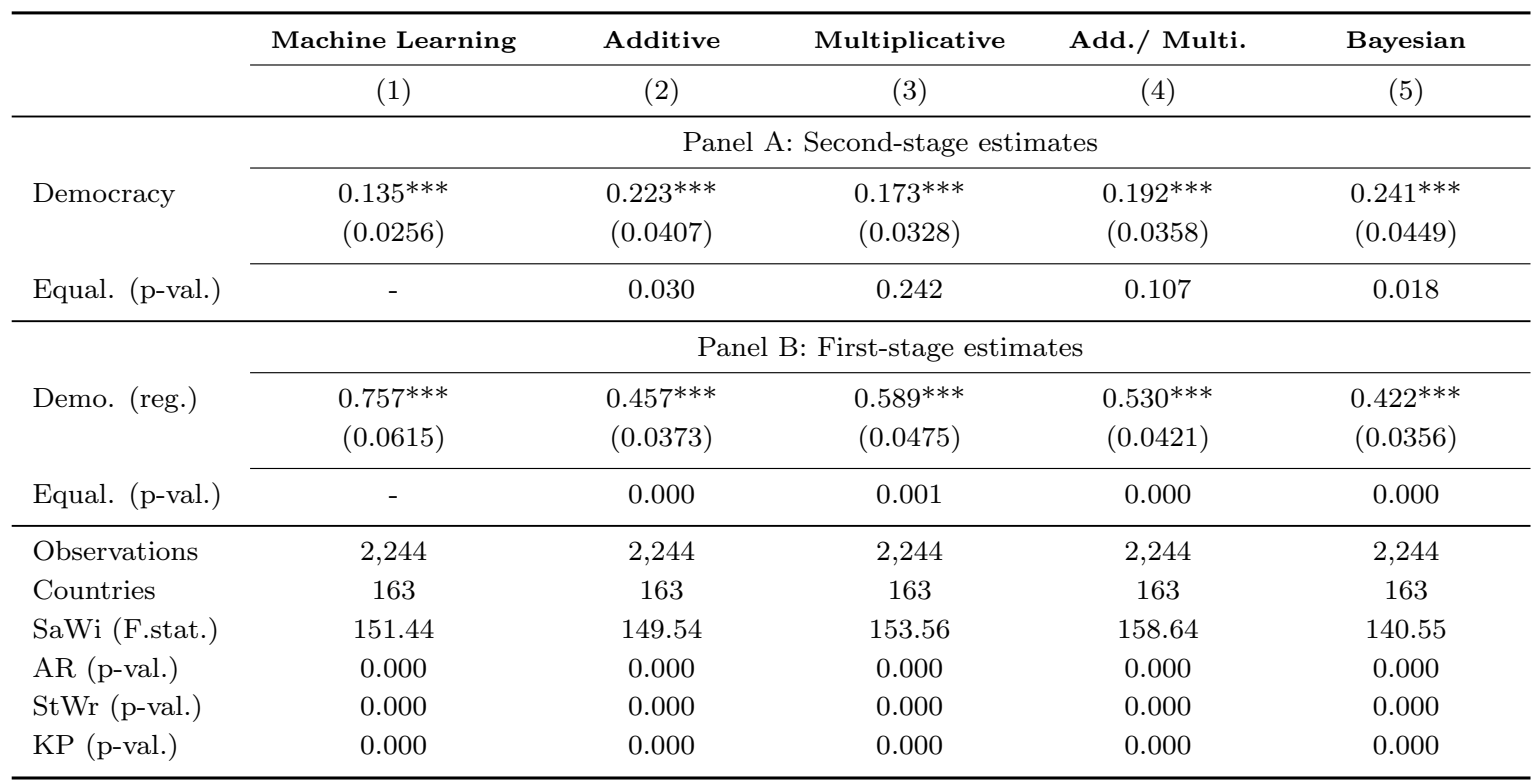

Notes: The table presents 2SLS estimates. The dependent variable is the log of GDP per capita. All regressions include the first lags of the dependent variable, country fixed effects, and period fixed effects. All democracy indicators are continuous and range from 0 to 1 . The first lag of the regional (jack-knifed) degree of democratization serves as the instrument for the domestic degree of democratization. The data is averaged over five-year periods $(1920-24,1925-29, \ldots)$. We report different first-stage diagnostics to indicate the strength and validity of our instrumental variable. Standard errors clustered by country are reported in parentheses. We report results from a Wald test to show whether the estimates reported in Columns $2-5$ are significantly different from the estimates reported in Column 1 . The following notation is used to highlight coefficients that are significantly different from zero: ${ }^{*}$ p-value $<0.10,{ }^{* *}$ p-value $<0.05,{ }^{* * *}$ p-value $<0.01$. 
Table B.4 Democracy and economic growth - OLS estimates, subsample analysis (continent).

\begin{tabular}{|c|c|c|c|c|c|}
\hline & Machine Learning & Additive & Multiplicative & Add./ Multi. & Bayesian \\
\hline & $(1)$ & (2) & (3) & (4) & (5) \\
\hline & \multicolumn{5}{|c|}{ Panel A: Exclude Africa } \\
\hline Democracy & $\begin{array}{c}0.015^{* * *} \\
(0.0035)\end{array}$ & $\begin{array}{c}0.027^{* * *} \\
(0.0054)\end{array}$ & $\begin{array}{c}0.021^{* * *} \\
(0.0043)\end{array}$ & $\begin{array}{c}0.024^{* * *} \\
(0.0048)\end{array}$ & $\begin{array}{c}0.025^{* * *} \\
(0.0048)\end{array}$ \\
\hline Observations & 7,539 & 7,539 & 7,539 & 7,539 & 7,539 \\
\hline Countries & 112 & 112 & 112 & 112 & 112 \\
\hline \multirow[t]{2}{*}{ Equal. (p-val.) } & - & 0.041 & 0.252 & 0.094 & 0.041 \\
\hline & \multicolumn{5}{|c|}{ Panel B: Exclude America } \\
\hline Democracy & $\begin{array}{c}0.020^{* * *} \\
(0.0035)\end{array}$ & $\begin{array}{c}0.034^{* * *} \\
(0.0056)\end{array}$ & $\begin{array}{c}0.028^{* * *} \\
(0.0046)\end{array}$ & $\begin{array}{c}0.032^{* * *} \\
(0.0050)\end{array}$ & $\begin{array}{r}0.030^{* * *} \\
(0.0051)\end{array}$ \\
\hline Observations & 8,807 & 8,807 & 8,807 & 8,807 & 8,807 \\
\hline Countries & 136 & 136 & 136 & 136 & 136 \\
\hline \multirow[t]{2}{*}{ Equal. (p-val.) } & - & 0.014 & 0.099 & 0.023 & 0.055 \\
\hline & \multicolumn{5}{|c|}{ Panel C: Exclude Asia } \\
\hline Democracy & $\begin{array}{c}0.013^{* * *} \\
(0.0029)\end{array}$ & $\begin{array}{c}0.021^{* * *} \\
(0.0047)\end{array}$ & $\begin{array}{c}0.019 * * * \\
(0.0039)\end{array}$ & $\begin{array}{c}0.021^{* * * *} \\
(0.0043)\end{array}$ & $\begin{array}{c}0.021^{* * *} \\
(0.0046)\end{array}$ \\
\hline Observations & 8,249 & 8,249 & 8,249 & 8,249 & 8,249 \\
\hline Countries & 120 & 120 & 120 & 120 & 120 \\
\hline \multirow[t]{2}{*}{ Equal. (p-val.) } & - & 0.067 & 0.114 & 0.062 & 0.079 \\
\hline & \multicolumn{5}{|c|}{ Panel D: Exclude Europe } \\
\hline Democracy & $\begin{array}{c}0.019^{* * *} \\
(0.0031)\end{array}$ & $\begin{array}{c}0.028^{* * *} \\
(0.0049)\end{array}$ & $\begin{array}{c}0.025^{* * *} \\
(0.0041)\end{array}$ & $\begin{array}{c}0.028^{* * *} \\
(0.0045)\end{array}$ & $\begin{array}{r}0.026^{* * *} \\
(0.0047)\end{array}$ \\
\hline Observations & 8,164 & 8,164 & 8,164 & 8,164 & 8,164 \\
\hline Countries & 123 & 123 & 123 & 123 & 123 \\
\hline Equal. (p-val.) & - & 0.056 & 0.127 & 0.053 & 0.143 \\
\hline
\end{tabular}

Notes: The table presents OLS estimates. The dependent variable is the log of GDP per capita. All regressions include four lags of the dependent variable, country fixed effects, and year fixed effects. All democracy indicators are continuous and range from 0 to 1 . Standard errors clustered by country are reported in parentheses. We report results from a Wald test to show whether the estimates reported in Columns $2-5$ are significantly different from the estimates reported in Column 1. The following notation is used to highlight coefficients that are significantly different from zero: ${ }^{*} \mathrm{p}$-value $<0.10,{ }^{* *}$ $\mathrm{p}$-value $<0.05,{ }^{* * *} \mathrm{p}$-value $<0.01$. 
Table B.5 Democracy and economic growth — Second-stage estimates, subsample analysis (continent).

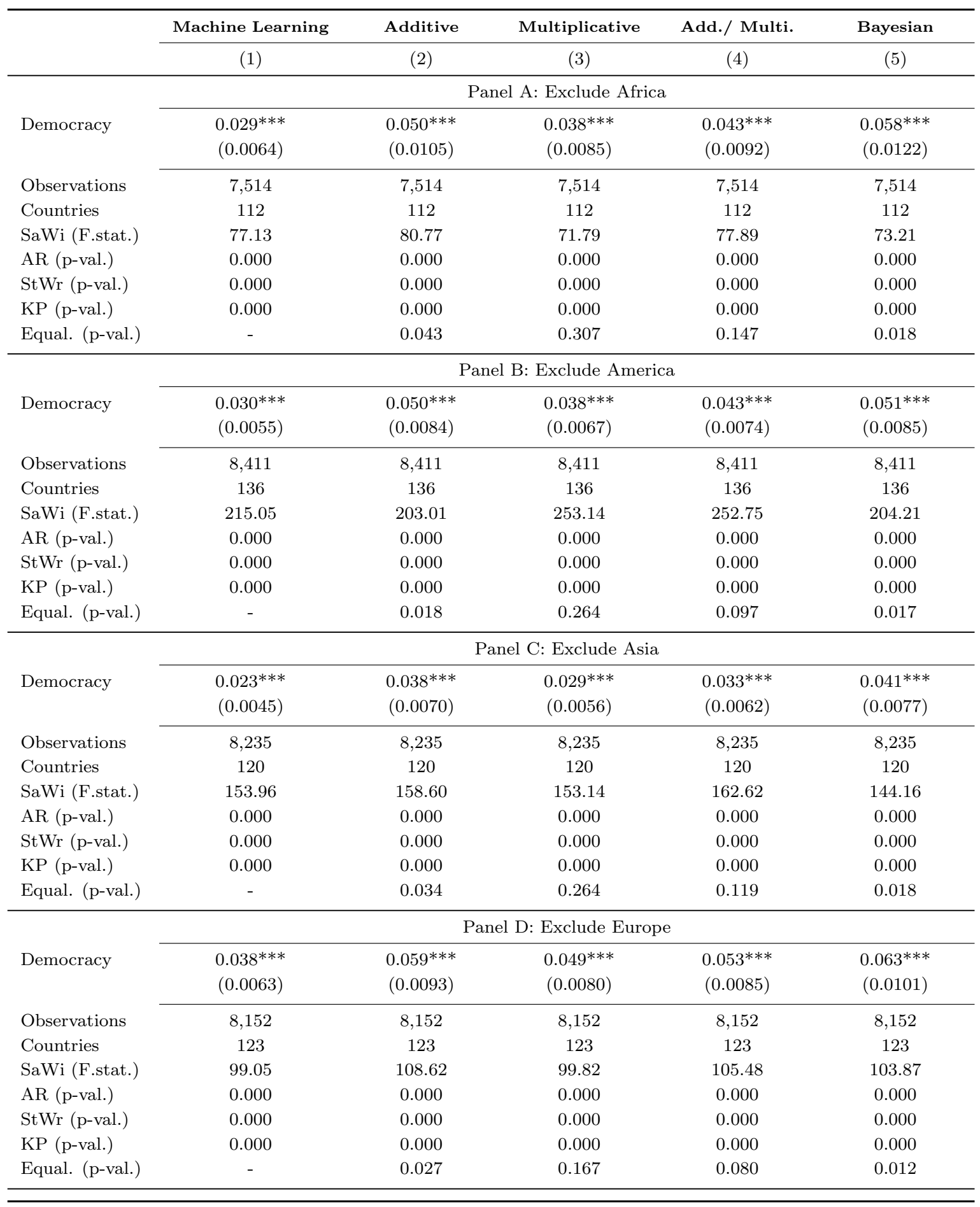

Notes: The table presents 2SLS estimates. The dependent variable is the log of GDP per capita. All regressions include four lags of the dependent variable, country fixed effects, and year fixed effects. All democracy indicators are continuous and range from 0 to 1 . The first lag of the regional (jack-knifed) degree of democratization serves as the instrument for the domestic degree of democratization. We report different first-stage diagnostics to indicate the strength and validity of our instrumental variable. Standard errors clustered by country are reported in parentheses. We report results from a Wald test to show whether the estimates reported in Columns $2-5$ are significantly different from the estimates reported in Column 1. The following notation is used to highlight coefficients that are significantly different from zero: ${ }^{*}$ p-value $<0.10,{ }^{* *}$ p-value $<0.05,{ }^{* * *}$ p-value $<0.01$. 
Table B.6 Democracy and economic growth - OLS estimates, subsample analysis (periods).

\begin{tabular}{lccccc}
\hline & Machine Learning & Additive & Multiplicative & Add./ Multi. & Bayesian \\
\cline { 2 - 6 } & $(1)$ & $(2)$ & $(3)$ & $(4)$ & $(5)$ \\
\cline { 2 - 5 } Democracy & $0.021^{* * *}$ & $0.037^{* * *}$ & $0.028^{* * *}$ & $0.033^{* * *}$ & $0.033^{* * *}$ \\
& $(0.0030)$ & $(0.0055)$ & $(0.0041)$ & $(0.0047)$ & $(0.0054)$ \\
\cline { 2 - 6 } Observations & 7,041 & 7,041 & 7,041 & 7,041 & 7,041 \\
Countries & 163 & 163 & 163 & 163 & 163 \\
Equal. (p-val.) & - & 0.005 & 0.092 & 0.014 & 0.024 \\
\hline & & & Panel B: $1946-2016$ & $0.024^{* * *}$ \\
Democracy & $0.015^{* * *}$ & $0.026^{* * *}$ & $0.021^{* * *}$ & $0.024^{* * *}$ & $(0.0042)$ \\
\cline { 2 - 6 } & $(0.0026)$ & $(0.0044)$ & $(0.0034)$ & $(0.0038)$ & 9,679 \\
Observations & 9,679 & 9,679 & 9,679 & 9,679 & 163 \\
Countries & 163 & 163 & 163 & 163 & 0.039 \\
Equal. (p-val.) & & 0.019 & 0.094 & 0.026 & \\
\hline Z & & & & & \\
\hline
\end{tabular}

Notes: The table presents OLS estimates. The dependent variable is the log of GDP per capita. All regressions include four lags of the dependent variable, country fixed effects, and year fixed effects. All democracy indicators are continuous and range from 0 to 1 . Standard errors clustered by country are reported in parentheses. We report results from a Wald test to show whether the estimates reported in Columns $2-5$ are significantly different from the estimates reported in Column 1. The following notation is used to highlight coefficients that are significantly different from zero: ${ }^{*} \mathrm{p}$-value $<0.10,{ }^{* *}$ p-value $<0.05,{ }^{* * *}$ p-value $<0.01$. 
Table B.7 Democracy and economic growth — Second-stage estimates, subsample analysis (periods).

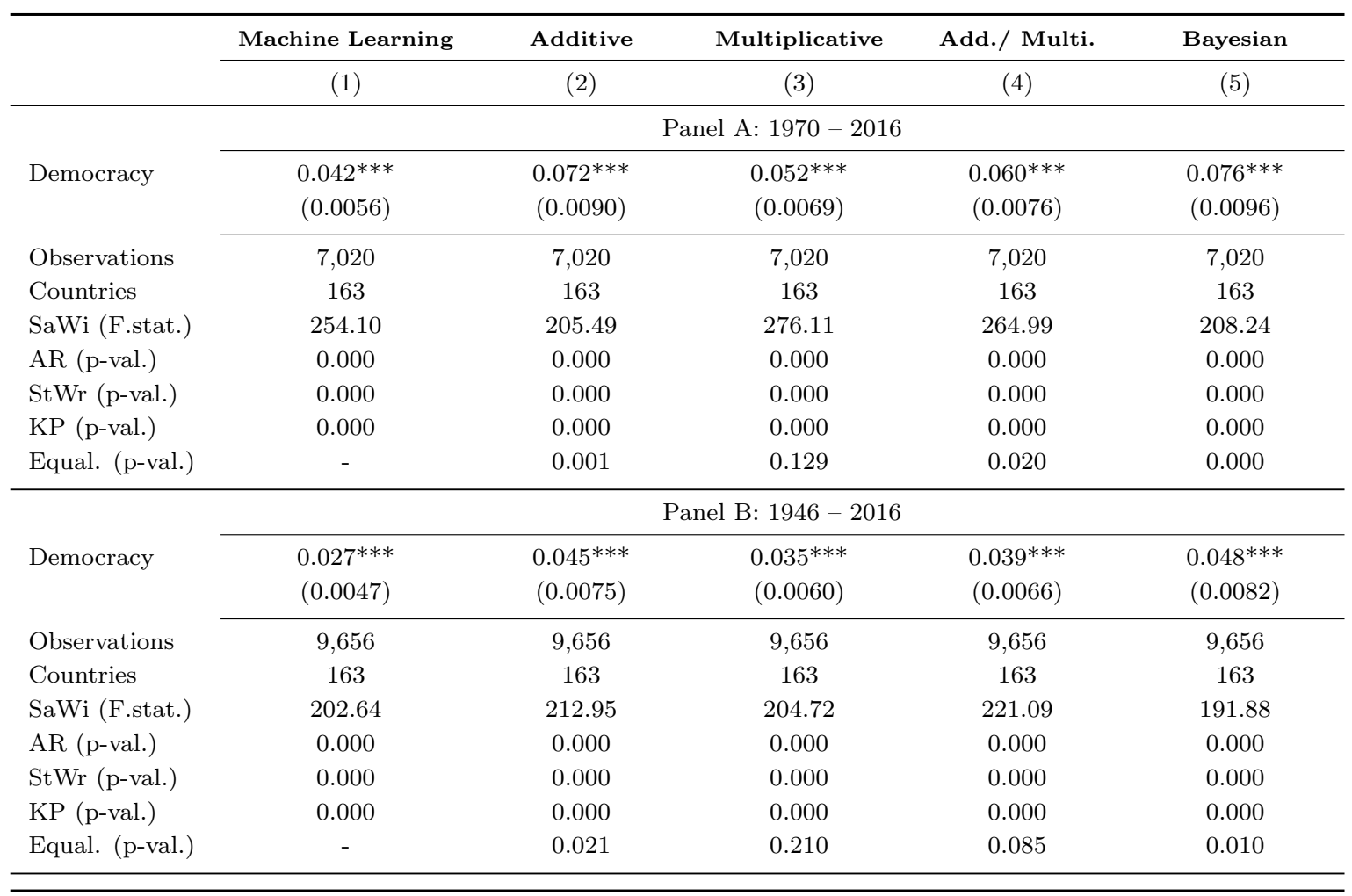

Notes: The table presents 2SLS estimates. The dependent variable is the log of GDP per capita. All regressions include four lags of the dependent variable, country fixed effects, and year fixed effects. All democracy indicators are continuous and range from 0 to 1 . The first lag of the regional (jack-knifed) degree of democratization serves as the instrument for the domestic degree of democratization. We report different first-stage diagnostics to indicate the strength and validity of our instrumental variable. Standard errors clustered by country are reported in parentheses. We report results from a Wald test to show whether the estimates reported in Columns $2-5$ are significantly different from the estimates reported in Column 1. The following notation is used to highlight coefficients that are significantly different from zero: ${ }^{*} \mathrm{p}$-value $<0.10,{ }^{* *}$ p-value $<0.05,{ }^{* * *}$ p-value $<0.01$. 
Table B.8 Democracy and economic growth — OLS estimates, additional controls.

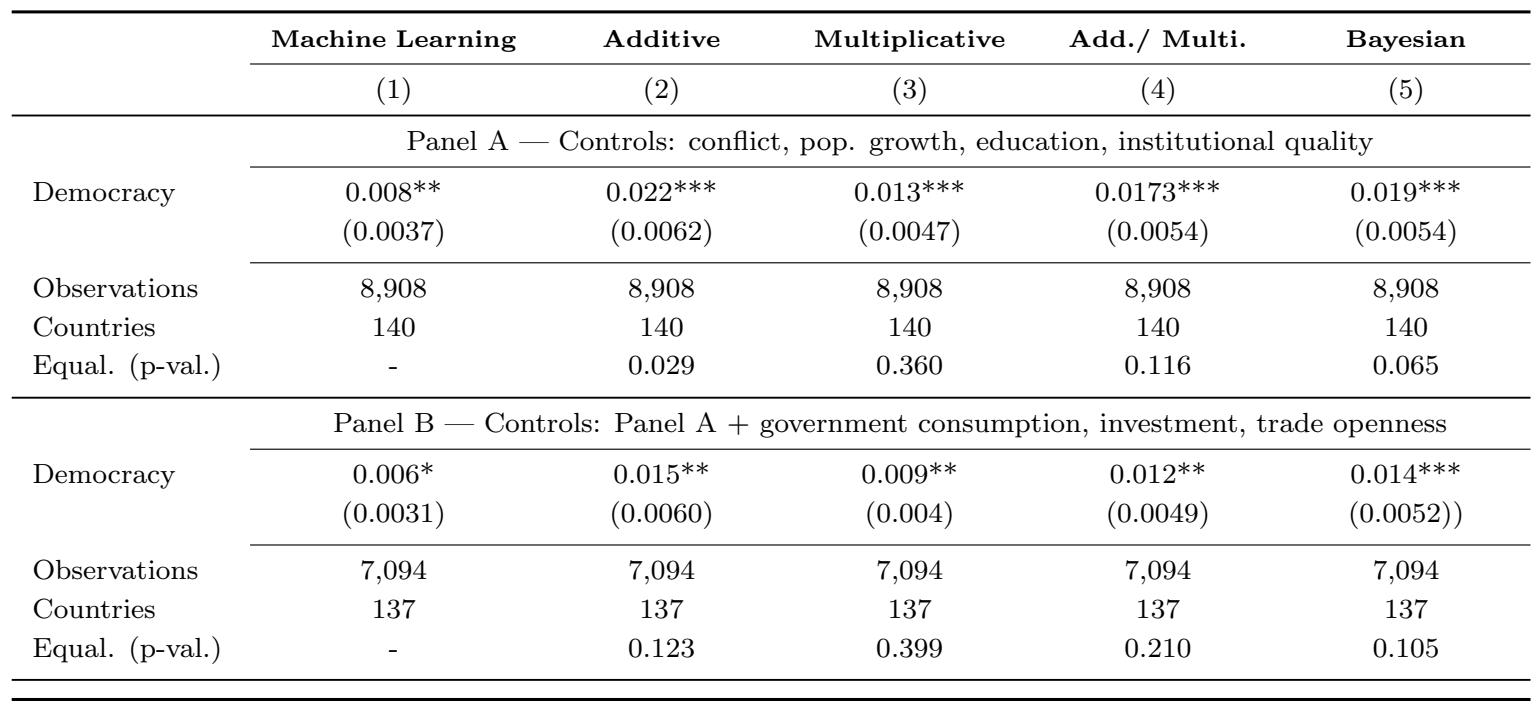

Notes: The table presents OLS estimates. The dependent variable is the log of GDP per capita. All regressions include four lags of the dependent variable, the first lag of various control variables (civil conflict, education, population growth, court independence). In Panel B, we additionally control for government consumption, investment, and trade openness. All democracy indicators are continuous and range from 0 to 1 . Standard errors clustered by country are reported in parentheses. We report results from a Wald test to show whether the estimates reported in Columns $2-5$ are significantly different from the estimates reported in Column 1. The following notation is used to highlight coefficients that are significantly different from zero: ${ }^{*}$ p-value $<0.10,{ }^{* *}$ p-value $<0.05,{ }^{* * *}$ p-value $<0.01$. 
Table B.9 Democracy and economic growth — Second-stage estimates, additional controls.

\begin{tabular}{lccccc}
\hline & Machine Learning & Additive & Multiplicative & Add./ Multi. & Bayesian \\
\cline { 2 - 5 } & $(1)$ & $(2)$ & $(3)$ & $(4)$ & $(5)$ \\
\cline { 2 - 5 } Democracy & \multicolumn{2}{c}{ Panel A - Controls: conflict, pop. growth, education, institutional quality } \\
\cline { 2 - 5 } & $\left(0.021^{* *}\right.$ & $0.038^{* *}$ & $0.026^{* *}$ & $0.031^{* *}$ & $0.044^{* *}$ \\
Observations & 8,908 & $(0.0165)$ & $(0.0112)$ & $(0.0130)$ & $(0.0188)$ \\
Countries & 140 & 8,908 & 8,908 & 8,908 & 8,908 \\
SaWi (F.stat.) & 54.33 & 140 & 140 & 140 & 140 \\
AR (p-val.) & 0.026 & 44.61 & 59.09 & 55.89 & 0.029 \\
StWr (p-val.) & 0.013 & 0.026 & 0.026 & 0.026 & 0.013 \\
KP (p-val.) & 0.000 & 0.013 & 0.013 & 0.013 & 0.000 \\
Equal. (p-val.) & - & 0.000 & 0.000 & 0.000 & 0.226 \\
\hline & 0.285 & 0.640 & 0.461 & $0.047^{* *}$ \\
Democracy & Panel B Controls: Panel A government consumption, investment, trade openness \\
\cline { 2 - 5 } & $0.023^{* *}$ & $0.042^{* *}$ & $0.029^{* *}$ & $0.034^{* *}$ & $(0.0202)$ \\
Observations & $(0.0098)$ & $(0.0182)$ & $(0.0123)$ & $(0.0143)$ & 7,094 \\
Countries & 7,094 & 7,094 & 7,094 & 7,094 & 137 \\
SaWi (F.stat.) & 137 & 137 & 137 & 137 & 43.17 \\
AR (p-val.) & 53.44 & 44.72 & 56.31 & 54.59 & 0.018 \\
StWr (p-val.) & 0.018 & 0.018 & 0.018 & 0.018 & 0.007 \\
KP (p-val.) & 0.007 & 0.007 & 0.007 & 0.007 & 0.000 \\
Equal. (p-val.) & 0.000 & 0.000 & 0.000 & 0.000 & 0.248 \\
\hline Z & - & 0.296 & 0.638 & 0.464 & \\
\hline
\end{tabular}

Notes: The table presents 2SLS estimates. The dependent variable is the log of GDP per capita. All regressions include four lags of the dependent variable, the first lag of various control variables (civil conflict, education, population growth, court independence). In Panel B, we additionally control for government consumption, investment, and trade openness. All democracy indicators are continuous and range from 0 to 1 . The first lag of the regional (jack-knifed) degree of democratization serves as the instrument for the domestic degree of democratization. We report different first-stage diagnostics to indicate the strength and validity of our instrumental variable. Standard errors clustered by country are reported in parentheses. We report results from a Wald test to show whether the estimates reported in Columns $2-5$ are significantly different from the estimates reported in Column 1 . The following notation is used to highlight coefficients that are significantly different from zero: ${ }^{*}$ p-value $<0.10,{ }^{* *}$ p-value $<0.05,{ }^{* * *}$ p-value $<0.01$. 
Table B.10 Democracy and education - OLS estimates, five-year data.

\begin{tabular}{|c|c|c|c|c|c|}
\hline & Machine Learning & Additive & Multiplicative & Add./ Multi. & Bayesian \\
\hline Democracy & $\begin{array}{c}0.212^{* * *} \\
(0.0441)\end{array}$ & $\begin{array}{c}0.348^{* * *} \\
(0.0606)\end{array}$ & $\begin{array}{c}0.273^{* * *} \\
(0.0558)\end{array}$ & $\begin{array}{c}0.315^{* * *} \\
(0.0595)\end{array}$ & $\begin{array}{c}0.282^{* * *} \\
(0.0555)\end{array}$ \\
\hline Observations & 1,979 & 1,979 & 1,979 & 1,979 & 1,979 \\
\hline Equal. (p-val.) & - & 0.027 & 0.280 & 0.084 & 0.207 \\
\hline
\end{tabular}

Notes: The table presents OLS estimates. The dependent variable is the average years of schooling. All regressions include the first lag of the dependent variable, the first lag of the log of GDP per capita, country fixed effects, and period fixed effects. All democracy indicators are continuous and range from 0 to 1 . The democracy indices are averaged over five-year periods $(1920-24,1925-29, \ldots)$ since annual data on the average years of schooling does not exist. Standard errors clustered by country are reported in parentheses. We report results from a Wald test to show whether the estimates reported in Columns $2-5$ are significantly different from the estimates reported in Column 1. The following notation is used to highlight coefficients that are significantly different from zero: ${ }^{*}$ p-value $<0.10,{ }^{* *}$ p-value $<0.05,{ }^{* * *}$ p-value $<0.01$.

Table B.11 Democracy and education - 2SLS estimates, five year data.

\begin{tabular}{lccccc}
\hline & Machine Learning & Additive & Multiplicative & Add./ Multi. & Bayesian \\
\cline { 2 - 5 } & $(1)$ & $(2)$ & $(3)$ & $(4)$ & $(5)$ \\
\hline & \multicolumn{7}{c}{ Panel A: Second-stage estimates } \\
\cline { 2 - 5 } Democracy & $0.337^{* * *}$ & $0.569^{* * *}$ & $0.436^{* * *}$ & $0.487^{* * *}$ & $0.650^{* * *}$ \\
& $(0.1282)$ & $(0.2093)$ & $(0.1679)$ & $(0.1839)$ & $(0.2495)$ \\
\cline { 2 - 6 } Equal. (p-val.) & - & 0.267 & 0.556 & 0.210 \\
\hline & \multicolumn{2}{c}{ Panel B: First-stage estimates } \\
Demo. (reg.) & $0.599^{* * *}$ & $0.355^{* * *}$ & $0.463^{* * *}$ & $0.415^{* * *}$ & $0.311^{* * *}$ \\
& $(0.0666)$ & $(0.0398)$ & $(0.0513)$ & $(0.0450)$ & $(0.0380$ \\
Equal. (p-val.) & - & 0.000 & 0.009 & 0.000 & 0.000 \\
\hline Observations & 1,976 & 1,976 & 1,976 & 1,976 & 1,976 \\
Countries & 141 & 141 & 141 & 141 & 141 \\
SaWi (F.stat.) & 81.15 & 79.52 & 81.60 & 85.14 & 66.90 \\
AR (p-val.) & 0.011 & 0.011 & 0.011 & 0.011 & 0.011 \\
StWr (p-val.) & 0.008 & 0.008 & 0.008 & 0.008 & 0.008 \\
KP (p-val.) & 0.000 & 0.000 & 0.000 & 0.000 & 0.000 \\
\hline
\end{tabular}

Notes: The table presents 2SLS estimates. The dependent variable is the average years of schooling. All regressions include the first lag of the dependent variable, the first lag of the log of GDP per capita, country fixed effects, and period fixed effects. All democracy indicators are continuous and range from 0 to 1 . The democracy indices are averaged over five-year periods $(1920-24,1925-29, \ldots)$ since annual data on the average years of schooling does not exist. The first lag of the regional (jack-knifed) degree of democratization serves as the instrument for the domestic degree of democratization. We report different first-stage diagnostics to indicate the strength and validity of our instrumental variable. Standard errors clustered by country are reported in parentheses. We report results from a Wald test to show whether the estimates reported in Columns $2-5$ are significantly different from the estimates reported in Column 1 . The following notation is used to highlight coefficients that are significantly different from zero: ${ }^{*}$ p-value $<0.10,{ }^{* *}$ p-value $<0.05$, ${ }^{* * *}$ p-value $<0.01$. 


\title{
Chapter 4
}

\section{Democracy and institutional quality: Theory and evidence}

\begin{abstract}
We present a simple model that illustrates how democracy may improve the quality of economic institutions. The model further suggests that institutional quality varies more across autocracies than across democracy and that the positive effect of democracy on institutional quality is increasing in people's human capital. Using a new panel data set, covering 140 countries and the period from 1920 to 2015, and different measures of institutional quality, we present results from fixed effect and two-stage least squares regressions that confirm the predictions of our model.
\end{abstract}




\subsection{Introduction}

It is widely acknowledged that institutions play an important role in explaining crosscountry differences in economic development. ${ }^{1}$ A pending question is, however, which factors promote the emergence of growth-enhancing institutions. We address this issue and examine whether transitions from autocracy to democracy cause improvements in institutional quality.

We start from the observation that the level of democracy positively correlates with institutional quality. Figure 4.1 illustrates this stylized fact for four years (1920, 1950, 1980, 2010), using a continuous index of democracy and an expert-based indicator of private property protection. Economic theory provides two explanations for the positive correlation between democracy and institutional quality: the first is that a democratic transition requires well-developed economic institutions (Friedman, 1962, Hayek, 1944), while the second suggests that democratic governments have a greater interest in good institutions than autocratic governments (Olson, 1993, Przeworski and Limongi, 1993).

This study elaborates on the latter argument and presents a simple theoretical model to explain why an increase in the degree of democratization can lead to an increase in institutional quality. The model considers a society that consists of two groups: the elite and the people. Agents belong to either of the two groups and the elite constitutes the minority of the population. The elite derives utility from consumption which is financed through expropriations, whereas the people enjoy consumption and leisure, engage in commercial activities, and face an expropriation risk. The people and the elite send a signal to the government that indicates the desired level of institutional quality. The elite wants some room for expropriation, whereas the people prefer institutions that fully protect them against expropriation. In our model, democracy has a positive effect on institutional quality because democratic governments are more likely to take people's preferences into account

Figure 4.1 also shows that cross-country differences in institutional quality are larger between autocracies than between democracies. Our model explains this pattern and suggests in particular that autocratic governments implement weaker institutions when the people command a high level of human capital.

We use a novel panel data set, covering 140 countries and the 1920 - 2015 period, and different measures of institutional quality — provided by the Varieties of Democracy Database - to study the accuracy of our model. We emphasize two predictions: first, the quality of the economic institutions improves after a transition from autocracy to democracy, and second, the effect of democracy on institutional quality increases in

\footnotetext{
${ }^{1}$ For studies that confirm this view, see Acemoglu et al. (2001, 2002, 2005a,b), Acemoglu and Robinson (2013), De Long and Shleifer (1993), Hall and Jones (1999), Knack and Keefer (1995), North (1991), North and Weingast (1989), Pinkovskiy (2017), Rodrik et al. (2004), Rodrik (2008), and Sokoloff and Engerman (2000).
} 
Figure 4.1 Democracy and institutional quality — Scatter plots.

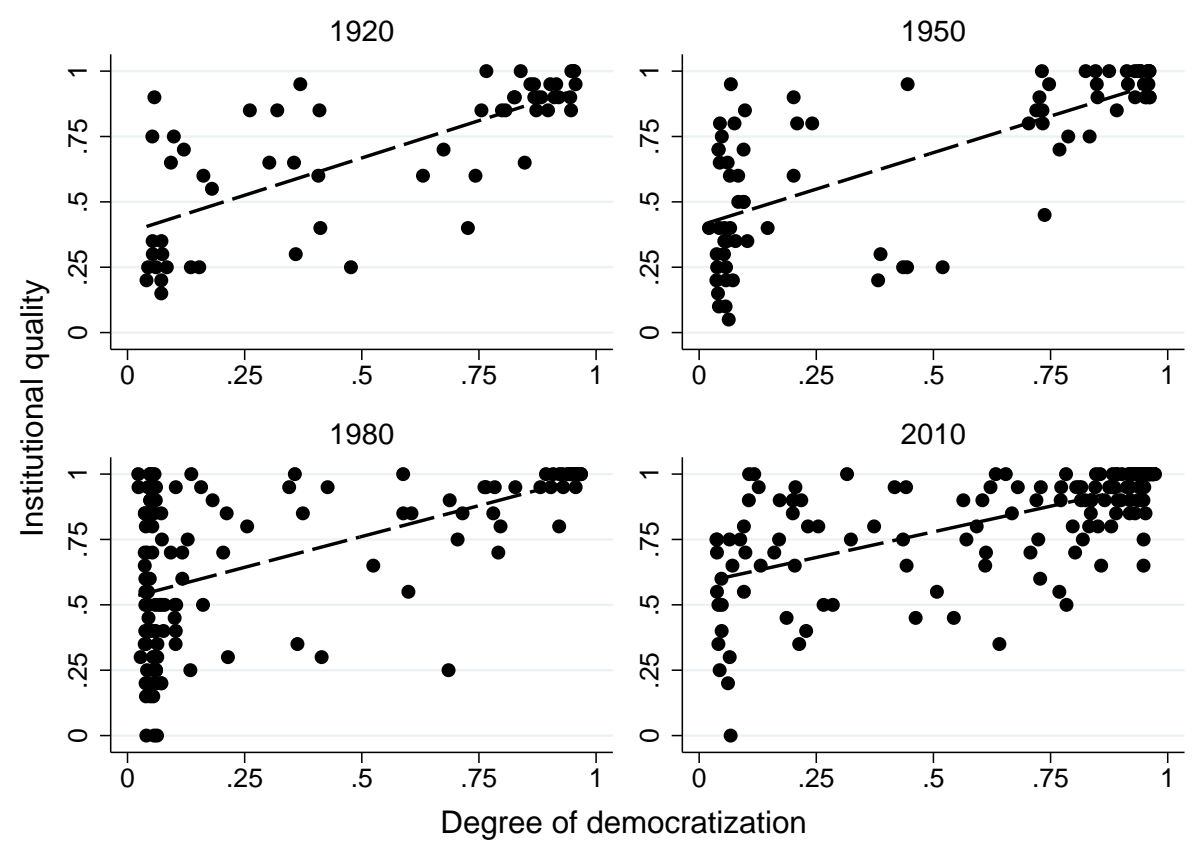

Notes: The figures show the correlation between democracy and institutional quality for the years 1920, 1950, 1980, and 2010. We use an expert-based index on private property protection-provided by the Varieties of Democracy Database-to measure institutional quality and the machine learning democracy index of Gründler and Krieger (2018). For details on the data, see Section 4.3.1.

the level of human capital. Our estimation results confirm both predictions.

We contribute to the literature that studies the relationship between democracy and institutional quality. ${ }^{2}$ A major difference between previous empirical studies and our analysis is the length of the examination period: while previous studies use data from 1970/80 onward, our examination period starts in 1920. Another difference concerns the identification strategy: we apply a two-stage least squares approach to confirm that democracy positively affects institutional quality, whereas previous studies rely on OLS and GMM methods.

Only a few studies examine whether the effect of democracy on institutional quality depends on other socioeconomic factors. Acemoglu (2008), Acemoglu and Robinson (2006) develop a model suggesting that a high level of income inequality erodes the positive effect of democracy on institutional quality. Sunde et al. (2008), Krieger and Meierrieks (2016), and Kotschy and Sunde (2017) report empirical results that confirm this prediction.

Fortunato and Panizza (2015) suggest that the effect of democracy on institutional

\footnotetext{
${ }^{2}$ For empirical studies that examine this relationship, see Adsera et al. (2003), Assiotis and Sylwester (2015), De Haan and Sturm (2003), Knutsen (2011), Leblang (1996), Lundström (2005), Méon and Sekkat (2016), Pitlik (2008), and Rode and Gwartney (2012). The dominant view is that democratic regimes have better economic institutions than autocratic regimes. Another but somehow related strand of research investigates the effect of democracy on economic liberalization (Giavazzi and Tabellini, 2005, Giuliano et al., 2013, Grosjean and Senik, 2011).
} 
quality depends positively on human capital. Their study differs from our analysis for three reasons: first, we use a much more comprehensive dataset; second, we address endogeneity issues with an instrumental variable approach; and finally, we explain the positive effect of the interaction between democracy and human capital on institutional quality with differences between autocratic regimes rather than with differences between democratic regimes. Fortunato and Panizza (2015) assume in particular that education improves voters' ability to select competent leaders and that these competent leaders implement better economic institutions. We update Besley and Reynal-Querol's (2011) database to study whether the mechanism suggested by Fortunato and Panizza (2015) applies. Our results do not support the view that higher ability of politicians explains why the positive effect of democracy on institutional quality depends positively on the level of human capital.

The remainder of the paper is structured as follows. Section 4.2 presents the theoretical model. Section 4.3 presents the empirical model, the identification strategy, and the empirical results. Section 4.4 concludes.

\subsection{Theory}

\subsubsection{Basic model}

We consider a society consisting of two groups of citizens: the people (P) and the elite (E). Agents belong to one of the groups and the people constitute the majority of the population. Since the members of a specific group are identical, we can interchangeably speak about the entire group or a representative group member. All citizens are risk neutral and population size is normalized to 1 .

\subsubsection{The government}

The elite and the people send a signal to the government that indicates their preferred level of institutional quality. The government uses these two preferences to specify the actual level of institutional quality $(\rho)$ :

$$
\rho=(1-\delta) \cdot \rho^{E}+\delta \cdot \rho^{P}
$$

where $\rho^{E} \in[0,1]$ reflects the level of institutional quality signaled by the elite and $\rho^{P} \in[0,1]$ the level of institutional quality signaled by the people. The exogenously given parameter $\delta \in[0,1]$ indicates the extent to which the government takes people's preferences into account when determining the quality of the institutions. Below, we interpret $\delta$ as the level of democracy since the people constitute the majority of the population. We refer to a regime as democratic when $\delta$ is close to 1 and as autocratic when $\delta$ is close to 0 . 


\subsubsection{The people}

The people use a fraction of their time $z^{P} \in[0,1]$ for commercial activities and the fraction of time $l^{P}=1-z^{P}$ for leisure. Income from commercial activities $\left(y^{P}\right)$ is uncertain since the people face an expropriation risk. Expropriation takes place with probability $\lambda=1-\rho$.

The people consume all their income and choose $z^{P}$ to maximize their expected utility

$$
u^{P}=\mathbb{E}\left[y^{P}\right]+\beta \cdot u\left(l^{P}\right)=(1-\lambda) \cdot\left(z^{P} \cdot h\right)^{0.5}+\beta \cdot\left(1-z^{P}\right)^{0.5}
$$

where $h>0$ denotes the level of human capital, $\left(z^{P} \cdot h\right)^{0.5}$ the production function of the gross income $y^{P}$, and $u\left(l^{P}\right)=\left(1-z^{P}\right)^{0.5}$ the utility that the people derive from leisure. $\beta>0$ is the intensity of leisure preferences relative to consumption.

The first-order condition implies

$$
z^{P}=\frac{h \cdot(1-\lambda)^{2}}{\beta^{2}+h \cdot(1-\lambda)^{2}}=\left(1+\frac{\beta^{2}}{h \cdot(1-\lambda)^{2}}\right)^{-1} .
$$

From (4.2) and (4.3), we obtain the following results.

Proposition 1. (a) The expected utility of the people is given by:

$$
u^{P}=\left(1+h \cdot(1-\lambda)^{2}\right)^{0.5} .
$$

(b) Institutional quality $(\rho=1-\lambda)$ positively affects people's expected utility $\left(u^{P}\right)$ and engagement in commercial activities $\left(z^{P}\right)$ :

$$
\frac{\partial u^{P}}{\partial \rho}>0 \quad \text { and } \quad \frac{\partial z^{P}}{\partial \rho}>0
$$

(c) Human capital $(h)$ positively affects people's expected utility $\left(u^{P}\right)$ and engagement in commercial activities $\left(z^{P}\right)$ :

$$
\frac{\partial u^{P}}{\partial h}>0 \quad \text { and } \quad \frac{\partial z^{P}}{\partial h}>0 .
$$

(d) People's expected utility is maximized when the expropriation risk is zero:

$$
\rho^{P^{*}}=\underset{\rho}{\arg \max } u^{P}=1 .
$$

\subsubsection{The elite}

The elite derives utility from consumption which is financed through expropriation and 
faces a revolution constraint. We assume that the elite loses its income if a revolution takes place. The probability of revolution $(\alpha)$ depends on the quality of the economic institutions $(\rho)$ :

$$
\alpha=1-\rho^{\theta}=1-(1-\lambda)^{\theta}
$$

where $\theta \geq 0$ captures cultural and environmental factors affecting the likelihood of a revolution.

The expected utility of the elite is thus given by:

$$
\begin{aligned}
u^{E} & =(1-\alpha) \cdot \lambda \cdot\left(z^{P} \cdot h\right)^{0.5} \\
& =(1-\lambda)^{\theta+1} \cdot \lambda \cdot h \cdot\left[\beta^{2}+(1-\lambda)^{2} \cdot h\right]^{-0.5} .
\end{aligned}
$$

We obtain from (4.10) the following results.

Proposition 2. (a) The expected utility of the elite is maximized for an intermediate level of institutional quality $(\rho=1-\lambda)$ :

$$
\rho^{E^{*}}=\underset{\rho}{\arg \max } u^{E}<1
$$

(b) The signal that the elite sends to the government to indicate its preferred level of institutional quality $\left(\rho^{E}\right)$ depends on the degree of democratization $(\delta)$ with:

$$
\frac{\partial \rho^{E}}{\partial \delta}\left\{\begin{array}{l}
<0, \quad \text { if } \quad \delta<\bar{\delta}=\rho^{E^{*}} \\
=0, \quad \text { if } \quad \delta \geq \bar{\delta}=\rho^{E^{*}}
\end{array}\right.
$$

(c) The level of institutional quality maximizing the expected utility of the elite $\left(\rho^{E^{*}}\right)$ decreases in the human capital of the people.

$$
\frac{\partial \rho^{E^{*}}}{\partial h}<0
$$

\subsubsection{Theoretical results}

Figures $4.2-4.3$ illustrate the model predictions. The sold line indicates the institutional quality $(\rho)$ that the government chooses, depending on the level of democracy $(\delta)$. The lower (upper) dashed line indicates the level of institutional quality that the elite (the people) signals to the government.

The people wish economic institutions that fully protect them against expropriation, while the elite prefers economic institutions that give room for expropriation. The logic behind these results is simple. The elite wants to expropriate because it finances its consumption through expropriation and loses its income source when the government prohibits expropriation. The people, by contrast, engage in commercial activities 
Figure 4.2 The effect of democracy on institutional quality.

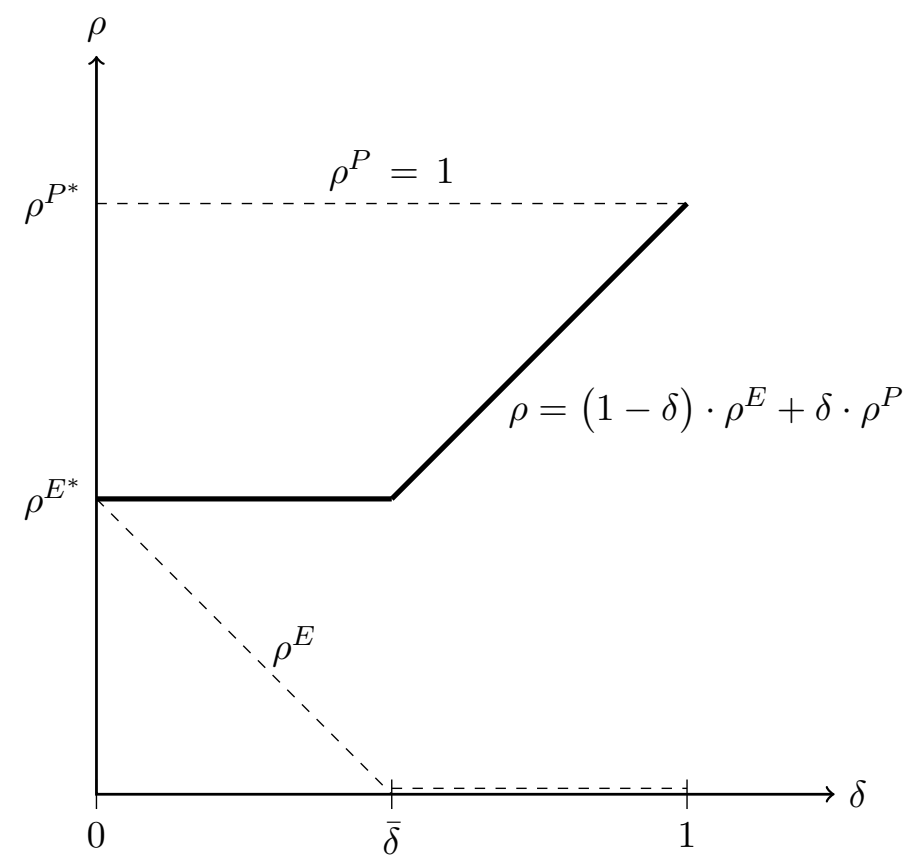

to finance their consumption and the greater the expropriation risk, the lower is the prospect of earning an income.

The signal $\left(\rho^{E}\right)$ that the elite sends to the government depends on the degree of democratization. In an autocratic regime, the government only gives attention to the signal of the elite. The elite exploits its influence and signals the level of institutional quality that maximizes its expected utility. If the people have some influence on the government decision $(\delta>0)$, the elite adjusts its signal to offset people's demand for better economic institutions.

A transition from a fully autocratic regimes to a fully democratic regimes increases institutional quality. This key result applies because the elite prefer better economic institutions than the elite, and because the influence of the people on the government increases in the process of democratization. However, a partial democratization is not necessarily associated with increasing institutional quality. The reason is that the elite adjusts its behavior, preventing thus changes in the quality of the economic institutions as long as the degree of democratization is relatively low $(\delta<\bar{\delta})$.

Finally, our model predicts that the elite prefers weaker economic institutions if the people command a high level of human capital. The explanation is simple. The elite wishes that the people engage in commercial activities: the more commercial activities, the greater are the possibilities for expropriation. Since the productivity of the people increases in their human capital, well educated people engage in commercial activities even when the institutions protecting them against expropriation are rather weak. Low 
Figure 4.3 The effect of democracy on institutional quality - The role of human capital.

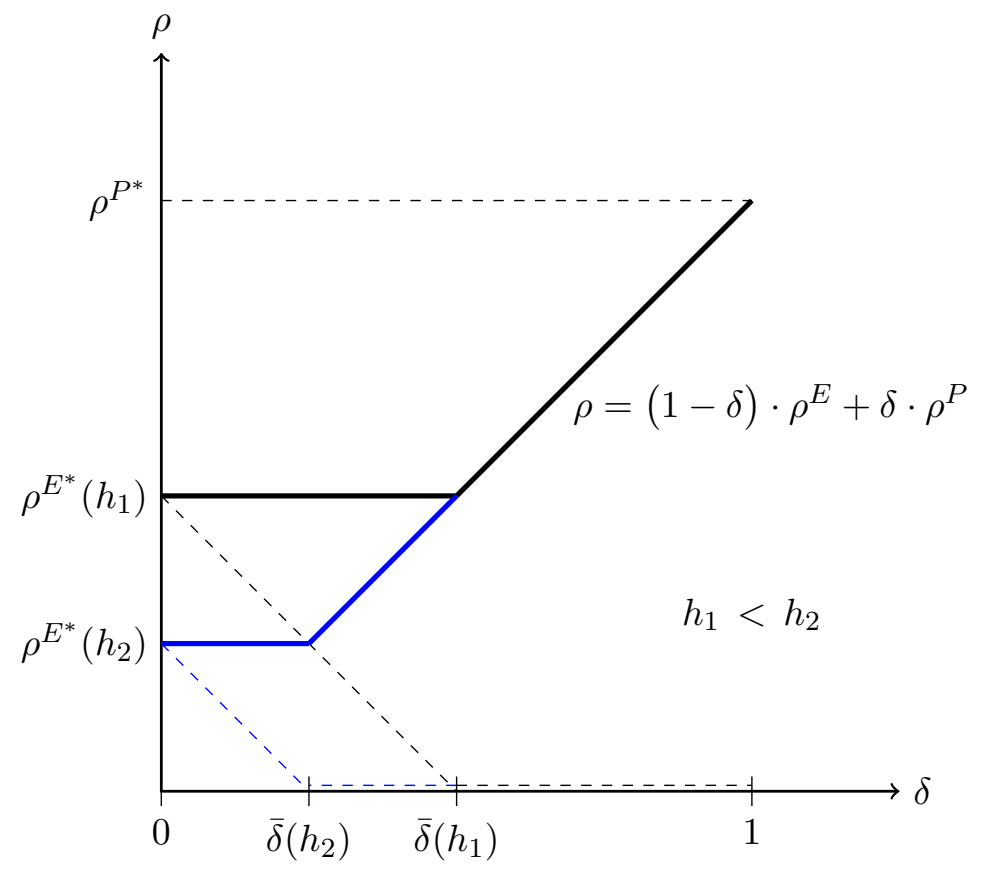

educated people, by contrast, are rather unproductive and thus must be incentivized through institutions that protect them relatively well against expropriation.

\subsubsection{Discussion}

Our model predicts that a transition from autocracy towards democracy improves the quality of the economic institutions (Figure 4.2) and suggests that the positive effect of democracy on institutional quality increases with increasing human capital (Figure 4.3). Section 4.3 presents empirical results that confirm these two key predictions. Before we turn to the empirical analysis, we comment, however, some aspects of our model.

\subsubsection{Effect heterogeneity}

Our strong focus on the role of human capital may give rise to the impression that we downplay other factors that may also cause heterogeneity in the effect of democracy on institutional quality. We argue that this concern is unfounded because the basic model suggests other sources of effect heterogeneity. In particular, the model predicts that the elite makes more concessions to the people when the threat of revolution is high. We can also invoke cultural effects by assuming that the leisure preference $(\beta)$ depends on cultural traits. We move these factors to the background to focus on the predictions that are subject to the empirical testing. 
Figure 4.4 The effect of democracy on institutional quality - De facto and de jure power.

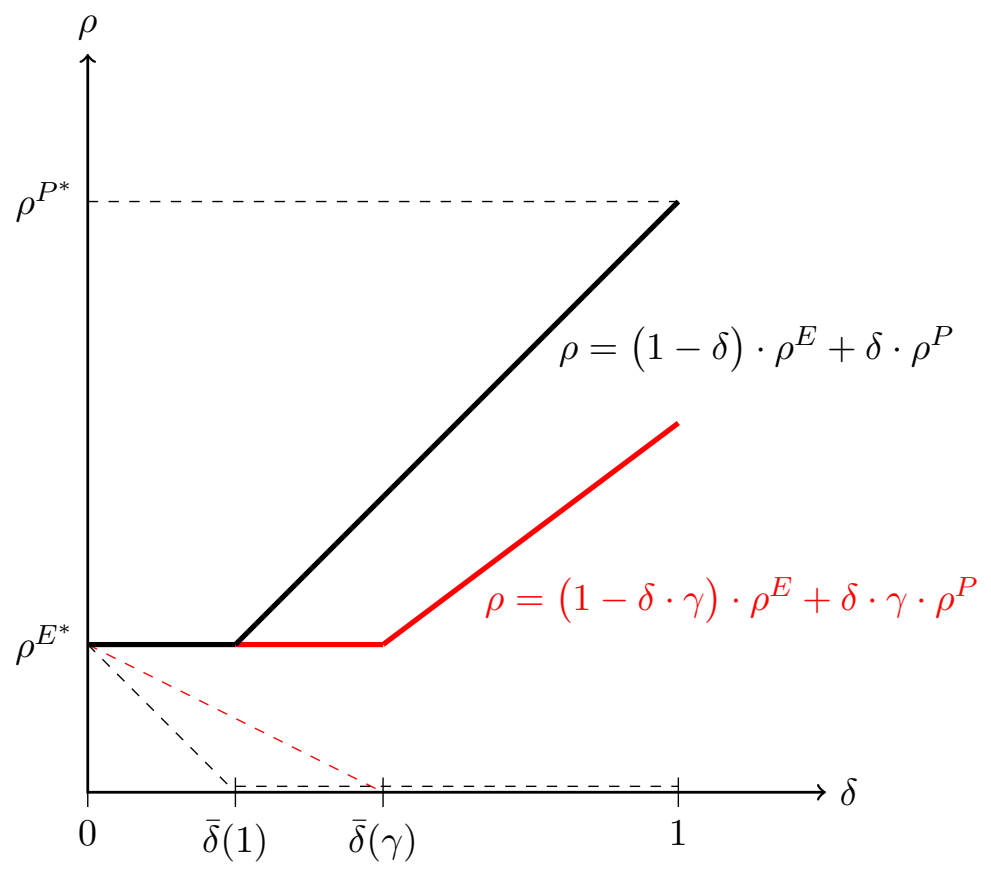

\subsubsection{Differences in institutional quality in democracies}

Figure 4.1 shows that the citizens of some democratic countries are not fully protected against expropriation. Our model does not explain this fact. Acemoglu (2008), Acemoglu and Robinson (2006) present a model that suggests conditions under which a transition from autocracy to democracy does not improve institutional quality. A key feature of their model is that political power has a de facto and a de jure component. Acemoglu (2008) argue that the degree of democratization is the de facto component, whereas cultural, economic, and geographical factors determine the de jure component. We can incorporate this distinction in our model by assuming that the government uses the following rule to set the quality of the economic institutions:

$$
\rho=(1-\gamma \cdot \delta) \cdot \rho^{E}+\gamma \cdot \delta \cdot \rho^{P}
$$

where $\gamma \in(0,1)$ reflects the de facto power of the people. Figure 4.4 shows that this extension suffices to predict institutional differences between democracies.

\subsubsection{Institutional persistence}

Our model predicts that a partial democratization does not necessarily induce a change in institutional quality. Acemoglu (2008), Acemoglu and Robinson (2006) reach the same conclusion, using a model of endogenous political transitions. Our explanation 
for the institutional persistence differs to some extent from the explanation given by Acemoglu (2008), Acemoglu and Robinson (2006). In our model, the elite adjusts the policy preference that it signals to the government and can thereby fully offset people's demand for better institutions if the degree of democratization is low. Acemoglu (2008), Acemoglu and Robinson (2006) suggest, by contrast, that the elite sticks to its political views but increases its lobbying effort to compensate the loss in political influence caused by the democratization. ${ }^{3}$

\subsubsection{Human capital as exogenous factor}

Another concern may be that the level of human capital is an exogenous factor in our model. This objection is not far-fetched given that various empirical studies report a positive effect of democracy on human capital (Baum and Lake, 2003, Fujiwara, 2015, Stasavage, 2005). We still think that the model assumption is plausible in our context since the purpose of our model is to illustrate the short-run consequences of political transitions for institutional quality and a potential source of effect heterogeneity. We argue that focusing on immediate effects is adequate since Méon and Sekkat (2016) and Rode and Gwartney (2012) suggest that most of the changes in economic institutions occur within the first few years after a political transition. Since the level of human capital changes relatively slowly, we can treat it as exogenous factor in our model.

\subsubsection{Human capital and the threat of revolution}

In our model, the level of human capital only affects the productivity of the people. Another factor that may depend on human capital is the probability of revolution. An argument might be that educated people can better organize a revolt and that thus the probability of revolution increases in the level of human capital. When extending the model in this direction, the result that the positive effect of democracy on institutional quality increases in the human capital of the people does no long hold because human capital then affects the preferences of the elite in two opposing ways. For reasons of convenience, the basic model focus one channel. Our empirical findings (see Section 4.3) imply that the channel suggested by the basic model (see Section 4.2.2) clearly dominates the opposing channel explained in this section.

\footnotetext{
${ }^{3}$ Studying whether our explanation or the explanation given by Acemoglu (2008), Acemoglu and Robinson (2006) applies may be an interesting question for future research. In this project, we do not address this issue, but focus primarily on the role of human capital for the effect of democracy on institutional quality.
} 


\subsection{Empirical analysis}

\subsubsection{Data}

\subsubsection{Institutional quality}

The literature offers different definitions of "institutional quality". Gutmann and Voigt (2018) and Voigt (2012) distinguish between thin (narrow) and thick (broad) definitions and explain why a thin definition is more suitable for empirical purposes. We share this view and use a narrow definition. ${ }^{4}$

From the Varieties of Democracy (V-Dem) Database, we obtain four subjective measures of institutional quality. ${ }^{5}$ These measures indicate whether (i) citizens enjoy private property rights, (ii) citizens have secure and effective access to justice, (iii) law enforcement is transparent, and (iv) public officials are impartial. All indices have an ordinal scale and reach from 0 to 1 (for details, see Appendix C.1).

\subsubsection{Democracy}

We use the machine learning index developed by Gründler and Krieger $(2016,2018)$ to measure democracy. This new index has a continuous scale, reaches from 0 to 1 , and includes three core aspects of democracy: political participation, political competition, and the freedom of speech. ${ }^{6}$ We choose this index for conceptual and methodological reasons.

A generally acknowledged definition of "democracy" does not exist: narrow concepts only consider political participation and political competition, while broad concepts also consider press freedom, judiciary independence, and specific civil liberties (Dahl, 1971, Merkel, 2004, O’Donnell, 2001). A narrow concept is better suited for examining the effect of democratization on institutional quality since a broad concept would overlap with our concept of institutional quality. ${ }^{7}$

All democracy indices consist of several sub-indices. Combining these sub-indices to arrive at a single index requires the selection of an aggregation procedure. The standard approach is to weight the sub-indices and then to apply an additive or multiplicative aggregation rule. Gründler and Krieger $(2016,2018)$ show that this approach creates implausible regime classifications and argue that implausible classifications become less

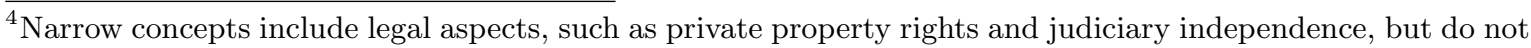
require specific economic policies, such as low tax burden, budgetary discipline, or central bank independence. We use a thin definition for three reasons: (i) better data availability, (ii) the empirical results are easier to interpret, and (iii) consistency with our theoretical model.

${ }^{5} \mathrm{~V}$-Dem is one of the largest social science databases and includes rich data on political regimes and institutions (180 countries, $1900-2017$ ). The V-Dem project is supervised by leading social scientists and more than 2,500 local experts are involved in the data collection process. V-Dem is an open source database and attracts great attention among political scientists. For details, see Coppedge et al. (2018) and https://www.v-dem.net/en/. ${ }^{6}$ The most recent version of the index is available for 186 countries and the period from 1919 to 2016.

${ }^{7}$ The Polity IV index, for example, defines that a democracy must have an independent judiciary. A conceptual overlap would also exist when we use the Freedom House index, the index developed by Acemoglu et al. (2019), or the Unified Democracy Score (Pemstein et al., 2010).
} 
likely when a machine learning technique is used for aggregation.

\subsubsection{Human capital}

We use the Barro and Lee (2013) data on years of schooling to measure population's human capital. The data is available in five-year intervals and for 145 countries. We exploit the Cohen and Soto (2007) database to increase our sample by five countries (Angola, Burkina Faso, Ethiopia, Mozambique, Nigeria). For data availability reasons, we cannot apply a measure of education quality as proposed by Hanushek and Woessmann (2012).

\subsubsection{Instrumental variables}

Three endogeneity problems complicate the empirical examination of our model. First, autocracies may differ from democracies in unobserved characteristics that also affect institutional quality. Second, the causality may run from institutional quality to human capital and democracy. Finally, errors in the index of democracy and the measure of human capital may cause an attenuation bias.

We use established instruments for democracy and human capital to address these endogeneity issues. We exploit two facts: first, differences in human capital are often historically rooted and persist over time (Gallego, 2010, Huillery, 2009, Rocha et al., 2017), and second, changes from autocracy to democracy (or vice versa) often occur in regional waves (Huntington, 1993, Teorell, 2010). ${ }^{8}$ We therefore instrument the stock of human capital with a lagged value (Acemoglu et al., 2014, Becker et al., 2011, Madsen and Murtin, 2017) ${ }^{9}$ and use the average level of democracy in nearby countries as an instrumental variable for the domestic level of democracy (Acemoglu et al., 2019, Aidt and Jensen, 2014, Dorsch and Maarek, 2019, Persson and Tabellini, 2009):

$$
Z_{i, t}^{\left(r_{i}\right)}=\frac{1}{|\mathcal{R}|} \sum_{j \in \mathcal{R}} D_{j, t}^{\left(r_{j}\right)} \quad \text { with } \quad \mathcal{R}=\left\{j: j \neq i, r_{j}=r_{i}\right\}
$$

where $r_{i}$ denotes the region in which country $i$ is located, $D$ the domestic degree of democratization, and $Z$ the regional (jack-knifed) degree of democratization. ${ }^{10}$

\subsubsection{Baseline results}

To examine the explanatory power of our theoretical model, we estimate the regression model

\footnotetext{
${ }^{8}$ Popular examples of regional waves are the political transitions in the Mediterranean area in the 1970s, in South America in the 1980s, and in East Europe in the 1990s.

${ }^{9}$ We tried different lags and observed that the estimation results are fairly robust to changes in the lag structure. Below, we use the stock of human capital 40 years ago (8th lag) as an instrument for the current stock of human capital. Results for other lags are available upon request.

${ }^{10}$ In our baseline analysis, we use the classification of the United Nations to divide the world into 19 regions. Estimation results for other classifications look similar and are available upon request.
} 


$$
P_{i, t}^{\left(r_{i}\right)}=\beta_{1} D_{i, t}^{\left(r_{i}\right)}+\beta_{2} H_{i, t}^{\left(r_{i}\right)}+\beta_{3} D_{i, t}^{\left(r_{i}\right)} H_{i, t}^{\left(r_{i}\right)}+\alpha_{1} P_{i, t-1}^{\left(r_{i}\right)}+\alpha_{2} Y_{i, t-1}^{\left(r_{i}\right)}+\xi_{i}+\theta_{t}+\varepsilon_{i, t}
$$

with the first-stage equations:

$$
\begin{aligned}
D_{i, t}^{\left(r_{i}\right)} & =\delta_{1} Z_{i, t}^{\left(r_{i}\right)}+\delta_{2} H_{i, t-8}^{\left(r_{i}\right)}+\delta_{3} Z_{i, t}^{\left(r_{i}\right)} H_{i, t-8}^{\left(r_{i}\right)}+\eta_{1} P_{i, t-1}^{\left(r_{i}\right)}+\eta_{2} Y_{i, t-1}^{\left(r_{i}\right)}+\mu_{i}+\kappa_{t}+\nu_{i, t} \\
H_{i, t}^{\left(r_{i}\right)} & =\lambda_{1} Z_{i, t}^{\left(r_{i}\right)}+\lambda_{2} H_{i, t-8}^{\left(r_{i}\right)}+\lambda_{3} Z_{i, t}^{\left(r_{i}\right)} H_{i, t-8}^{\left(r_{i}\right)}+\gamma_{1} P_{i, t-1}^{\left(r_{i}\right)}+\gamma_{2} Y_{i, t-1}^{\left(r_{i}\right)}+\sigma_{i}+\tau_{t}+\iota_{i, t} \\
D_{i, t}^{\left(r_{i}\right)} H_{i, t}^{\left(r_{i}\right)} & =\pi_{1} Z_{i, t}^{\left(r_{i}\right)}+\pi_{2} H_{i, t-8}^{\left(r_{i}\right)}+\pi_{3} Z_{i, t}^{\left(r_{i}\right)} H_{i, t-8}^{\left(r_{i}\right)}+\rho_{1} P_{i, t-1}^{\left(r_{i}\right)}+\rho_{2} Y_{i, t-1}^{\left(r_{i}\right)}+\zeta_{i}+\psi_{t}+\omega_{i, t}
\end{aligned}
$$

where $t$ is a five-year period $(1920-24,1925-29, \ldots)$ and $r_{i}$ the region in which country $i$ is located. $P$ measures institutional quality, $D$ democracy, and $H$ human capital. $Y$ is the log of GDP per capita. The instrumental variable $Z$ is the regional (jack-knifed) degree of democratization. All equations include country $(\xi, \mu, \sigma, \zeta)$ and period $(\theta, \kappa, \tau, \psi)$ fixed effects, and error terms $(\varepsilon, \nu, \iota, \omega){ }^{11}$

Our theoretical model implies that a complete transition from a pure autocracy to a pure democracy improves the quality of economic institutions, regardless of the level of human capital. We thus expect a positive estimate for $\beta_{1}$. Our model also predicts that the effect of democracy on institutional quality increases with increasing human capital. We therefore expect $\beta_{3}$ to be positive as well.

Column 1 of Table 4.1 shows results from estimating (4.15) - (4.18) when using an index of private property protection as measure for the quality of economic institutions. Our unbalanced sample includes 140 countries and covers the period from 1920 to 2015. We observe that the estimates of the coefficients $\beta_{1}$ and $\beta_{3}$ are positive and statistically significant at conventional levels. Columns $2-4$ show that the results do not change when we use other measures of institutional quality.

Standard first-stage diagnostics are also reported in Table 4.1. These statistics confirm that the instrumental variables are sufficiently correlated with the included endogenous variables. We show first-stage F-statistics as suggested by Sanderson and Windmeijer (2016) and Cragg and Donald (1993) and find that they exceed the relevant Stock and Yogo (2005) critical values. $^{12}$ We also report the p-values of the Anderson and Rubin (1949) test and the Stock and Wright (2000) test. None of these tests indicate a weak instrument problem. The strength of our instrumental variables is not surprising given that several studies document the persistence of human capital through time (Huillery, 2009, Rocha et al., 2017) and the existence of regional spillovers during transitions from autocracy to democracy (Teorell, 2010). ${ }^{13}$

\footnotetext{
${ }^{11}$ We use the income data from the Maddison Project Database 2018 since it is the only database that provides systematic cross-country information on GDP per capita for the period before 1950. Note that excluding $Y$ from the regression model does not significantly change the estimation results.

${ }^{12}$ The Stock and Yogo (2005) critical values are 22.3 for $10 \%$ maximal IV size and 13.9 for $5 \%$ maximal IV relative bias.

${ }^{13}$ Because of space reasons, the main text only presents the second-stage estimates and the standard first-stage diagnostics. The first-stage estimates are reported in Appendix Table C.1.
} 
Table 4.1 Democracy, human capital, and institutional quality.

\begin{tabular}{|c|c|c|c|c|}
\hline & $\begin{array}{l}\text { Private property } \\
\text { protection }\end{array}$ & $\begin{array}{l}\text { Effective access } \\
\quad \text { to justice }\end{array}$ & $\begin{array}{l}\text { Transparent law } \\
\text { enforcement }\end{array}$ & $\begin{array}{c}\text { Impartial } \\
\text { administration }\end{array}$ \\
\hline & (1) & $(2)$ & (3) & $(4)$ \\
\hline Democracy & $\begin{array}{c}0.169^{* * * *} \\
(0.0407)\end{array}$ & $\begin{array}{c}0.123^{* * *} \\
(0.0391)\end{array}$ & $\begin{array}{c}0.176^{* * *} \\
(0.0399)\end{array}$ & $\begin{array}{l}0.091^{* * * *} \\
(0.0310)\end{array}$ \\
\hline Democracy $\times$ & $0.012^{* *}$ & $0.024 * * *$ & $0.010^{*}$ & $0.013^{* *}$ \\
\hline Human Capital & $(0.0054)$ & $(0.0067)$ & $(0.0057)$ & $(0.0055)$ \\
\hline Observations & 1,802 & 1,802 & 1,802 & 1,802 \\
\hline Countries & 140 & 140 & 140 & 140 \\
\hline SaWi (F-stat.) - Democracy & 101.09 & 104.57 & 126.66 & 141.05 \\
\hline SaWi (F-stat.) - Human Cap & 44.17 & 32.43 & 42.07 & 33.67 \\
\hline SaWi (F-stat.) - Interaction & 48.73 & 26.16 & 45.84 & 33.38 \\
\hline CD (F-stat.) & 68.75 & 59.06 & 72.00 & 72.01 \\
\hline AR (p-value) & 0.000 & 0.000 & 0.000 & 0.000 \\
\hline StWr (p-value) & 0.000 & 0.000 & 0.000 & 0.000 \\
\hline KP (p-value) & 0.000 & 0.000 & 0.000 & 0.000 \\
\hline
\end{tabular}

Notes: The table presents second-stage estimates. The dependent variables are expert-based indices of institutional quality, ranging from 0 to 1 . All regressions include the first lag of the dependent variable, the first lag of the log of GDP per capita, country and year fixed effects. The democracy index is continuous and ranges from 0 to 1. Data on years of schooling is used to measure human capital. The instruments are: (i) the regional (jack-knifed) degree of democratization, (ii) the level of human capital 40 years ago, and (iii) the interaction of the first two instruments. We report different first-stage diagnostics to indicate the strength and validity of our instrumental variables. Standard errors clustered by country are reported in parenthesis. The following notation is used to highlight coefficients that are significantly different from zero: ${ }^{*}$ p-value $<0.10,{ }^{* *}$ p-value $<0.05,{ }^{* * *}$ p-value $<0.01$.

\subsubsection{Robustness checks}

The appendix presents the results of several robustness checks. Appendix Table C.2 presents the OLS estimates of (4.15). The estimates of the coefficient $\beta_{1}$ are positive and statistically significant at the 1 percent level. The estimates of the coefficient $\beta_{3}$ remain positive as well, but their size and statistical significance decrease slightly. The changes are plausible since the historical human capital data is subject to considerable measurement errors and thus likely to cause an attenuation bias.

Appendix Table C.3 reports the results of various subsample analyses. Panels A D exclude all countries from Asia, Africa, America, and Europe. Panels E - G limit the analysis to specific periods $(1970-2015,1950-2015,1920-1990)$. We find that the estimates of the coefficients $\beta_{1}$ and $\beta_{3}$ are always positive and often statistically significant. The robustness is reassuring because it allays the concern that the results presented in Table 4.1 are driven by a particular group of countries.

We use the Lexical Index of Electoral Democracy of Skaaning et al. (2015) and the binary index of Boix et al. (2013) to examine whether the baseline results are robust to changes in the measure of democracy. We choose these alternative measures because of their data coverage and their concept of democracy. ${ }^{14}$ Appendix Tables C.4 and C.5 report that the estimates of $\beta_{1}$ and $\beta_{3}$ remain positive and statistically significant at conventional levels when we use our alternative measures of democracy.

The baseline analysis uses five-year data averages to study the relationship between democracy, human capital, and institutional quality because data on human capital is

\footnotetext{
${ }^{14}$ Both indices are available for all independent countries since 1800 and assume a minimal concept of democracy, requiring political participation and political competition.
} 
available in five-year intervals. Appendix Tables C.6 shows that our baseline results are robust to the use of ten-year data averages.

We add time-varying control variables to the empirical model to block off alternative channels through which the instrumental variables may affect institutional quality. We control for civil conflict, population growth, investment, government consumption, trade openness, and the regional (jack-knifed) level of institutional quality. The estimation results are reported Appendix Table C.7 and suggest that the estimates of $\beta_{1}$ and $\beta_{3}$ are robust to the inclusion of additional variables.

\subsubsection{Discussion}

We have found only one empirical analysis that investigates the relationship between democracy, human capital, and institutional quality. Fortunato and Panizza (2015) use data from the International Country Risk Guide to show that the interaction between democracy and human capital positively correlates with institutional quality. Fortunato and Panizza (2015) explain their finding with differences between democratic regimes. They argue that highly educated voters elect more competent political leaders and that competent leaders implement better economic institutions. Fortunato and Panizza (2015) provide, however, no empirical evidence confirming their argument.

Our theoretical model suggests that differences between autocracies explain why the effect of democracy on institutional quality increases in human capital (see Section 4.2). Our explanation therefore differs considerably from the explanation given by Fortunato and Panizza (2015). Below, we present regression results that contradict Fortunato and Panizza's (2015) presumption of a mechanism running from the interaction of human capital and democracy to the competence of political leaders.

Our analysis includes two parts. First, we examine whether democracies have more competent political leaders than autocracies and whether the effect of democracy on the competence of political leaders depends on the education level of the population. We follow the related literature and use education to measure the competence of the political leaders (Besley et al., 2011, Galasso and Nannicini, 2011). We label a political leader as competent if he (or she) has a collage degree. Data on leaders' education mainly comes from Besley and Reynal-Querol (2011). ${ }^{15}$

Column 1 of Table 4.2 presents results from estimating the regression model:

$$
L_{i, t}=\psi_{1} D_{i, t}+\psi_{2} H_{i, t}+\psi_{3} D_{i, t} H_{i, t}+\alpha L_{i, t-1}+\xi_{i}+\theta_{t}+\varepsilon_{i, t}
$$

where $t$ denotes a five-year period and $i$ a country. $L$ measures the competence of the political leader, $D$ democracy, and $H$ the education of the population. The regression model also includes country fixed effects $\zeta$, year fixed effects $\theta$, and error terms $\varepsilon$.

We observe a positive estimate of the coefficient $\psi_{1}$ suggesting that democracies have

\footnotetext{
${ }^{15}$ The database of Besley and Reynal-Querol (2011) ends in 2004, while we need data until 2016. We collect the missing information from Wikipedia and other internet sources.
} 
Table 4.2 Democracy, human capital, and the competence of political leaders.

\begin{tabular}{lcccc}
\hline & $(1)$ & $(2)$ & $(3)$ & $(4)$ \\
\hline Democracy & $0.157^{* * *}$ & $0.168^{* *}$ & $0.155^{* * *}$ & $0.234^{* *}$ \\
& $(0.0443)$ & $(0.0746)$ & $(0.0519)$ & $(0.1041)$ \\
Democracy $\times$ & -0.006 & 0.004 & -0.002 & 0.021 \\
Human Capital & $(0.0080)$ & $(0.0135)$ & $(0.0092)$ & $(0.0174)$ \\
\hline Observations & 2,024 & 1,893 & 1,848 & 1,731 \\
Countries & 147 & 147 & 140 \\
$\mathrm{R}^{2}$ & 0.582 & & 0.543 & \\
SaWi (F-stat.) - Democracy & & 230.99 & \\
SaWi (F-stat.) - Human Cap. & & 34.64 & 42.01 \\
SaWi (F-stat.) - Interaction & & 89.33 & 42.14 \\
CD (F-stat.) & & 117.61 & 5.77 \\
AR (p-value) & & 0.000 & 0.044 \\
StWr (p-value) & & 0.000 & 0.049 \\
KP (p-value) & OLS & 0.000 & 0.000 \\
Estimation technique & & $2 \mathrm{SLS}$ & 2 SLS \\
\hline
\end{tabular}

Notes: The dependent variable indicates whether the political leader of a country has a university degree or not. All regressions include the first lag of the dependent variable, country fixed effects, and year fixed effect. The first lag of the log of GDP per capita and the first lag of an expert-based index of private property protection are included in Columns 3 and 4. The democracy index is continuous and ranges from 0 to 1 . Data on years of schooling is used to measure human capital. The instruments are: (i) the regional (jack-knifed) degree of democratization, (ii) the level of human capital 40 years ago, and (iii) the interaction of the first two instruments. We report different first-stage diagnostics to indicate the strength and validity of our instrumental variables. Standard errors clustered by country are reported in parenthesis. Standard errors clustered by country are reported in parenthesis. The following notation is used to highlight coefficients that are significantly different from zero: ${ }^{*}$ p-value $<0.10,{ }^{* *}$ p-value $<0.05$, ${ }^{* * *} \mathrm{p}$-value $<0.01$.

more competent leaders than autocracies. ${ }^{16}$ If the channel suggested by Fortunato and Panizza (2015) applies, the estimate of the coefficient $\psi_{3}$ should also be positive and statistically significant. The results shown in Column 1 do not confirm this prediction.

Columns $2-4$ of Table 4.2 report the results from our robustness checks. Column 2 instruments the degree of democratization, the level of education, and their interaction using the approach described in Section 4.3.2. Columns 3 and 4 control for the level of economic development and institutional quality. The estimate of the coefficient $\psi_{3}$ is statistically insignificant in all cases.

In the second part of our analysis, we examine how the results reported in Table 4.1 change if we control for the competence of political leaders. If Fortunato and Panizza (2015) were right, we should find that the positive effect of the interaction of human capital and democracy on institutional quality disappears. Table 4.3 shows, however, that the estimates change little when we add our measure of leaders' competence to the regression model. ${ }^{17}$

Taken together, the estimation results reported in Tables 4.2 and 4.3 speak against the hypothesis that the effect of the interaction between democracy and human capital on institutional quality derives from better educated voters electing more able politicians.

\footnotetext{
${ }^{16}$ Besley and Reynal-Querol (2011) examine the effect of democracy on leader's competence in greater detail. The estimate of the coefficient $\psi_{1}$ reported in Table 4.2 and its level of statistical significance closely resemble the figures reported by Besley and Reynal-Querol (2011).

${ }^{17}$ In Appendix Table C.8 (C.9), we define a leader as competent when he or she holds a law (doctoral) degree. Results remain virtually unchanged when we use these alternative definitions of "competent leader".
} 
Table 4.3 Democracy, human capital, leaders' competence, and institutional quality.

\begin{tabular}{|c|c|c|c|c|}
\hline & $\begin{array}{l}\text { Private property } \\
\text { protection }\end{array}$ & $\begin{array}{l}\text { Effective access } \\
\text { to justice }\end{array}$ & $\begin{array}{l}\text { Transparent law } \\
\text { enforcement }\end{array}$ & $\begin{array}{c}\text { Impartial } \\
\text { administration }\end{array}$ \\
\hline & (1) & $(2)$ & (3) & $(4)$ \\
\hline Competent Leader & $\begin{array}{c}-0.007 \\
(0.0104)\end{array}$ & $\begin{array}{c}0.006 \\
(0.0107)\end{array}$ & $\begin{array}{c}0.020^{*} \\
(0.0115)\end{array}$ & $\begin{array}{c}0.020 \\
(0.0129)\end{array}$ \\
\hline Democracy & $\begin{array}{c}0.179^{* * *} \\
(0.0427)\end{array}$ & $\begin{array}{c}0.129^{* * *} \\
(0.0417)\end{array}$ & $\begin{array}{l}0.172^{* * *} \\
(0.0415)\end{array}$ & $\begin{array}{c}0.087^{* * *} \\
(0.0336)\end{array}$ \\
\hline $\begin{array}{l}\text { Democracy } \times \\
\text { Human Capital }\end{array}$ & $\begin{array}{l}0.012^{* *} \\
(0.0055)\end{array}$ & $\begin{array}{l}0.024^{* * *} \\
(0.0107)\end{array}$ & $\begin{array}{c}0.009 \\
(0.0057)\end{array}$ & $\begin{array}{l}0.012^{* *} \\
(0.0055)\end{array}$ \\
\hline Observations & 1,770 & 1,770 & 1,770 & 1,770 \\
\hline Countries & 140 & 140 & 140 & 140 \\
\hline SaWi (F-stat.) - Democracy & 84.31 & 87.32 & 105.20 & 117.88 \\
\hline SaWi (F-stat.) - Human Cap. & 43.42 & 32.18 & 41.78 & 33.80 \\
\hline SaWi (F-stat.) - Interaction & 46.67 & 25.74 & 45.44 & 33.05 \\
\hline CD (F-stat.) & 60.46 & 52.19 & 64.63 & 65.83 \\
\hline AR (p-value) & 0.000 & 0.000 & 0.000 & 0.000 \\
\hline StWr (p-value) & 0.000 & 0.000 & 0.000 & 0.000 \\
\hline $\mathrm{KP}$ (p-value) & 0.000 & 0.000 & 0.000 & 0.000 \\
\hline
\end{tabular}

Notes: The table presents second-stage estimates. The dependent variables are expert-based indices of institutional quality, ranging from 0 to 1 . All regressions include the first lag of the dependent variable, the first lag of the log of GDP per capita, country and year fixed effects. The democracy index is continuous and ranges from 0 to 1. Data on years of schooling is used to measure human capital. The instruments are: (i) the regional (jack-knifed) degree of democratization, (ii) the level of human capital 40 years ago, and (iii) the interaction of the first two instruments. We report different first-stage diagnostics to indicate the strength and validity of our instrumental variables. A leader is classified as competent when he (or she) holds a university degree. Standard errors clustered by country are reported in parenthesis. The following notation is used to highlight coefficients that are significantly different from zero: ${ }^{*}$ p-value $<0.10,{ }^{* *}$ p-value $<0.05,{ }^{* * *}$ p-value $<0.01$.

\subsection{Conclusion}

This paper presents a theoretical model that predicts a positive relationship between democratization and institutional quality. Our model also predicts that the effect of democratic governance on institutional quality varies positively with the education level of the citizens.

Using a large panel data set (140 countries, 1920 - 2015) and different measures of institutional quality, we confirm the predictions of our theoretical model. We address potential endogeneity issues with an instrumental variable approach and show that our estimation results are robust to various sub-sample analysis.

Future research may focus on other factors that cause heterogeneity in the effect of democracy on institutional quality. Cultural traits or geographical conditions may serve as promising candidates. Another research topic may be to examine how the leaders of democratic countries can effectively promote the emergence and survival of democracy in transition countries. Finally, we think that it is important to analyze the heterogeneity between autocratic regimes in more detail. 


\section{C.1 Data on institutional quality}

We exploit the Varieties of Democracy (V-Dem) database to obtain four measures of institutional quality. The measures indicate whether (i) citizens enjoy private property rights, (ii) citizens have secure and effective access to justice, (iii) law enforcement is transparent, and (iv) public officials are impartial. All measures are based on subjective evaluations of country expert. Below, we list the related questionnaires (for additional information, see Coppedge et al. (2018)). ${ }^{18}$

\section{Private property protection}

Country experts were asked to provide a gender-specific evaluation. Our indicator of private property protection is the mean of the gender-specific indices.

Question. Do men (women) enjoy the right to private property?

Clarification. Private property includes the right to acquire, possess, inherit, and sell private property, including land. Limits on property rights may come from the state (which may legally limit rights or fail to enforce them); customary laws and practices; or religious or social norms. This question concerns the right to private property, not actual ownership of property. This question does not ask you to assess the relative rights of men and women. Thus, it is possible to assign the lowest possible score to a country even if men and women enjoy equal-and very minimal-property rights.

\section{Responses.}

0: Virtually no men (women) enjoy private property rights of any kind

1: Some men (women) enjoy some private property rights, but most have none

2: Many men (women) enjoy many private property rights, but a smaller proportion enjoys few or none.

3: More than half of men (women) enjoy most private property rights, yet a smaller share of men (women) have much more restricted rights.

4: Most men (women) enjoy most private property rights but a small minority does not.

5: Virtually all men (women) enjoy all, or almost all property rights.

\section{Effective access to justice}

Country experts were asked to provide a gender-specific evaluation. Our indicator of effective access to justice is the mean of the gender-specific indices.

\footnotetext{
${ }^{18}$ Note that we use italic font when we quote from Coppedge et al. (2018). Note also that we standardize all four measures to have a minimum of 0 and a maximum of 1 in our empirical analysis.
} 
Question. Do men (women) enjoy secure and effective access to justice?

Clarification. This question specifies the extent to which men (women) can bring cases before the courts without risk to their personal safety, trials are fair, and men (women) have effective ability to seek redress if public authorities violate their rights, including the rights to counsel, defense, and appeal. This question does not ask you to assess the relative access to justice men and women. Thus, it is possible to assign the lowest possible score to a country even if men and women enjoy equal-and extremely limited-access to justice.

\section{Responses.}

0: Secure and effective access to justice for men (women) is non-existent.

1: Secure and effective access to justice for men is usually not established or widely.

2: Secure and effective access to justice for men (women) is inconsistently observed. Minor problems characterize most cases or occur rather unevenly across different parts of the country.

3: Secure and effective access to justice for men (women) is usually observed.

4: Virtually all men (women) enjoy all, or almost all property rights.

\section{Transparent laws with predictable enforcement}

Question. Are the laws of the land clear, well publicized, coherent (consistent with each other), relatively stable from year to year, and enforced in a predictable manner?

Clarification. This question focuses on the transparency and predictability of the laws of the land.

\section{Responses.}

0: Transparency and predictability are almost non-existent. The laws of the land are created and/ or enforced in completely arbitrary fashion.

1: Transparency and predictability are severely limited. The laws of the land are more often than not created and/ or enforced in arbitrary fashion.

2: Transparency and predictability are somewhat limited. The laws of the land are mostly created in a non-arbitrary fashion but enforcement is rather arbitrary in some parts of the country.

3: Transparency and predictability are fairly strong. The laws of the land are usually created and enforced in a non-arbitrary fashion.

4: Transparency and predictability are very strong. The laws of the land are created and enforced in a non-arbitrary fashion. 


\section{Rigorous and impartial public administration}

Question. Are public officials rigorous and impartial in the performance of their duties?

Clarification. This question focuses on the extent to which public officials generally abide by the law and treat like cases alike, or conversely, the extent to which public administration is characterized by arbitrariness and biases (i.e., nepotism, cronyism,

or discrimination). The question covers the public officials that handle the cases of ordinary people. If no functioning public administration exists, the lowest score (0) applies.

\section{Responses.}

0: The law is not respected by public officials. Arbitrary or biased administration of the law is rampant.

1: The law is weakly respected by public officials. Arbitrary or biased administration of the law is widespread.

2: The law is modestly respected by public officials. Arbitrary or biased administration of the law is moderate.

3: The law is mostly respected by public officials. Arbitrary or biased administration of the law is limited.

4: The law is generally fully respected by the public officials. Arbitrary or biased administration of the law is very limited. 


\section{C.2 Additional tables}

Table C.1 Democracy, human capital, and institutional quality — First-stage estimates.

\begin{tabular}{|c|c|c|c|c|c|c|}
\hline & \multicolumn{3}{|c|}{ Panel A - Specification (1) } & \multicolumn{3}{|c|}{ Panel B - Specification (2) } \\
\hline & Democracy & Human Cap & Interaction & Democracy & Human Cap & Interaction \\
\hline \multirow{2}{*}{ Democracy (Reg.) } & $0.663^{* * *}$ & $3.712^{* * *}$ & $2.396^{* * *}$ & $0.721 * * *$ & $3.980 * * *$ & $2.803^{* * *}$ \\
\hline & $(0.0827)$ & $(0.3488)$ & $(0.5282)$ & $(0.0717)$ & $(0.3419)$ & $(0.4880)$ \\
\hline \multirow[t]{2}{*}{ Human capital $(t-8)$} & -0.015 & $1.075^{* * *}$ & 0.017 & 0.008 & $1.087 * * *$ & 0.158 \\
\hline & $(0.0230)$ & $(0.1263)$ & $(0.1888)$ & $(0.0227)$ & $(0.1272)$ & $(0.1846)$ \\
\hline Democracy (Reg.) $\times$ & -0.026 & $-0.507 * * *$ & $0.699^{* * *}$ & $-0.056^{* * *}$ & $-0.516^{* * *}$ & $0.518^{* * *}$ \\
\hline Human capital $(t-8)$ & $(0.0206)$ & $(0.1161)$ & $(0.1968)$ & $(0.0207)$ & $(0.1195)$ & $(0.2014)$ \\
\hline Observations & 1,802 & 1,802 & 1,802 & 1,802 & 1,802 & 1,802 \\
\hline Countries & 140 & 140 & 140 & 140 & 140 & 140 \\
\hline \multirow[t]{3}{*}{ SaWi (F-stat.) } & 101.09 & 44.17 & 48.73 & 104.57 & 32.43 & 26.16 \\
\hline & \multicolumn{3}{|c|}{ Panel C - Specification (3) } & \multicolumn{3}{|c|}{ Panel D - Specification (4) } \\
\hline & Democracy & Human Cap & Interaction & Democracy & Human Cap & Interaction \\
\hline \multirow[t]{2}{*}{ Democracy (Reg.) } & $0.722 * * *$ & $3.961 * * *$ & $2.864^{* * *}$ & $0.837 * * *$ & $4.018 * * *$ & $3.521 * * *$ \\
\hline & $(0.0733)$ & $(0.3432)$ & $(0.5011)$ & $(0.0770)$ & $(0.3439)$ & $(0.5134)$ \\
\hline \multirow[t]{2}{*}{ Human capital $(t-8)$} & -0.003 & $1.086^{* * *}$ & 0.091 & 0.013 & $1.075^{* * *}$ & 0.183 \\
\hline & $(0.0233)$ & $(0.1261)$ & $(0.1930)$ & $(0.0261)$ & $(0.1259)$ & $(0.2039)$ \\
\hline Democracy (Reg.) $\times$ & -0.033 & $-0.511 * * *$ & $0.660 * * *$ & $-0.053^{* *}$ & $-0.500 * * *$ & $0.538 * * *$ \\
\hline Human capital $(t-8)$ & $(0.0221)$ & $(0.1172)$ & $(0.2092)$ & $(0.0237)$ & $(0.1188)$ & $(0.2186)$ \\
\hline Observations & 1,802 & 1,802 & 1,802 & 1,802 & 1,802 & 1,802 \\
\hline Countries & 140 & 140 & 140 & 140 & 140 & 140 \\
\hline SaWi (F-stat.) & 126.66 & 42.07 & 45.84 & 141.05 & 33.67 & 33.38 \\
\hline
\end{tabular}

Notes: The table presents first-stage estimates. For the corresponding second-stage estimates, see Table 4.1. Standard errors clustered by country are reported in parenthesis. The following notation is used to highlight coefficients that are significantly different from zero: ${ }^{*} \mathrm{p}$-value $<0.10,{ }^{* *} \mathrm{p}$-value $<0.05,{ }^{* * *} \mathrm{p}$-value $<0.01$.

Table C.2 Democracy, human capital, and institutional quality — OLS estimates.

\begin{tabular}{|c|c|c|c|c|}
\hline & $\begin{array}{l}\text { Private property } \\
\text { protection }\end{array}$ & $\begin{array}{c}\text { Effective access to } \\
\text { justice }\end{array}$ & $\begin{array}{l}\text { Transparent law } \\
\text { enforcement }\end{array}$ & $\begin{array}{c}\text { Impartial } \\
\text { administration }\end{array}$ \\
\hline & (1) & (2) & (3) & (4) \\
\hline Democracy & $\begin{array}{l}0.101^{* * * *} \\
(0.0177)\end{array}$ & $\begin{array}{l}0.123^{* * * *} \\
(0.0194)\end{array}$ & $\begin{array}{l}0.190 * * * \\
(0.0241)\end{array}$ & $\begin{array}{l}0.123^{* * * *} \\
(0.0199)\end{array}$ \\
\hline $\begin{array}{l}\text { Democracy } \times \\
\text { Human Capital }\end{array}$ & $\begin{array}{c}0.003 \\
(0.0036)\end{array}$ & $\begin{array}{l}0.013 * * * \\
(0.0040)\end{array}$ & $\begin{array}{c}0.006 \\
(0.0039)\end{array}$ & $\begin{array}{c}0.007^{*} \\
(0.0040)\end{array}$ \\
\hline $\begin{array}{l}\text { Observations } \\
\text { Countries } \\
\mathrm{R}^{2}\end{array}$ & $\begin{array}{c}1,802 \\
140 \\
0.903\end{array}$ & $\begin{array}{c}1,802 \\
140 \\
0.884\end{array}$ & $\begin{array}{c}1,802 \\
140 \\
0.830\end{array}$ & $\begin{array}{c}1,802 \\
140 \\
0.878\end{array}$ \\
\hline
\end{tabular}

Notes: The table presents OLS estimates. The dependent variables are expert-based indices of institutional quality, ranging from 0 to 1. All regressions include the first lag of the dependent variable, the first lag of the log of GDP per capita, country and period fixed effects. The democracy index is continuous and ranges from 0 to 1 . Data on years of schooling is used to measure human capital. Standard errors clustered by country are reported in parenthesis. The following notation is used to highlight coefficients that are significantly different from zero: ${ }^{*} \mathrm{p}$-value $<0.10,{ }^{* *} \mathrm{p}$-value $<0.05,{ }^{* * *}$ p-value $<0.01$. 
Table C.3 Democracy, human capital, and institutional quality — Subsample results.

\begin{tabular}{|c|c|c|c|c|}
\hline & $\begin{array}{c}\text { Private property } \\
\text { protection }\end{array}$ & $\begin{array}{c}\text { Effective access to } \\
\text { justice }\end{array}$ & $\begin{array}{l}\text { Transparent law } \\
\text { enforcement }\end{array}$ & $\begin{array}{c}\text { Impartial } \\
\text { administration }\end{array}$ \\
\hline & (1) & $(2)$ & (3) & $(4)$ \\
\hline & \multicolumn{4}{|c|}{ Panel A - Exclude Asia } \\
\hline Democracy & $\begin{array}{c}0.158^{* * * *} \\
(0.0412)\end{array}$ & $\begin{array}{c}0.138^{* * * *} \\
(0.0417)\end{array}$ & $\begin{array}{l}0.186 * * * \\
(0.0413)\end{array}$ & $\begin{array}{c}0.107 * * * \\
(0.0335)\end{array}$ \\
\hline $\begin{array}{l}\text { Democracy } \times \\
\text { Human Capital }\end{array}$ & $\begin{array}{c}0.007 \\
(0.0056)\end{array}$ & $\begin{array}{l}0.020^{* * *} \\
(0.0064)\end{array}$ & $\begin{array}{c}0.005 \\
(0.0052)\end{array}$ & $\begin{array}{c}0.010^{*} \\
(0.0050)\end{array}$ \\
\hline \multirow[t]{2}{*}{ Countries } & $\begin{array}{c}1,412 \\
104\end{array}$ & $\begin{array}{c}1,412 \\
104\end{array}$ & $\begin{array}{c}1,412 \\
104\end{array}$ & $\begin{array}{c}1,412 \\
104\end{array}$ \\
\hline & \multicolumn{4}{|c|}{ Panel B - Exclude Africa } \\
\hline Democracy & $\begin{array}{c}0.178^{* * * *} \\
(0.0446)\end{array}$ & $\begin{array}{c}0.132 * * * \\
(0.0445)\end{array}$ & $\begin{array}{c}0.188^{* * *} \\
(0.0452)\end{array}$ & $\begin{array}{c}0.115^{* * *} \\
(0.0374)\end{array}$ \\
\hline $\begin{array}{l}\text { Democracy } \times \\
\text { Human Capital }\end{array}$ & $\begin{array}{c}0.009 \\
(0.0059)\end{array}$ & $\begin{array}{c}0.023^{* * *} \\
(0.0081)\end{array}$ & $\begin{array}{c}0.009 \\
(0.0065)\end{array}$ & $\begin{array}{c}0.010 \\
(0.0060)\end{array}$ \\
\hline \multirow[t]{2}{*}{ Countries } & $\begin{array}{c}1,393 \\
98\end{array}$ & $\begin{array}{c}1,393 \\
98\end{array}$ & $\begin{array}{c}1,393 \\
98\end{array}$ & $\begin{array}{c}1,393 \\
98\end{array}$ \\
\hline & \multicolumn{4}{|c|}{ Panel C - Exclude America } \\
\hline Democracy & $\begin{array}{c}0.224^{* * *} \\
(0.0476)\end{array}$ & $\begin{array}{l}0.154^{* * *} \\
(0.0435)\end{array}$ & $\begin{array}{l}0.182^{* * *} \\
(0.0423)\end{array}$ & $\begin{array}{l}0.054^{*} \\
(0.0310)\end{array}$ \\
\hline $\begin{array}{l}\text { Democracy } \times \\
\text { Human Capital }\end{array}$ & $\begin{array}{c}0.019^{* * *} \\
(0.0068)\end{array}$ & $\begin{array}{c}0.020^{* * *} \\
(0.0068)\end{array}$ & $\begin{array}{c}0.006 \\
(0.0051)\end{array}$ & $\begin{array}{c}0.0089 \\
(0.0041)\end{array}$ \\
\hline \multirow[t]{2}{*}{ Countries } & $\begin{array}{c}1,349 \\
115\end{array}$ & $\begin{array}{c}1,349 \\
115\end{array}$ & $\begin{array}{c}1,349 \\
115\end{array}$ & $\begin{array}{c}1,349 \\
115\end{array}$ \\
\hline & \multicolumn{4}{|c|}{ Panel D - Exclude Europe } \\
\hline Democracy & $\begin{array}{l}0.135 * * \\
(0.0606)\end{array}$ & $\begin{array}{c}0.071 \\
(0.0549)\end{array}$ & $\begin{array}{c}0.171^{* * *} \\
(0.0757)\end{array}$ & $\begin{array}{c}0.115^{*} \\
(0.0620)\end{array}$ \\
\hline $\begin{array}{l}\text { Democracy } \times \\
\text { Human Capital }\end{array}$ & $\begin{array}{c}0.011 \\
(0.0095)\end{array}$ & $\begin{array}{l}0.045^{* * *} * \\
(0.0159)\end{array}$ & $\begin{array}{l}0.030^{* *} \\
(0.0142)\end{array}$ & $\begin{array}{l}0.042^{* *} \\
(0.0199)\end{array}$ \\
\hline \multirow[t]{2}{*}{ Countries } & $\begin{array}{c}1,292 \\
105\end{array}$ & $\begin{array}{c}1,292 \\
105\end{array}$ & $\begin{array}{c}1,292 \\
105\end{array}$ & $\begin{array}{c}1,292 \\
105\end{array}$ \\
\hline & \multicolumn{4}{|c|}{ Panel E - From 1970 to 2015} \\
\hline Democracy & $\begin{array}{c}0.214^{* * * *} \\
(0.0584)\end{array}$ & $\begin{array}{c}0.212 * * * \\
(0.0518)\end{array}$ & $\begin{array}{c}0.250^{* * *} \\
(0.0603)\end{array}$ & $\begin{array}{c}0.192 * * * \\
(0.0494)\end{array}$ \\
\hline $\begin{array}{l}\text { Democracy } \times \\
\text { Human Capital }\end{array}$ & $\begin{array}{c}0.010^{*} \\
(0.0058)\end{array}$ & $\begin{array}{l}0.018^{* * * *} \\
(0.0062)\end{array}$ & $\begin{array}{c}0.002 \\
(0.0055)\end{array}$ & $\begin{array}{c}0.005 \\
(0.0055)\end{array}$ \\
\hline \multirow[t]{2}{*}{ Countries } & $\begin{array}{c}1,231 \\
140\end{array}$ & $\begin{array}{c}1,231 \\
140\end{array}$ & $\begin{array}{c}1,231 \\
140\end{array}$ & $\begin{array}{c}1,231 \\
140\end{array}$ \\
\hline & \multicolumn{4}{|c|}{ Panel F - From 1950 to 2015} \\
\hline Democracy & $\begin{array}{c}0.186^{* * *} \\
(0.0473)\end{array}$ & $\begin{array}{c}0.173^{* * *} \\
(0.0403)\end{array}$ & $\begin{array}{c}0.206^{* * *} \\
(0.0489)\end{array}$ & $\begin{array}{c}0.141^{* * *} \\
(0.0400)\end{array}$ \\
\hline $\begin{array}{l}\text { Democracy } \times \\
\text { Human Capital }\end{array}$ & $\begin{array}{c}0.010^{*} \\
(0.0053)\end{array}$ & $\begin{array}{c}0.020 * * * \\
(0.0062)\end{array}$ & $\begin{array}{c}0.005 \\
(0.0055)\end{array}$ & $\begin{array}{c}0.009^{*} \\
(0.0054)\end{array}$ \\
\hline \multirow[t]{2}{*}{ Countries } & $\begin{array}{c}1,548 \\
140\end{array}$ & $\begin{array}{c}1,548 \\
140\end{array}$ & $\begin{array}{c}1,548 \\
140\end{array}$ & $\begin{array}{c}1,548 \\
140\end{array}$ \\
\hline & \multicolumn{4}{|c|}{ Panel G - From 1920 to 1990} \\
\hline Democracy & $\begin{array}{c}0.233^{* * *} * \\
(0.0568)\end{array}$ & $\begin{array}{l}0.142^{* *} \\
(0.0595)\end{array}$ & $\begin{array}{c}0.249^{* * *} \\
(0.0476)\end{array}$ & $\begin{array}{c}0.067 \\
(0.0458)\end{array}$ \\
\hline $\begin{array}{l}\text { Democracy } \times \\
\text { Human Capital }\end{array}$ & $\begin{array}{l}0.020^{* *} \\
(0.0083)\end{array}$ & $\begin{array}{c}0.046^{* * *} \\
(0.0133)\end{array}$ & $\begin{array}{l}0.019^{* *} \\
(0.0099)\end{array}$ & $\begin{array}{c}0.031^{* * *} \\
(0.0093)\end{array}$ \\
\hline $\begin{array}{l}\text { Observations } \\
\text { Countries }\end{array}$ & $\begin{array}{c}1,089 \\
105\end{array}$ & 1,089 & 1,089 & 1,089 \\
\hline
\end{tabular}

Notes: The table presents second-stage estimates for different sub-samples. The dependent variables are expert-based indices of institutional quality, ranging from 0 to 1 . All regressions include the first lag of the dependent variable, the first lag of the log of GDP per capita, country and period fixed effects. The democracy index is continuous and ranges from 0 to 1 . Data on years of schooling is used to measure human capital. The instruments are: (i) the regional (jack-knifed) degree of democratization, (ii) the level of human capital 40 years ago, and (iii) the interaction of the first two instruments. Standard errors clustered by country are reported in parenthesis. The following notation is used to highlight coefficients that are significantly different from zero: ${ }^{*}$ p-value $<0.10,{ }^{* *}$ p-value $<0.05,{ }^{* * *}$ p-value $<0.01$. 
Table C.4 Democracy, human capital, and institutional quality — Lexical Index of Electoral Democracy.

\begin{tabular}{|c|c|c|c|c|}
\hline & $\begin{array}{l}\text { Private property } \\
\text { protection }\end{array}$ & $\begin{array}{c}\text { Effective access } \\
\text { to justice }\end{array}$ & $\begin{array}{l}\text { Transparent law } \\
\text { enforcement }\end{array}$ & $\begin{array}{c}\text { Impartial } \\
\text { administration }\end{array}$ \\
\hline & $(1)$ & $(2)$ & (3) & $(4)$ \\
\hline Democracy & $\begin{array}{c}0.199 * * * \\
(0.0509)\end{array}$ & $\begin{array}{c}0.164^{* * *} \\
(0.0523)\end{array}$ & $\begin{array}{c}0.228^{* * *} \\
(0.0478)\end{array}$ & $\begin{array}{c}0.124^{* * *} \\
(0.0393)\end{array}$ \\
\hline Democracy $\times$ & $0.014^{* *}$ & $0.032^{* * *}$ & $0.012^{*}$ & $0.017^{* *}$ \\
\hline Human Capital & $(0.0068)$ & $(0.0092)$ & $(0.0073)$ & $(0.0077)$ \\
\hline Observations & 1,800 & 1,800 & 1,800 & 1,800 \\
\hline Countries & 140 & 140 & 140 & 140 \\
\hline SaWi (F-stat.) - Democracy & 49.98 & 44.54 & 63.12 & 70.89 \\
\hline SaWi (F-stat.) - Human Cap & 33.19 & 22.61 & 32.09 & 25.84 \\
\hline SaWi (F-stat.) - Interaction & 27.79 & 16.65 & 26.80 & 20.45 \\
\hline CD (F-stat.) & 38.10 & 30.39 & 40.61 & 41.54 \\
\hline AR (p-value) & 0.000 & 0.000 & 0.000 & 0.000 \\
\hline StWr (p-value) & 0.000 & 0.000 & 0.000 & 0.000 \\
\hline $\mathrm{KP}$ (p-value) & 0.000 & 0.000 & 0.000 & 0.000 \\
\hline
\end{tabular}

Notes: The table presents second-stage estimates. The dependent variables are expert-based indices of institutional quality, ranging from 0 to 1 . All regressions include the first lag of the dependent variable, the first lag of the log of GDP per capita, country and period fixed effects. The democracy index is ordinal and ranges from 0 to 1. Data on years of schooling is used to measure human capital. The instruments are: (i) the regional (jack-knifed) degree of democratization, (ii) the level of human capital 40 years ago, and (iii) the interaction of the first two instruments. We report different first-stage diagnostics to indicate the strength and validity of our instrumental variables. Standard errors clustered by country are reported in parenthesis. The following notation is used to highlight coefficients that are significantly different from zero: ${ }^{*}$ p-value $<0.10,{ }^{* *}$ p-value $<0.05,{ }^{* * *}$ p-value $<0.01$.

Table C.5 Democracy, human capital, and institutional quality — Boix, Miller, Rosata (2013) index.

\begin{tabular}{lcccc}
\hline & $\begin{array}{c}\text { Private property } \\
\text { protection }\end{array}$ & $\begin{array}{c}\text { Effective access } \\
\text { to justice }\end{array}$ & $\begin{array}{c}\text { Transparent law } \\
\text { enforcement }\end{array}$ & $\begin{array}{c}\text { Impartial } \\
\text { administration }\end{array}$ \\
\hline Democracy & $(1)$ & $(2)$ & $(3)$ & $(4)$ \\
Democracy & $0.202^{* * *}$ & $0.159^{* * *}$ & $0.233^{* * *}$ & $0.135^{* *}$ \\
Human Capital & $(0.0540)$ & $(0.0607)$ & $(0.0536)$ & $(0.0471)$ \\
Observations & $0.019^{* *}$ & $0.037^{* * *}$ & $0.018^{*}$ & $\left(0.024^{* *}\right.$ \\
Countries & $(0.0081)$ & $(0.0121)$ & 1,662 & $10.0111)$ \\
SaWi (F-stat.) - Democracy & 1,662 & 1,662 & 1,662 \\
SaWi (F-stat.) - Human Cap & 140 & 140 & 140 \\
SaWi (F-stat.) - Interaction & 17.68 & 28.61 & 14.99 & 41.82 \\
CD (F-stat.) & 17.57 & 10.74 & 13.57 & 11.79 \\
AR (p-value) & 23.84 & 8.62 & 9.29 \\
StWr (p-value) & 0.000 & 17.11 & 0.000 & 19.81 \\
KP (p-value) & 0.000 & 0.000 & 0.000 & 0.000 \\
\hline
\end{tabular}

Notes: The table presents second-stage estimates. The dependent variables are expert-based indices of institutional quality, ranging from 0 to 1 . All regressions include the first lag of the dependent variable, the first lag of the log of GDP per capita, country and period fixed effects. The democracy index is binary. Data on years of schooling is used to measure human capital. The instruments are: (i) the regional (jack-knifed) degree of democratization, (ii) the level of human capital 40 years ago, and (iii) the interaction of the first two instruments. We report different first-stage diagnostics to indicate the strength and validity of our instrumental variables. Standard errors clustered by country are reported in parenthesis. The following notation is used to highlight coefficients that are significantly different from zero: ${ }^{*}$ p-value $<0.10,{ }^{* *}$ p-value $<0.05,{ }^{* * *}$ p-value $<0.01$. 
Table C.6 Democracy, human capital, and institutional quality — Ten-year data.

\begin{tabular}{lcccc}
\hline & $\begin{array}{c}\text { Private property } \\
\text { protection }\end{array}$ & $\begin{array}{c}\text { Effective access } \\
\text { to justice }\end{array}$ & $\begin{array}{c}\text { Transparent law } \\
\text { enforcement }\end{array}$ & $\begin{array}{c}\text { Impartial } \\
\text { administration }\end{array}$ \\
\hline Democracy & $(1)$ & $(2)$ & $(3)$ & $(4)$ \\
& $0.258^{* * *}$ & $0.159^{* * *}$ & $0.225^{* * *}$ & $0.120^{* *}$ \\
Democracy & $(0.0576)$ & $(0.0514)$ & $(0.0509)$ & $(0.0490)$ \\
Human Capital & $0.018^{* *}$ & $0.031^{* * *}$ & $0.013^{*}$ & $0.020^{* *}$ \\
\hline Observations & $(0.0079)$ & $(0.0076)$ & $(0.0075)$ & $(0.0079)$ \\
Countries & 886 & 886 & 886 & 886 \\
SaWi (F-stat.) - Democracy & 140 & 140 & 140 & 140 \\
SaWi (F-stat.) - Human Cap & 118.59 & 133.60 & 42.06 & 144.52 \\
SaWi (F-stat.) - Interaction & 42.76 & 36.28 & 35.47 \\
CD (F-stat.) & 57.99 & 37.59 & 35.03 & 43.13 \\
AR (p-value) & 38.65 & 35.49 & 38.83 & 37.31 \\
StWr (p-value) & 0.000 & 0.000 & 0.000 & 0.000 \\
KP (p-value) & 0.000 & 0.000 & 0.000 & 0.000 \\
\hline
\end{tabular}

Notes: The table presents second-stage estimates. The dependent variables are expert-based indices of institutional quality, ranging from 0 to 1 . All regressions include the first lag of the dependent variable, the first lag of the log of GDP per capita, country and year fixed effects. The democracy index is continuous and ranges from 0 to 1. Data on years of schooling is used to measure human capital. The instruments are: (i) the regional (jack-knifed) degree of democratization, (ii) the level of human capital 40 years ago, and (iii) the interaction of the first two instruments. We report different first-stage diagnostics to indicate the strength and validity of our instrumental variables. Standard errors clustered by country are reported in parenthesis. The following notation is used to highlight coefficients that are significantly different from zero: ${ }^{*}$ p-value $<0.10,{ }^{* *}$ p-value $<0.05,{ }^{* * *}$ p-value $<0.01$. 
Table C.7 Democracy, human capital, and institutional quality - Additional control variables.

\begin{tabular}{|c|c|c|c|c|}
\hline & $\begin{array}{l}\text { Private property } \\
\text { protection }\end{array}$ & $\begin{array}{c}\text { Effective access } \\
\text { to justice }\end{array}$ & $\begin{array}{l}\text { Transparent law } \\
\text { enforcement }\end{array}$ & $\begin{array}{c}\text { Impartial } \\
\text { administration }\end{array}$ \\
\hline & $(1)$ & $(2)$ & $(3)$ & $(4)$ \\
\hline & \multicolumn{4}{|c|}{ Panel A - Controls: conflict, pop. growth, institutional quality (region) } \\
\hline \multirow[t]{2}{*}{ Democracy } & $0.221 * * *$ & $0.217^{* * *}$ & $0.267^{* * *}$ & $0.192^{* * *}$ \\
\hline & $(0.0484)$ & $(0.0516)$ & $(0.0556)$ & $(0.0462)$ \\
\hline Democracy $\times$ & $0.013^{* *}$ & $0.031^{* * *}$ & $0.016^{* *}$ & $0.021 * * *$ \\
\hline Human Capital & $(0.0066)$ & $(0.0088)$ & $(0.0068)$ & $(0.0071)$ \\
\hline Observations & 1,725 & 1,725 & 1,725 & 1,725 \\
\hline Countries & 140 & 140 & 140 & 140 \\
\hline SaWi (F-stat.) - Democracy & 60.39 & 52.87 & 58.40 & 63.20 \\
\hline SaWi (F-stat.) - Human Cap & 47.49 & 30.42 & 44.21 & 32.00 \\
\hline SaWi (F-stat.) - Interaction & 29.06 & 16.06 & 26.00 & 19.76 \\
\hline CD (F-stat.) & 46.70 & 37.02 & 44.27 & 42.44 \\
\hline AR (p-value) & 0.000 & 0.000 & 0.000 & 0.000 \\
\hline StWr (p-value) & 0.000 & 0.000 & 0.000 & 0.000 \\
\hline \multirow[t]{2}{*}{$\mathrm{KP}$ (p-value) } & 0.000 & 0.000 & 0.000 & 0.000 \\
\hline & \multicolumn{4}{|c|}{ Panel B - Controls: Panel A + gov. consumption, invest., trade openness } \\
\hline \multirow[t]{2}{*}{ Democracy } & $0.151^{* * *}$ & $0.162^{* * *}$ & $0.254^{* * *}$ & $0.156^{* * *}$ \\
\hline & $(0.0541)$ & $(0.0564)$ & $(0.0717)$ & $(0.0532)$ \\
\hline Democracy $\times$ & $0.015^{*}$ & $0.033^{* * *}$ & 0.011 & $0.024^{* * *}$ \\
\hline Human Capital & $(0.0083)$ & $(0.0093)$ & $(0.0083)$ & $(0.0088)$ \\
\hline Observations & 1,360 & 1,360 & 1,360 & 1,360 \\
\hline Countries & 137 & 137 & 137 & 137 \\
\hline SaWi (F-stat.) - Democracy & 59.65 & 58.53 & 54.37 & 59.05 \\
\hline SaWi (F-stat.) - Human Cap & 56.21 & 39.17 & 51.59 & 40.49 \\
\hline SaWi (F-stat.) - Interaction & 25.42 & 20.15 & 26.41 & 23.45 \\
\hline CD (F-stat.) & 40.13 & 32.50 & 35.25 & 37.96 \\
\hline AR (p-value) & 0.000 & 0.000 & 0.000 & 0.000 \\
\hline StWr (p-value) & 0.001 & 0.000 & 0.000 & 0.000 \\
\hline KP (p-value) & 0.000 & 0.000 & 0.000 & 0.000 \\
\hline
\end{tabular}

Notes: The table presents second-stage estimates. The dependent variables are expert-based indices of institutional quality, ranging from 0 to 1 . All regressions include the first lag of the dependent variable, and country and period fixed effects. We also control for the first lag of civil conflict, population growth, the log of GDP per capita, and the regional (jack-knifed) level of institutional quality. In Panel B, we additionally control for the first lag of trade openness, investment, and government consumption. The democracy index is continuous and ranges from 0 to 1 . Data on years of schooling is used to measure human capital. The instruments are: (i) the regional (jack-knifed) degree of democratization, (ii) the level of human capital 40 years ago, and (iii) the interaction of the first two instruments. We report different first-stage diagnostics to indicate the strength and validity of our instrumental variables. Standard errors clustered by country are reported in parenthesis. The following notation is used to highlight coefficients that are significantly different from zero: ${ }^{*}$ p-value $<0.10,{ }^{* *}$ p-value $<0.05,{ }^{* * *}$ p-value $<0.01$ 
Table C.8 Democracy, human capital, leaders' competence (law degree), and institutional quality.

\begin{tabular}{lcccc}
\hline & $\begin{array}{c}\text { Private property } \\
\text { protection }\end{array}$ & $\begin{array}{c}\text { Effective access } \\
\text { to justice }\end{array}$ & $\begin{array}{c}\text { Transparent law } \\
\text { enforcement }\end{array}$ & $\begin{array}{c}\text { Impartial } \\
\text { administration }\end{array}$ \\
\hline Competent Leader & $(1)$ & $(2)$ & $(3)$ & $(4)$ \\
Democracy & -0.013 & -0.001 & 0.011 & -0.001 \\
& $(0.0084)$ & $(0.0082)$ & $(0.0095)$ & $(0.0105)$ \\
Democracy & $0.170^{* * *}$ & $0.123^{* * *}$ & $0.176^{* * *}$ & $0.091^{* * *}$ \\
Human Capital & $(0.0409)$ & $(0.0392)$ & $(0.0396)$ & $(0.0311)$ \\
\hline Observations & $0.012^{* *}$ & $0.024^{* * *}$ & $0.010^{*}$ & $0.013^{* *}$ \\
Countries & $(0.0055)$ & $(0.0067)$ & $(0.0057)$ & $(0.0055)$ \\
SaWi (F-stat.) - Democracy & 1,802 & 1,802 & 1,802 & 140 \\
SaWi (F-stat.) - Human Cap. & 140 & 140 & 124.21 & 1,802 \\
SaWi (F-stat.) - Interaction & 99.69 & 101.04 & 40.92 & 140 \\
CD (F-stat.) & 43.05 & 31.61 & 44.79 & 33.07 \\
AR (p-value) & 47.28 & 25.92 & 71.96 & 32.86 \\
StWr (p-value) & 68.44 & 59.09 & 0.000 & 71.95 \\
KP (p-value) & 0.000 & 0.000 & 0.000 & 0.000 \\
\hline
\end{tabular}

Notes: The table presents second-stage estimates. The dependent variables are expert-based indices of institutional quality, ranging from 0 to 1 . All regressions include the first lag of the dependent variable, the first lag of the log of GDP per capita, country and year fixed effects. The democracy index is continuous and ranges from 0 to 1 . Data on years of schooling is used to measure human capital. The instruments are: (i) the regional (jack-knifed) degree of democratization, (ii) the level of human capital 40 years ago, and (iii) the interaction of the first two instruments. We report different first-stage diagnostics to indicate the strength and validity of our instrumental variables. A leader is classified as competent when he (or she) holds a law degree. Standard errors clustered by country are reported in parenthesis. The following notation is used to highlight coefficients that are significantly different from zero: ${ }^{*}$ p-value $<0.10,{ }^{* *}$ p-value $<0.05,{ }^{* * *}$ p-value $<0.01$.

Table C.9 Democracy, human capital, leaders' competence ( $\mathrm{PhD})$, and institutional quality.

\begin{tabular}{|c|c|c|c|c|}
\hline & $\begin{array}{l}\text { Private property } \\
\text { protection }\end{array}$ & $\begin{array}{c}\text { Effective access } \\
\text { to justice }\end{array}$ & $\begin{array}{l}\text { Transparent law } \\
\text { enforcement }\end{array}$ & $\begin{array}{c}\text { Impartial } \\
\text { administration }\end{array}$ \\
\hline & (1) & (2) & (3) & $(4)$ \\
\hline Competent Leader & $\begin{array}{c}-0.001 \\
(0.0116)\end{array}$ & $\begin{array}{c}-0.000 \\
(0.0126)\end{array}$ & $\begin{array}{c}0.002 \\
(0.0117)\end{array}$ & $\begin{array}{c}0.015 \\
(0.0128)\end{array}$ \\
\hline Democracy & $\begin{array}{l}0.169^{* * * *} \\
(0.0406)\end{array}$ & $\begin{array}{l}0.123^{* * *} \\
(0.0392)\end{array}$ & $\begin{array}{l}0.176^{* * * *} \\
(0.0399)\end{array}$ & $\begin{array}{l}0.091^{* * * *} \\
(0.0307)\end{array}$ \\
\hline $\begin{array}{l}\text { Democracy } \times \\
\text { Human Capital }\end{array}$ & $\begin{array}{l}0.012^{* *} \\
(0.0055)\end{array}$ & $\begin{array}{l}0.024^{* * * *} \\
(0.0067)\end{array}$ & $\begin{array}{c}0.010^{*} \\
(0.0057)\end{array}$ & $\begin{array}{l}0.012^{* *} \\
(0.0128)\end{array}$ \\
\hline Observations & 1,802 & 1,802 & 1,802 & 1,802 \\
\hline Countries & 140 & 140 & 140 & 140 \\
\hline SaWi (F-stat.) - Democracy & 101.72 & 107.27 & 127.18 & 139.02 \\
\hline SaWi (F-stat.) - Human Cap. & 43.25 & 31.97 & 41.36 & 33.12 \\
\hline SaWi (F-stat.) - Interaction & 47.56 & 25.61 & 44.60 & 32.83 \\
\hline CD (F-stat.) & 68.13 & 58.48 & 71.28 & 71.40 \\
\hline AR (p-value) & 0.000 & 0.000 & 0.000 & 0.000 \\
\hline StWr (p-value) & 0.000 & 0.000 & 0.000 & 0.000 \\
\hline $\mathrm{KP}$ (p-value) & 0.000 & 0.000 & 0.000 & 0.000 \\
\hline
\end{tabular}

Notes: The table presents second-stage estimates. The dependent variables are expert-based indices of institutional quality, ranging from 0 to 1 . All regressions include the first lag of the dependent variable, the first lag of the log of GDP per capita, country and year fixed effects. The democracy index is continuous and ranges from 0 to 1. Data on years of schooling is used to measure human capital. The instruments are: (i) the regional (jack-knifed) degree of democratization, (ii) the level of human capital 40 years ago, and (iii) the interaction of the first two instruments. We report different first-stage diagnostics to indicate the strength and validity of our instrumental variables. A leader is classified as competent when he (or she) holds a PhD degree. Standard errors clustered by country are reported in parenthesis. The following notation is used to highlight coefficients that are significantly different from zero: ${ }^{*} \mathrm{p}$-value $<0.10,{ }^{* *}$ p-value $<0.05,{ }^{* * *}$ p-value $<0.01$. 


\section{Bibliography}

Abe, S. (2005). Support Vector Machines for pattern classification. Springer.

Acemoglu, D. (2008). Oligarchic versus democratic societies. Journal of the European Economic Association, 6(1):1-44.

Acemoglu, D., Gallego, F. A., and Robinson, J. A. (2014). Institutions, human capital, and development. Annual Review of Economics, 6(1):875-912.

Acemoglu, D., Johnson, S., and Robinson, J. A. (2001). The colonial origins of comparative development: An empirical investigation. American Economic Review, 91(5):1369-1401.

Acemoglu, D., Johnson, S., and Robinson, J. A. (2002). Reversal of fortune: Geography and institutions in the making of the modern world income distribution. Quarterly Journal of Economics, 117(4):1231-1294.

Acemoglu, D., Johnson, S., and Robinson, J. A. (2005a). Institutions as a fundamental cause of long-run growth. In Handbook of economic growth, pages 385-472. Elsevier.

Acemoglu, D., Johnson, S., and Robinson, J. A. (2005b). The rise of europe: Atlantic trade, institutional change, and economic growth. American Economic Review, 95(3):546-579.

Acemoglu, D., Johnson, S., Robinson, J. A., and Yared, P. (2008). Income and democracy. American Economic Review, 98(3):808-42.

Acemoglu, D., Naidu, S., Restrepo, P., and Robinson, J. A. (2019). Democracy does cause growth. Journal of Political Economy, forthcoming.

Acemoglu, D. and Robinson, J. A. (2006). De facto political power and institutional persistence. American Economic Review, 96(2):325-330.

Acemoglu, D. and Robinson, J. A. (2013). Why nations fail: The origins of power, prosperity, and poverty. Crown Business.

Adsera, A., Boix, C., and Payne, M. (2003). Are you being served? Political accountability and quality of government. Journal of Law, Economics, and Organization, 19(2):445-490.

Aidt, T. S. and Franck, R. (2015). Democratization under the threat of revolution: Evidence from the great reform act of 1832. Econometrica, 83(2):505-547.

Aidt, T. S. and Jensen, P. S. (2014). Workers of the world, unite! Franchise extensions and the threat of revolution in Europe, 1820-1938. European Economic Review, 72(1):52-75.

Aidt, T. S. and Leon, G. (2016). The democratic window of opportunity: Evidence from riots in Sub-Saharan Africa. Journal of Conflict Resolution, 60(4):694-717.

Aisen, A. and Veiga, F. J. (2013). How does political instability affect economic growth? European Journal of Political Economy, 29(1):151-167.

Alvarez, M., Cheibub, J. A., Limongi, F., and Przeworski, A. (1996). Classifying political regimes. Studies in Comparative International Development, 31(2):3-36.

Anderson, T. W. and Rubin, H. (1949). Estimation of the parameters of a single equation in a complete system of stochastic equations. Annals of Mathematical Statistics, 20(1):46-63.

Angrist, J. D. and Pischke, J. S. (2009). Mostly harmless econometrics: An empiricist's companion. Princeton University Press.

Apolte, T. (2011). Democracy and prosperity in two decades of transition. Economics of Transition, 19(1):693-722.

Assiotis, A. and Sylwester, K. (2015). Does democracy promote the rule of law? Journal of Economic Development, 40(1):63.

Barany, Z. (2016). Moving toward democracy: The 2015 parliamentary elections in Myanmar. Electoral Studies, 42(1):75-77.

Barro, R. J. (1996). Democracy and Growth. Journal of Economic Growth, 1(1):1-27.

Barro, R. J. and Lee, J. W. (2013). A new data set of educational attainment in the world, 1950-2010. Journal of Development Economics, 104(1):184-198.

Baum, M. A. and Lake, D. A. (2003). The political economy of growth: Democracy and human capital. American Journal of Political Science, 47(2):333-347.

Beck, R. B. (2013). The History of South Africa. ABC-CLIO.

Becker, S. O., Hornung, E., and Woessmann, L. (2011). Education and catch-up in the industrial revolution. American Economic Journal: Macroeconomics, 3(3):92-126.

Beller, S. (2006). A concise history of Austria. Cambridge University Press.

Bennett, K. P. and Campbell, C. (2000). Support vector machines: hype or hallelujah? ACM SIGKDD Explorations Newsletter, 2(2):1-13. 
Besley, T. and Coate, S. (1998). Sources of inefficiency in a representative democracy: A dynamic analysis. American Economic Review, 88(1):139-156.

Besley, T., Montalvo, J. G., and Reynal-Querol, M. (2011). Do educated leaders matter? Economic Journal, 121(554):F205-F227.

Besley, T. and Reynal-Querol, M. (2011). Do democracies select more educated leaders? American Political Science Review, 105(3):552-566.

Bjørnskov, C. and Rode, M. (2018). Regime types and regime change: A new dataset. Unpublished Manuscript.

Bogaards, M. (2010). Measures of democratization: From degree to type to war. Political Research Quarterly, 63(2):475-488.

Boix, C., Miller, M., and Rosato, S. (2013). A complete data set of political regimes, 1800-2007. Comparative Political Studies, 46(12):1523-1554.

Bollen, K. A. and Jackman, R. W. (1989). Democracy, stability, and dichotomies. American Sociological Review, 54(4):612-621.

Bolt, J., Inklaar, R., de Jong, H., and van Zanden, J. L. (2018). Rebasing 'Maddison': New income comparisons and the shape of long-run economic development. Unpublished Manuscript.

Boser, B. E., Guyon, I. M., and Vapnik, V. N. (1992). A training algorithm for optimal margin classifiers. In Proceedings of the 5th Annual ACM Workshop on Computational Learning Theory, pages 144-152. ACM Press.

Brecke, P. (1999). Violent conflicts 1400 AD to the present in different regions of the world. Unpublished Manuscript.

Breiman, L. et al. (2001). Statistical modeling: The two cultures. Statistical Science, 16(3):199-231.

Brückner, M. and Ciccone, A. (2011). Rain and the democratic window of opportunity. Econometrica, $79(3): 923-947$.

Casper, G. and Tufis, C. (2003). Correlation versus interchangeability: The limited robustness of empirical findings on democracy using highly correlated data sets. Political Analysis, 11(2):196203.

Cervellati, M., Jung, F., Sunde, U., and Vischer, T. (2014). Income and democracy: Comment. American Economic Review, 104(2):707-719.

Cheibub, J. A., Gandhi, J., and Vreeland, J. R. (2010). Democracy and dictatorship revisited. Public Choice, 143(1/2):67-101.

Cohen, D. and Soto, M. (2007). Growth and human capital: Good data, good results. Journal of Economic Growth, 12(1):51-76.

Coppedge, M., Alvarez, A., and Maldonado, C. (2008). Two persistent dimensions of democracy: Contestation and inclusiveness. Journal of Politics, 70(03):632-647.

Coppedge, M., Gerring, J., Knutsen, C. H., Lindberg, S. I., Skaaning, S.-E., and Teorell, J. (2018). V-dem codebook v8. Unpublished Manuscript.

Coppedge, M. and Reinicke, W. H. (1990). Measuring polyarchy. Studies in Comparative International Development, 25(1):51-72.

Cortes, C. and Vapnik, V. (1995). Support-Vector networks. Machine Learning, 20(3):273-297.

Cragg, J. G. and Donald, S. G. (1993). Testing identifiability and specification in instrumental variable models. Econometric Theory, 9(2):222-240.

Dahl, R. A. (1971). Polyarchy: Participation and Opposition. Yale University Press.

De Haan, J. and Sturm, J.-E. (2003). Does more democracy lead to greater economic freedom? New evidence for developing countries. European Journal of Political Economy, 19(3):547-563.

De Long, J. B. and Shleifer, A. (1993). Princes and merchants: European city growth before the industrial revolution. Journal of Law and Economics, 36(2):671-702.

Devi, K. S. (2014). Myanmar under the military rule 1962-1988. International Research Journal of Social Sciences, 3(10):46-50.

Diamond, L. J. (2002). Thinking about hybrid regimes. Journal of Democracy, 13(2):21-35.

Dorsch, M. T. and Maarek, P. (2019). Democratization and the conditional dynamics of income distribution. American Political Science Review, forthcoming.

Doucouliagos, H. and Ulubaşoğlu, M. A. (2008). Democracy and economic growth: A meta-analysis. American Journal of Political Science, 52(1):61-83.

Durlauf, S. N., Johnson, P. A., and Temple, Jonathan R. W. (2005). Growth econometrics. In Handbook of Economic Growth, pages 555-677. Elsevier.

Elkins, Z. (2000). Gradations of democracy? Empirical tests of alternative conceptuations. American 
Journal of Political Science, 44(2):293-300.

Elklit, J. and Svensson, P. (1997). What makes elections free and fair? Journal of Democracy, $8(3): 32-46$.

Feenstra, R. C., Inklaar, R., and Timmer, M. P. (2015). The next generation of the Penn World Table. American Economic Review, 105(10):3150-3182.

Flachaire, E., García-Peñalosa, C., and Konte, M. (2014). Political versus economic institutions in the growth process. Journal of Comparative Economics, 42(1):212-229.

Fortunato, P. and Panizza, U. (2015). Democracy, education and the quality of government. Journal of Economic Growth, 20(4):333-363.

Freedom House (2018). Freedom in the world database. Unpublished Manuscript.

Friedman, M. (1962). Capitalism and freedom. University of Chicago Press.

Fujiwara, T. (2015). Voting technology, political responsiveness, and infant health: Evidence from brazil. Econometrica, 83(2):423-464.

Galasso, V. and Nannicini, T. (2011). Competing on good politicians. American Political Science Review, 105(1):79-99.

Gallego, F. A. (2010). Historical origins of schooling: The role of democracy and political decentralization. Review of Economics and Statistics, 92(2):228-243.

Geddes, B., Wright, J., and Frantz, E. (2014). Autocratic breakdown and regime transitions: A new data set. Perspectives on Politics, 12(2):313-331.

Giavazzi, F. and Tabellini, G. (2005). Economic and political liberalizations. Journal of Monetary Economics, 52(7):1297-1330.

Giuliano, P., Mishra, P., and Spilimbergo, A. (2013). Democracy and reforms: Evidence from a new dataset. American Economic Journal: Macroeconomics, 5(4):179-204.

Goertz, G. (2006). Social science concepts: A user's guide. Princeton University Press.

Grosjean, P. and Senik, C. (2011). Democracy, market liberalization, and political preferences. Review of Economics and Statistics, 93(1):365-381.

Gründler, K. and Krieger, T. (2016). Democracy and growth: Evidence from a machine learning indicator. European Journal of Political Economy, 45(1):85-107.

Gründler, K. and Krieger, T. (2018). Machine learning indices, political institutions, and economic development. CESifo Working Paper Series.

Gundlach, E. and Paldam, M. (2009). A farewell to critical junctures: Sorting out long-run causality of income and democracy. European Journal of Political Economy, 25(3):340-354.

Gutmann, J. and Voigt, S. (2018). The rule of law: Measurement and deep roots. European Journal of Political Economy, 54(1):68-82.

Hale, H. E., McFaul, M., and Colton, T. J. (2004). Putin and the "delegative democracy" trap: Evidence from Russia's 2003-04 elections. Post-Soviet Affairs, 20(4):285-319.

Hall, R. E. and Jones, C. I. (1999). Why do some countries produce so much more output per worker than others? Quarterly Journal of Economics, 114(1):83-116.

Hanushek, E. A. and Woessmann, L. (2012). Do better schools lead to more growth? Cognitive skills, economic outcomes, and causation. Journal of Economic Growth, 17(4):267-321.

Harding, R. and Stasavage, D. (2013). What democracy does (and doesn't do) for basic services: School fees, school inputs, and African elections. Journal of Politics, 76(1):229-245.

Hayek, F. (1944). The road to serfdom. University of Chicago Press.

Huillery, E. (2009). History matters: The long-term impact of colonial public investments in French West Africa. American Economic Journal: Applied Economics, 1(2):176-215.

Huntington, S. P. (1993). The Third Wave: Democratization in the late twentieth century. University of Oklahoma Press.

Knack, S. and Keefer, P. (1995). Institutions and economic performance: Cross-country tests using alternative institutional measures. Economics and Politics, 7(3):207-227.

Knutsen, C. H. (2011). Democracy, dictatorship and protection of property rights. Journal of Development Studies, 47(1):164-182.

Knutsen, C. H. (2012). Democracy and economic growth: A survey of arguments and results. International Area Studies Review, 15(4):393-415.

Knutsen, C. H. (2015). Why democracies outgrow autocracies in the long run: Civil liberties, information flows and technological change. Kyklos, 68(3):357-384.

Kotschy, R. and Sunde, U. (2017). Democracy, inequality, and institutional quality. European Economic Review, 91(1):209-228. 
Krieger, T. and Meierrieks, D. (2016). Political capitalism: The interaction between income inequality, economic freedom and democracy. European Journal of Political Economy, 45(1):115-132.

Leblang, D. A. (1996). Property rights, democracy and economic growth. Political Research Quarterly, 49(1):5-26.

Lindberg, S. I., Coppedge, M., Gerring, J., and Teorell, J. (2014). V-dem: A new way to measure democracy. Journal of Democracy, 25(3):159-169.

Lipset, S. M. (1959). Some social requisites of democracy. American Political Science Review, 53(1):69105.

Lundström, S. (2005). The effect of democracy on different categories of economic freedom. European Journal of Political Economy, 21(4):967-980.

Madsen, J. B. and Murtin, F. (2017). British economic growth since 1270: The role of education. Journal of Economic Growth, 22(3):229-272.

Madsen, J. B., Raschky, P. A., and Skalil, A. (2015). Does democracy drive income in the world, 1500-2000? European Economic Review, 78(1):175-195.

Márquez, X. (2016). A quick method for extending the unified democracy scores. SSRN Working Paper Series.

Marshall, M., R., G. T., and Jaggers, K. (2018). Polity IV project. Political regime characteristics and transitions, 1800-2017. Unpublihed Manuscript.

Méon, P.-G. and Sekkat, K. (2016). A time to throw stones, a time to reap: How long does it take for democratic transitions to improve institutional outcomes? Working Papers CEB.

Mercer, J. (1909). Functions of positive and negative type and their connection with the theory of integral equations. Philosophical transactions of the Royal Society, 209(1):415-446.

Merkel, W. (2004). Embedded and defective democracies. Democratization, 11(5):33-58.

Munck, G. L. and Verkuilen, J. (2002). Conceptualizing and meassuring democracy: Evaluating alternative indices. Comparative Political Studies, 35(1):5-34.

Murtin, F. and Wacziarg, R. (2014). The democratic transition. Journal of Economic Growth, $19(2): 141-181$

Nohlen, D. (2005). Elections in the Americas: A data handbook. Oxford University Press.

Nohlen, D., Grotz, F., and Hartmann, C. (2001). Elections in Asia and the Pacific: A data handbook. Oxford University Press.

Nohlen, D. and Stöver, P. (2010). Elections in Europe: A data handbook. Nomos.

Nohlen, D., Thibaut, B., and Krennerich, M. (1999). Elections in Africa: A data handbook. Oxford University Press.

North, D. C. (1991). Institutions. Journal of Economic Perspectives, 5(1):97-112.

North, D. C. and Weingast, B. R. (1989). Constitutions and commitment: The evolution of institutions governing public choice in seventeenth-century england. Journal of Economic History, 49(4):803832 .

O'Donnell, G. A. (2001). Democracy, law, and comparative politics. Studies in Comparative International Development, 36(1):7-36.

Olson, M. (1993). Dictatorship, democracy, and development. American Political Science Review, $87(3): 567-576$.

Papaioannou, E. and Siourounis, G. (2008). Democratisation and growth. Economic Journal, 118(532):1520-1551.

Pemstein, D., Meserve, S. A., and Melton, J. (2010). Democratic compromise: A latent variable analysis of ten measures of regime type. Political Analysis, 18(4):426-449.

Persson, T. and Tabellini, G. (2005). The economic effects of constitutions. MIT Press.

Persson, T. and Tabellini, G. (2006). Democracy and development: The devil in the details. American Economic Review, 96(2):319-324.

Persson, T. and Tabellini, G. (2008). The growth effect of democracy: Is it heterogenous and how can it be estimated? In Institutions ans Economic Performance, pages 544-586. Harvard University Press.

Persson, T. and Tabellini, G. (2009). Democratic capital: The nexus of political and economic change. American Economic Journal: Macroeconomics, 1(2):88-126.

Pinkovskiy, M. L. (2017). Growth discontinuities at borders. Journal of Economic Growth, 22(2):145192.

Pitlik, H. (2008). The impact of growth performance and political regime type on economic policy liberalization. Kyklos, 61(2):258-278. 
Plattner, M. F. (2015). Is democracy in decline? Journal of Democracy, 26(1):5-10.

Przeworski, A. (1991). Democracy and the market: Political and economic reforms in Eastern Europe and Latin America. Cambridge University Press.

Przeworski, A. (2000). Democracy and development: Political institutions and well-being in the world, 1950-1990. Cambridge University Press.

Przeworski, A. and Limongi, F. (1993). Political regimes and economic growth. Journal of Economic Perspectives, 7(3):51-69.

Rieffel, L. (2013). Myanmar on the move: An overview of recent developments. Journal of Current Southeast Asian Affairs, 31(4):31-49.

Rocha, R., Ferraz, C., and Soares, R. R. (2017). Human capital persistence and development. American Economic Journal: Applied Economics, 9(4):105-36.

Rode, M. and Gwartney, J. D. (2012). Does democratization facilitate economic liberalization? European Journal of Political Economy, 28(4):607-619.

Rodrik, D. (2008). One economics, many recipes: Globalization, institutions, and economic growth. Princeton University Press.

Rodrik, D., Subramanian, A., and Trebbi, F. (2004). Institutions rule: The primacy of institutions over geography and integration in economic development. Journal of Economic Growth, 9(2):131-165.

Rodrik, D. and Wacziarg, R. (2005). Do democratic transitions produce bad economic outcomes? American Economic Review, 95(2):50-55.

Saint-Paul, G. and Verdier, T. (1993). Education, democracy and growth. Journal of Development Economics, 42(2):399-407.

Sakwa, R. (1990). Gorbachev and his Reforms, 1985-1990. Prentice Hall.

Sakwa, R. (2005). The rise and fall of the Soviet Union. Routledge.

Sakwa, R. (2010). The crisis of Russian democracy: The dual state, factionalism and the Medvedev succession. Cambridge University Press.

Sakwa, R. (2014). Putin redux: Power and contradiction in contemporary Russia. Routledge.

Sanderson, E. and Windmeijer, F. (2016). A weak instrument F-test in linear IV models with multiple endogenous variables. Journal of Econometrics, 190(2):212-221.

Schedler, A. (2002). The menu of manipulation. Journal of Democracy, 13(2):36-50.

Schölkopf, B., Smola, A., and Müller, K.-R. (1998). Nonlinear component analysis as a kernel eigenvalue problem. Neural Computation, 10(5):1299-1319.

Shirer, W. L. (1991). The rise and fall of the Third Reich: A history of Nazi Germany. Random House.

Skaaning, S.-E., Gerring, J., and Bartusevičius, H. (2015). A lexical index of electoral democracy. Comparative Political Studies, 48(12):1491-1525.

Smola, A. J. and Schölkopf, B. (2004). A tutorial on support vector regression. Statistics and Computing, 14(1):199-222.

Sokoloff, K. L. and Engerman, S. L. (2000). Institutions, factor endowments, and paths of development in the new world. Journal of Economic Perspectives, 14(3):217-232.

Stasavage, D. (2005). Democracy and education spending in Africa. American Journal of Political Science, 49(2):343-358.

Steinwart, I. and Christmann, A. (2008). Support Vector Machines. Springer Science.

Stock, J. H. and Wright, J. H. (2000). GMM with weak identification. Econometrica, 68(5):1055-1096.

Stock, J. H. and Yogo, M. (2005). Testing for weak instruments in linear iv regression. In Identification and Inference for Econometric Models, pages 80-108. Cambridge University Press.

Sunde, U., Cervellati, M., and Fortunato, P. (2008). Are all democracies equally good? The role of interactions between political environment and inequality for rule of law. Economics Letters, $99(3): 552-556$.

Tavares, J. and Wacziarg, R. (2001). How democracy affects growth. European Economic Review, 43(8):1341-1378.

Teorell, J. (2010). Determinants of democratization: Explaining regime change in the world, 19722006. Cambridge University Press.

Teorell, J., Coppedge, M., Lindberg, S., and Skaaning, S.-E. (2019). Measuring polyarchy across the globe, 1900-2017. Studies in Comparative International Development, forthcoming.

Treier, S. and Jackman, S. (2008). Democracy as a latent variable. American Journal of Political Science, 52(1):201-217.

Turner, M., Chuki, S., and Tshering, J. (2011). Democratization by decree: The case of Bhutan. 
Democratization, 18(1):184-210.

Turner, M. and Tshering, J. (2014). Second elections and democratic consolidation: The experience of Bhutan. Asian Journal of Political Science, 22(3):315-334.

United Nations (1948). Universal Declaration of Human Rights.

Vanhanen, T. (2000). A new dataset for measuring democracy, 1810-1998. Journal of Peace Research, $37(2): 251-265$.

Vapnik, V. (1995). The nature of statical learning theory. Springer.

Vapnik, V. N. (1998). Statistical Learning Theory. Wiley.

Voigt, S. (2012). How to measure the rule of law. Kyklos, 65(2):262-284.

Wike, R., Simmons, K., Stokes, B., and Fetterolf, J. (2017). Globally, broad support for representative and direct democracy. PEW Research Paper.

Wintrobe, R. (1990). The tinpot and the totalitarian: An economic theory of dictatorship. American Political Science Review, 84(3):849-872.

Wooldridge, J. M. (2010). Econometric analysis of cross section and panel data. MIT Press. 


\section{Abgrenzung}

Das zweite Kapitel dieser Dissertationsschrift (Using machine learning for measuring democracy) ist in Zusammenarbeit mit Herrn Dr. Klaus Gründler (LMU München, ifo Institut) entstanden. Mein Anteil bei der Erstellung dieses Aufsatzes beträgt $60 \%$.

Das dritte Kapitel dieser Dissertationsschrift (Should we care (more) about data aggregation? Evidence form the the democracy-growth-nexus) ist in Zusammenarbeit mit Herrn Dr. Klaus Gründler (LMU München, ifo Institut) entstanden. Mein Anteil bei der Erstellung dieses Aufsatzes beträgt ebenfalls $60 \%$.

Ich versichere, dass ich das vierte Kapitel dieser Dissertationsschrift (Democracy and institutional quality: Theory and evidence) ohne Hilfe Dritter verfasst habe. 